University of Arkansas, Fayetteville

ScholarWorks@UARK

Graduate Theses and Dissertations

8-2014

\title{
A Christian Value?: Faculty Diversity at Southern Evangelical Campuses
}

Marquita Smith

University of Arkansas, Fayetteville

Follow this and additional works at: https://scholarworks.uark.edu/etd

Part of the Higher Education Commons, and the Other Education Commons

Citation

Smith, M. (2014). A Christian Value?: Faculty Diversity at Southern Evangelical Campuses. Graduate Theses and Dissertations Retrieved from https://scholarworks.uark.edu/etd/2240

This Dissertation is brought to you for free and open access by ScholarWorks@UARK. It has been accepted for inclusion in Graduate Theses and Dissertations by an authorized administrator of ScholarWorks@UARK. For more information, please contact scholar@uark.edu. 
A Christian Value?: Faculty Diversity at Southern Evangelical Campuses 
A Christian Value?: Faculty Diversity at Southern Evangelical Campuses

A dissertation submitted in partial fulfillment

of the requirements for the degree of

Doctor of Education in Higher Education

by

\author{
Marquita Smith \\ University of Tennessee \\ Bachelor of Science in Communications, 1995 \\ University of Maryland \\ Master of Arts in Journalism, 1998
}

August 2014

University of Arkansas

This dissertation is approved for recommendation to the Graduate Council.

Dr. Ketevan Mamiseishvili

Dissertation Director

Dr. Michael T. Miller

Dr. Charles F. Robinson

Committee Member

Committee Member 


\begin{abstract}
This study explored institutional efforts to increase faculty diversity at three southern Christian universities and provided descriptions of what promoted or curtailed faculty diversity at those institutions. Daryl G. Smith's (2009) dimensions of diversity were used to evaluate the role of institutional missions, and how they were connected to diversity efforts. Smith's 2009 conceptual framework offered four areas for studying diversity: access and success, institutional vitality and viability, education and scholarship, and intergroup relations and campus climate. A qualitative multiple or collective case study design was used. The sample included 20 total participants; 19 from the three case institutions and one Council of Christian Colleges and Universities (CCCU) administrator. The study participants consisted of 12 males and 8 females; 11 faculty, 7 administrators, and 2 students. A combination of personal interviews, observations, field notes, documents and textual analysis provided faculty diversity themes at the different institutions.

Although institutions have made great strides in diversity efforts, this study revealed that more intentional and methodic processes need to be established to increase faculty diversity at CCCU institutions. The more interaction students have with diverse populations the better prepared they will be to work and serve in global communities. Consequently, faculty diversity efforts can be maximized by implementing better recruitment and retention strategies. This study highlighted a few recruitment and retention strategies which included the active pursuit of faculty of color and the purposeful management of mentorship programs.
\end{abstract}




\section{ACKNOWLEDGEMENTS}

The inspiration, contribution, collaboration, and reassurance of many individuals including my sister friends: Denise Berkhalter, Denise Bridges, Katina Broadway and Candy Hatcher - who helped make this important project possible. This study is a reflection of that circle and our countless discussions about diversity and multiculturalism and the possibilities at faith institutions. Since the start of the project, these women have served as prayer partners, coaches, and editors. I am forever grateful for their long-term friendships, encouragement, and care.

\section{Special Thanks}

To my mother Jacqueline M. Smith, who explained to me in $10^{\text {th }}$ grade that "anybody can get a 'C' - it's just average." I am so very thankful that she has always challenged me to be better.

I also wish to thank Dr. Kate Mamiseishvili, my dissertation director, whose investment in the research project has been invaluable and whose insight has guided and helped focus the study. I am also appreciative of the wise counsel from committee members, Dr. Charles Robinson and Dr. Mike Miller. To my John Brown University staff, colleagues, administrators and students, especially my former teaching assistant Emma Bentley, I appreciate your continued support, patience and understanding as I worked to complete this project. Lastly, I am humbled and delighted for the opportunity to meet and talk with 20 participants, who are committed to better reflecting Christ's kingdom at CCCU institutions. "Thank you" for your candor and stories. 


\section{DEDICATION}

This dissertation project is dedicated in loving memory of my father, Freddie Frank Donnell, who died of cancer on November 1, 2013. Months before he passed away, he no longer called me Marquita, but he simply referred to me as "the scholar." At that time it was unclear, but I now understand in his own way he was affirming me, encouraging me to complete the journey I had started. Like diversity work, family relationships can be complicated. I'm forever grateful to the Lord, my Savior, who demonstrates that even in death, there is still healing.

I also dedicate this project to the small number of faculty of color who choose to teach and serve at Council of Christian Colleges and University (CCCU) institutions. I understand the

call, the mission, the conflict and the joy that come with that decision. May the Lord continue to bless and keep each and every one of you. 


\section{TABLE OF CONTENTS}

I. INTRODUCTION 1

A. Statement of the Research Problem 3

B. Purpose of the Study 7

C. Research Questions 8

D. Definitions 8

E. Delimitations and Limitations 12

F. Significance of the Study 12

G. Conceptual Framework 14

H. Chapter Summary 18

II. LITERATURE REVIEW 20

A. History and Mission and Faith-based Institutions 21

1. Faith Plays Both Sides $\quad 24$

2. CCCU Promotes Christian Colleges 25

3. Evangelical Defined 26

4. Evangelicals Struggle With Difference 27

5. Campus Diversity Efforts Endure 28

6. Evangelicals Stand on Statement $\quad 30$

B. The Diversity Imperative 31

1. Scholars Talk Diversity Business $\quad 32$

2. Access and Success 33

3. Campus Climate and Intergroup Relations

4. Education and Scholarship $\quad 36$

5. Institutional Viability and Vitality 39

6. Challenges for Diversity in Higher Education 41

C. Hiring Diverse Faculty 43

1. Discussing the Broken Pipeline 44

2. Challenges for Diverse Faculty 44

3. Professors of Color Make a Difference 46

4. Shaping the Scholarship 48

5. Faculty Diversity at Evangelical Campuses 49

6. Strategies that Work 51

7. Minority Faculty Seek Community 54

8. Diversity Still Eludes Evangelicals $\quad 55$

D. Chapter Summary 56

III. METHODOLOGY

A. Research Design $\quad 58$

1. Case Institution Selection 60

2. Participant Selection 62

B. Data Collection 64

1. Personal Interviews 64

2. Observations and Field Notes 65

3. Documents and Textual Analysis 66

C. Research Rigor $\quad 67$

1. Peer debriefing 68 
2. Researcher reflexivity 68

3. Triangulation 69

4. Participant member checks 69

D. Additional Strategies for Ensuring Research Validity 69

1. Credibility 69

2. Transferability 70

3. Dependability 70

4. Confirmability and Researcher's Role 70

5. Data Protocol 73

E. Data Analysis 73

F. Chapter Summary 74

IV. FINDINGS

A. Research Questions 76

B. Data Collection 76

C. Data Analysis $\quad 79$

D. Faith University 79

1. Diversity Rhetoric 83

2. Intentional Diversity 83

3. Environmental Dynamics $\quad 85$

4. Expanding the Globe $\quad 87$

5. Diversity Top-down 88

E. Peace University 88

1. Diversity Rhetoric 90

2. Spirit-led Initiatives 91

3. Environmental Dynamics 92

4. Diversity Top-heavy Approach 94

F. Love University 95

1. Diversity Rhetoric 98

2. Promoting Intentionality 99

3. Power and Access 101

4. Environmental Dynamics 102

5. Diversity Ground-Up 105

G. Cross-Case Analysis and Synthesis 106

1. Diversity Defined 106

2. Faith versus Diversity Work 107

3. Culture and Climate 108

4. Administrative Commitment 110

H. Chapter Summary $\quad 111$

$\begin{array}{ll}\text { V. DISCUSSION } & 113\end{array}$

1. Research Questions 114

2. Conceptual Framework 114

3. Methods 116

A. Summary of Themes 117

1. Access and Success 117

2. Education and Scholarship 119

3. Climate/Intergroup Relations 120 
4. Institutional Vitality and Viability 121

B. Discussion and Conclusions 122

1. Institutional Vitality and Viability 123

2. Access and Success 126

3. Climate/Intergroup Relations 128

4. Education and Scholarship 131

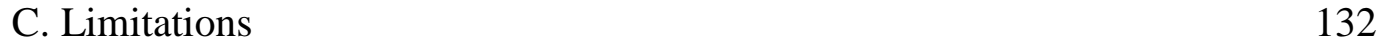

D. Recommendations for Future Research 134

E. Implications for Practice 136

1. Recommendations for Recruitment 137

2. Recommendations for Retention 138

$\begin{array}{lr}\text { F. Conclusion } & 139\end{array}$

VI. REFERENCES 142

$\begin{array}{ll}\text { VII. APPENDICES } & 157\end{array}$

A. Email Seeking Institutional Participation 157

B. Consent to Participate in Research Study 158

C. University of Arkansas IRB APPROVAL 160

D. University of Arkansas Modified IRB APPROVAL 161

E. E-mail Request to Participants 162

F. Participant Interview Protocol 163

G. Case Study Protocol 165 


\section{CHAPTER I}

\section{INTRODUCTION}

Five decades after Martin Luther King Jr.'s historic “I Have a Dream” speech in Washington, D.C., the inequality he spoke of still carries into higher education. Although colleges and universities have increased enrollment, equal strides have not been made to ensure that more students actually complete four-year degrees (Laird, DeBell, \& Chapman, 2006), especially students from underrepresented groups. The National Center for Education Statistics (2009) noted the percentage of students of color in higher education continues to consistently rise. In 2006-07, African-American students made up 12.8\% of students in U.S. higher education; Hispanics made up 11.1\%; Asian and Pacific Islanders made up 6.6\%; and Native American or Alaskan Natives represented only 1\% (Hussar \& Bailey, 2009). As universities become more diverse, additional challenges are emerging, forcing leaders to question how to respond to the rapidly shifting demographics of students (Gohn \& Albin, 2006).

In February 2014, the Council of Christian Colleges and Universities (CCCU) hosted the Engaged Community conference at the Westin Bonaventure Hotel in Los Angeles. More than 640 people attended to discuss challenges and opportunities for the CCCU member schools. The conversation there mirrored discussions around the country as higher education leaders prepare to serve the rapidly changing demographics of students. The conference officially opened Wednesday, February 12, in the afternoon with a plenary session featuring comments from Charles W. Pollard, president of John Brown University and the CCCU board chair, and a speech by CCCU Interim President William P. (Bill) Robinson. Pollard stated at the gathering: "We expect these three days will stimulate your mind, encourage your spirit and renew your commitment to the importance of work in Christian higher education" (CCCU, 2014, para. 5). 
On Thursday, Samuel Rodriguez, president of the National Hispanic Christian Leadership Conference, and Erwin McManus, founder of Mosaic Church in Los Angeles, discussed the importance of planning for and including in Christian higher education the growing minority population, especially the Hispanic population. Rodriguez told attendees that as:

America becomes more ethnically and culturally diverse, recruiting and retaining ethnic students no longer stands as a luxury or as an act of political correctness ... but rather diversification represents nothing more and nothing less than the very future, and to a great degree the very viability of American evangelicalism and American orthodox Christianity into the 21st century. In essence, the future of Christ-centered, Bible-based American Christianity lies in the effective equipping, education, and empowering of America's ethnic minority communities. (CCCU, 2014, para. 9)

Moreover, higher education institutions, faith-based organizations included, must answer the needs of the changing labor force, responding to employers, parents, and students with improved diversity among faculty ranks.

Faculty play a critical role in the teaching, service, and research functions of colleges and universities. They lead efforts in teaching and learning, knowledge development, and university governance (Antonio, 2000; Smith, 2009; Turner, 2000). Vanessa Armstrong (2011) discusses the need for higher education leaders to better understand the benefits of hiring a diverse professoriate. For instance, diverse faculty generate a more robust, varied body of research, while creating more innovative approaches to responding to the nation's changing demographics (Antonio, 2000; Turner, 2000). According to Armstrong (2011), if the academy hopes to continue educational and societal legitimacy, administrators must do a better job of making sure faculty reflect the diversity of the population. While most scholars agree that higher education has reached a crossroads and diversity strategies should already be in place, institutional leaders continue to struggle with how to best recruit and retain diverse faculty (Smith, Turner, OsefiKofi, \& Richards, 2004). Colleges and universities striving to remain relevant and hoping to 
recruit from the quickly expanding pool of minority students know they can no longer ignore multicultural concerns (McMinn, 1998). They also must develop a plan to recruit and retain faculty of color.

\section{Statement of the Research Problem}

Within the evangelical Christian college community, diversity efforts generally lag behind non-Christian institutions of higher education. Neither students nor faculty in the CCCU reflect the general population, the rest of higher education, and the church body (Laney \& Daniels, 2006). The CCCU is an international association of faith-based colleges and universities. Beginning with 38 members in 1976, the Council has grown to 120 members in North America and 69 affiliate institutions in 24 countries (Council for Christian Colleges and Universities, 2013). The CCCU offers religious diversity; 28 different denominations are represented, and member institutions differ in price, size, and resources (Rine \& LoMaglio, 2012).

McMinn (1998) believed "the evangelical Christian college community struggles to be more accommodating and tolerant by adapting to trends in society and education, and yet resistant as well, fearful that welcoming secular influences might hurt their ability to maintain distinctives as Christian colleges" (p. 24). McMinn (1998) also observed that the low enrollment of minority students at evangelical colleges often reflect the institutions' lack of commitment to multiculturalism and becoming more diverse and inclusive. Conversely, Joel Perez (2010) noted that several Christian institutions were moving towards more multicultural campuses and promoting diversity and inclusion. He discovered that in order to create viable change, faithbased colleges and universities must link diversity efforts to their history, to their mission, and to biblical principles (Perez, 2010). Still, empirical research indicates secular universities outpace 
Christian institutions when it comes to advancing diversity initiatives involving multicultural awareness of students (Sheridan \& Anderson, 2001; Yancey, 2010); the ethnic and cultural diversity of their faculty, staff, and student body (Nieves, 1991; Rine \& LoMaglio, 2012); and, on a larger scale, the institution's commitment to diversity (Mayer, 1997; McMinn, 1998; Perez, 2010).

A large body of work describes the needs and challenges involved with maintaining a diverse professoriate. For example, Daryl Smith (2009) discussed the importance of identifying talent and finding creative ways to hire diverse faculty. Smith et al. (2004) provided empirical work that considers the different circumstances that lead to hiring diverse faculty beyond filling teaching positions that specifically focused on race and ethnicity course. Turner and Myers (2000) are among dozens of researchers who report that despite affirmative action and other efforts, faculty of color continue to be underrepresented in the academy. While the literature offers numerous explanations for the low number of minority faculty, limited research exists on diverse faculty recruitment and retention at Christian colleges and universities. In Christian institutions, diversity research has primarily focused on student populations, institutional mission, and student development efforts (Kratt, 2004; McMinn, 1998; Perez 2010). In Charting the Terrain of Christian Higher Education in America: A Profile of the Member Institutions of the Council for Christian Colleges \& Universities, Rine and LoMaglio (2012) reported that CCCU member institutions employed more than 20,000 faculty members as of May 2009. In 2007, 91.3\% of those full-time faculty employed at CCCU institutions identified as White (Rine \& LoMaglio, 2012). However, when examining the changes in faculty diversity over time, "it becomes clear that faculty serving at CCCU institutions have become more racially diverse over time" (Rine \& LoMaglio, 2012, p. 37-38). The CCCU provided 
statistics to show the changes in faculty and student diversity over a ten-year period (2001-2011) at CCCU institutions. The data showed:

- $4 \%$ increase in White students

- $64 \%$ increase in African-American students

- $134 \%$ increase in Hispanic students

- $29 \%$ increase in Native-American students

- $72 \%$ increase in Asian students

- $15 \%$ increase in White faculty

- $87 \%$ increase in African-American faculty

- $76 \%$ increase in Hispanic faculty

- $68 \%$ increase in Native-American faculty

- $145 \%$ increase in Asian faculty. (CCCU, 2013, para. 8)

The statistics provide a snapshot of 119 CCCU institutions. For the 2011 academic year, total student enrollment increased $18 \%$, with white students comprising $75 \%$ and $25 \%$ representing minorities. Total full-time faculty members increased $23 \%$ with white faculty comprising $89 \%$ and $11 \%$ representing minorities that same year. Statistical data were not yet available for 2012 or 2013 (CCCU, 2013). Interim CCCU President Bill Robinson also maintained that the CCCU will continue to support the goal of increasing faculty diversity (B. Robinson, personal communication, February 1, 2014). According to Robinson, the numbers have improved over the years but more needs to be done in terms of hiring more diverse faculty members for CCCU institutions. CCCU Board Chair Pollard said the CCCU remains committed to increasing faculty diversity (C. Pollard, personal communication, October 29, 2013). However, the CCCU does not provide a top-down structure for managing member institutions. Boards of trustees govern member institutions separately, and it would be up to each university to set goals for improving faculty diversity and measuring the success of those efforts (Rine \& LoMaglio, 2012).

To show the concerns of minority faculty members, author Anthony Bradley (2013) compiled the narratives in his book Aliens in the Promised Land: Why Minority Leadership is Overlooked in White Christian Churches and Institutions. Bradley (2013) shared the stories of 
Asian-Americans, Hispanics and African-Americans discussing their experiences in denominational leadership structures, church planting and Christian education. Furthermore, the chapters offered examples of the complexities of being a faculty person of color at evangelical colleges. Bradley, an associate professor of theology and ethics at the Kings College in New York, explained why minority leaders are overlooked in their respective communities and made the case that evangelical college leaders could no longer afford to ignore those experiences (Bradley, 2013). Bradley (2013) also explained that the Imago Dei - that humans are all made in the image of God — is really the starting point in addressing issues of why multi-ethnicity is important for all evangelical institutions.

After reading Bradley's book, Christena Cleveland, a social psychologist, recalled the isolation and challenges she experienced as the only African-American female faculty member at Westmont University in Santa Barbara, CA. Cleveland (2013) wrote in her blog post that she believes the experience of minority students mirrors that of faculty. Her concern prompted her in August 2013 to begin a blogging project titled "Black to School: African American Voices at Christian Colleges.” The blog offers personal accounts from recent college graduates on their experiences at evangelical Christian campuses. The sentiments expressed in the blogs echo the findings in William Kratt's (2004) dissertation on diversity in Christian higher education. He found students of color perceived the campus climate to be less positive than white students, had lower retention rates than white students, and were less satisfied with their college experience than White students. Moreover, Kratt (2004) concluded the white evangelical culture at these institutions continues to be a major hurdle to improvements in diversity and racial inclusion. CCCU leaders understand that while some progress has been made in increasing student 
diversity, more research needs to be done to help Christian colleges and universities increase faculty diversity.

\section{Purpose of the Study}

Higher education leaders acknowledge that faculty diversity plays an important role in building institutional capacity for diversity. Still, discovering ways and developing plans to improve diversity remain significant challenges for institutions (Smith et al., 2004; Springer, 2004). When evaluating diversity efforts, including the hiring of faculty, evangelical Christian colleges lag behind private, non-religious, and state institutions (McMinn, 1998). McMinn described Christian universities as being "pushed to be more diverse by a pluralistic environment that values diversity, yet they are pulled away from that diversity by an evangelical culture that seeks to reproduce itself rather than be the dominant culture" (p. 24).

The purpose of this qualitative study was to explore institutional efforts to increase faculty diversity at three southern Christian universities and examine how these efforts relate to institutional missions. The study offers descriptions of what promotes or curtails diverse faculty as well as highlight recruitment and retention efforts at the three institutions. I used Daryl G. Smith's (2009) dimensions of diversity to evaluate the role of institutional missions, and how they are connected to diversity efforts. Smith's conceptual framework offers four areas for studying diversity: access and success, institutional vitality and viability, education and scholarship, and intergroup relations and campus climate. Additionally, the study gives insight on what tenets of faith may be shaping the diversity conversation on the respective campuses. This study would be of great value to leaders at CCCU institutions and would add to the general knowledge base on faculty diversity. 


\section{Research Questions}

With Daryl G. Smith's dimensions of diversity as the conceptual framework, this study examines the following five questions:

1. What diversity efforts exist at three Christian universities in the South?

2. What aspects within the history of evangelicalism promote or deter the hiring of diverse faculty at these three Christian universities in the South?

3. What are Christian colleges doing to recruit and retain diverse faculty?

4. What is the climate for minority faculty at Christian universities?

5. How does faculty diversity or the lack of it impact Christian universities' educational and scholarly missions?

\section{Definitions}

The following definitions are provided to ensure uniformity and understanding of the key terms throughout the study. While they are not unusual, I have included the definitions for clarity purposes. Additionally, I listed several standard definitions and common acronyms without a citation.

Campus Climate: Behaviors within a learning environment that can influence whether an individual feels safe, heard, valued, respected and treated fairly provide the campus climate (Campus Climate Network Group, 2004).

Cultural Competence: A developmental process that advances over time is called cultural competence. During this phase, both individuals and organizations are engaged in levels of awareness, knowledge and skills along the cultural competence scale (Cross, Bazron, Dennis, \& Isaacs, 1989).

Cultural competence requires that organizations: 
- Have a defined set of values and principles, and demonstrate behaviors, attitudes, policies, and structures that enable them to work effectively cross-culturally.

- Have the capacity to (1) value diversity, (2) perform self-assessments, (3) evaluate the dynamics of difference, (4) integrate cultural knowledge, and (5) adapt to diversity and the cultural contexts of communities they serve (Cross et al., 1989).

Cultural Diversity: The diversity that shapes a variety of cultures or individuals from the same culture who "share basic values and beliefs" and form an identity based on their culture is cultural diversity (Stahl, Maznevski, Voigt, \& Jonsen, 2010b, p. 691).

Culture: A common system of values, behaviors, beliefs, and relationships that forms a sense of community among individuals is a culture (Brumann, 1999).

Diversity: The term diversity refers to categories such as age, race, ethnicity, class, sexual orientation, nationality, and gender, or mental and physical ability (Albelda, Drago, \& Shulman, 2010).

Equality of Opportunity: Equality of opportunity is the assignment of individuals to places in the social hierarchy. The hierarchy is determined by some form of competitive process, and all members of society are eligible to compete on equal terms (Arneson, 2008).

Ethnicity: A description of groups that share historical, religious, or cultural experiences that are independent of race is called ethnicity (Wsevolod, 1992).

Ethnocentrism: The state of believing in the supremacy of one's own race and culture is ethnocentrism (McMinn, 1998).

Evangelical: In this study, evangelical is a general description based on whether individuals belong to a denomination historically connected to the theology of the evangelical movement that emerged in the $20^{\text {th }}$ century out of Protestant fundamentalism (Hackett \& Lindsay, 2008). 
Inclusion: Diversity inclusion exists when disadvantaged communities and designated group members share power and decision-making at all levels in projects, programs, organizations, and institutions (Roberson, 2004).

Informational Diversity: Informational diversity exists when individuals bring differing information, opinions, and perspectives to the group (Phillips \& Thomas-Hunt, 2007). Inequality: The condition of being unequal; lack of equality or social and economic disparity (Bourne, 2001). Inequity: The lack of fairness or injustice describes inequity (Bourne, 2001).

Institutional Racism: Also called systematic racism, institutional racism is experienced through social institutions, practices, and procedures as well as through the organizational culture (Bourne, 2001).

Marginalization: The systematic and/or individual process of making certain demographic groups' issues and concerns low priorities is termed marginalization (Garcia \& Guerra, 2004). Minority group: Minority group members are United States citizens who are Asian, Black, Hispanic, and Native American. Minority refers to a group of people within a given society that has little or no access to social, economic, political, or religious power (Peart, 2000).

Multiculturalism: Multiculturalism acknowledges and promotes the acceptance and understanding of several different cultures living together within a community (Rosado, 1997). Pluralism: Organizational culture that incorporates mutual respect, acceptance, teamwork, and productivity among people who are diverse in human dimensions diversity is called pluralism (Eck, 2006).

Race: The term refers to a socially defined group in its common descent or external features, such as skin color, hair texture, or facial characteristics (Blank, Dabady, \& Citro, 2004). 
Racial Discrimination: The definition of racial discrimination includes two components: (1) on the basis of race, individuals or racial groups are disadvantaged and (2) treatment on the basis of unjustified factors other than race that disadvantages a racial group (Blank et al., 2004).

Social justice: This term is based on the belief that each individual and group in a given society has a right to equal opportunity, fairness, civil liberties, and participation in the social, education, economic, institutional, and moral freedoms and responsibilities valued by the community (Coates, 2008).

\section{Delimitations and Limitations}

I have chosen to limit the study to three southern evangelical Christian institutions. Several assumptions are made about the phenomenon under investigation and the participants selected. One assumption is that institutions value diversity and are committed to increasing the number of ethnically diverse faculty. Another assumption is that those participating reflect the sentiments of the campus on any given topic. Given the small number of participants and absence of statistical analyses, qualitative data are not usually generalizable. As a result, it is important to not suggest that the findings can be generalized to other populations or settings (Morrow \& Smith, 2000). Regardless of the strength of the research design, the study relies on data from a small group of CCCU institutions, which may limit the scope of the analysis. Primarily due to the small/unique sample available for study, findings may not be transferrable beyond the case institutions in the study.

The reported data contain several potential sources of bias from participants that should be noted as limitations: (a) selective memory (remembering or not remembering experiences or events that occurred at some point in the past); (b) telescoping (recalling events that occurred at one time as if they occurred at another time); (c) attribution (the act of attributing positive events 
and outcomes to one's own agency but attributing negative events and outcomes to external forces); and (d) exaggeration (the act of representing outcomes or embellishing events as more significant than is actually suggested from other data) (Creswell, 2009).

To avoid researcher bias, I must be transparent about my personal interest in this research agenda. For 15 years, I worked as an editor and reporter for newspapers across the United States. While working as an editor, I served as a member of several diversity committees responsible for recruiting and retaining diverse employees. Currently, I work as a faculty member at John Brown University, a small Christian campus. I serve on the institution's diversity committee and act as sponsor for the multicultural student organization. In both roles, I am often an advocate for diversity.

\section{Significance of the Study}

By 2050, the white, non-Hispanic population will account for an estimated $50 \%$ of the total population (Passel \& Cohn, 2008). All institutions of higher education should look at ethnic diversity, not only in numbers but also in how they approach diversity within the curriculum, campus climate, and institutional operating strategies in order to appeal to and educate the student body (Perez, 2010). Although institutions strive to facilitate change in institutional diversity, research shows that hiring a diverse professoriate can help improve overall diversity on campus (Armstrong, 2011). Higher education leaders understand that as minority populations continue to grow, the competition to enroll minority students will increase among peer institutions, online universities, and community colleges.

Again, King's “I Have a Dream Speech” highlighted the inequities of segregation 50 years ago. Today colleges and universities continue to struggle with how to be more inclusive in higher education, particularly in making sure faculty reflect the diversity of campus 
communities. Within evangelical circles, the charge to create more diverse institutions often conflicts with the theological mission. Martin Luther King, Jr. said, "11:00 Sunday morning is America's most segregated hour." Not many Christians have refuted King's statement, and often the statement is credited with inspiring multicultural congregations. Nonetheless, while some evangelicals respond that segregation is an embarrassment (McMinn, 1998), other more conservative evangelicals argue that having separate churches is better for the evangelical movement (Lee, 1991; Nieves 1991).

Bradley (2013) cautioned that in an age when church growth is centered in Africa, Asia, and Latin America, evangelicals must adapt to changing demographics or risk losing relevance. He stated that often evangelicals only value the perspectives similar to their own, while denying any proof of racial concerns in organizations (Bradley, 2013). Bradley also said he wants to help evangelicals show the world that the gospel brings people from all tribes, languages, and cultures together. Despite different denominational affiliations and differing opinions of what it means to be evangelical, the chapters offer discussion on how institutional missions connect with faculty diversity efforts.

Using Daryl G. Smith's dimensions for diversity, this qualitative study primarily focuses on faculty diversity efforts at three CCCU institutions in Mississippi, Oklahoma, and Texas. The CCCU divides the South into Southeast and a Southwest region. Two of the universities are located in the southeast and the other one in the southwest. Given the national changing demographics and the competitive nature of growing campus enrollments, the timing of the study is well-suited to add to an ongoing higher education conversation. The literature on race/ethnicity and faculty at private and public schools is significant (Turner \& Smith, 2002). However, 
research that focuses on Christian campuses is limited. This study offers deeper understanding of diversity efforts and what drives faculty diversity at three southern Christian campuses.

Reyes and Case (2011) reported the total number of persons of color at CCCU included 1,244 full-time faculty and 58,313 students in 2009. The CCCU made gradual but steady gains in the recruitment and enrollment of students of color. The overall percentage of students of color at CCCU institutions increased gradually from $16.6 \%$ in 2003 to $19.9 \%$ in 2009. In comparison, the level of diversity among non-CCCU institutions increased from $20.5 \%$ in 2003 to $23.2 \%$ in 2009 . That leaves a $3.3 \%$ gap in the two groups that year (Reyes \& Case, 2011).

Despite the slight progress with increasing the number of students of color, the representation of faculty continues to be an issue with CCCU members (Reyes \& Case, 2011). Among CCCU institutions, the majority faculty of color are non-tenured. Nationally, racial and ethnic faculty comprise $13.8 \%$ of the faculty on majority campuses (Turner, 2002). At CCCU campuses, racial and ethnic minorities comprise $6.5 \%$ of full time faculty (Laney \& Daniels, 2006). Moreover, Reyes and Case (2011) reported that in the Southeast, non-tenured faculty at CCCU campuses increased from $7.5 \%$ in 2005 to $10 \%$ in 2009 . In the Southwest, non-tenured faculty had the highest percentage overall with a high of $13.4 \%$ in 2007 and a low of $8.5 \%$ in 2005. Given the struggles to increase faculty diversity at CCCU campuses, this study provides three case studies highlighting institutional efforts to increase faculty diversity.

\section{Conceptual Framework}

Daryl G. Smith, a professor of education and psychology at The Claremont Graduate School, developed a conceptual framework that maps four separate but interconnected dimensions of diversity. Scholars described the dimensions as helpful when capturing and evaluating campus diversity work and useful for establishing a structure to discuss those efforts. 
According to Smith (2009), in the last 50 years, scholars have developed keen interests in the four dimensions on campus when examining the commitment to diversifying higher education in the United States.

- Access and Success. Research began on this dimension in the 1960s. This dimension relates to an institution's undergraduate and graduate student populations and is generally concerned with the achievement of previously underrepresented or minority groups (e.g., graduation rates, persistence, and retention) (Clayton-Pedersen, Parker, Smith, Moreno, \& Teraguchi, 2007). Most conversations in regard to diversity center on this dimension. This dimension emerged from a social and historical context of past wrongs, including the exclusion of minorities.

- Campus Climate and Intergroup Relations. This dimension encompasses the type and quality of campus relations among students, faculty, and staff. It focuses on the question of whether or not the campus celebrates and acknowledges diversity (Clayton-Pedersen et al., 2007). University leaders have found that when discussing access and success, the issue of campus climate often surfaces. This dimension addresses how the campus environment influences student success. Another objective of this dimension involves efforts to promote and foster intergroup dialogues and relationships.

- Educational and Scholarly Mission. This dimension involves the availability of courses with significant diversity content, electives verses required, but also considers the sequence of diversity courses, faculty engagement with diversity issues, and studentlearning outcomes related to diversity (Clayton-Pedersen et al., 2007). Additionally, this dimension involves making sure diversity exists in the curriculum, understanding how 
diversity affects teaching methods, and acknowledging how societal diversity shapes scholarly works.

- Institutional Vitality and Viability. The final dimension refers to questions, which build upon the many changes mentioned in the earlier dimensions. How can administrators, faculty, and staff make sure diversity becomes a part of the campus ethos? This dimension is an all-encompassing dimension primarily dedicated to understanding the history of diversity issues; institutional strategies; framework for monitoring diversity; and measurement of diversity among faculty and staff (Smith \& Parker, 2005). The institutional vitality and viability addresses the overall university commitment to diversity, including policies, strategic plans, and missions.

During the CCCU Engaged Community forum, Daymond Glenn (2014) discussed several frameworks including Smith's (2009); Williams, Berger, and McClendon's (2005); and Hurtado, Milem, Clayton-Pedersen, and Allen's (1999) with chief diversity officers. He noted the frameworks all have common roots. Glenn also emphasized the importance of choosing a framework to guide projects and diversity work at their institutions. Glenn (2014), vice president for Community Life and chief diversity officer at Warner Pacific University asked questions about required diversity courses, and then he shared his institution's diversity framework, which consists of five tenets:

- Multicultural education

- Multicultural programs

- Equitable campus culture

- Community collaborations

- Social justice and action 
Afterward, Glenn discussed the Hurtado et al. (1999) framework "Enacting Diverse Learning Communities." The framework consists of the following dimensions:

- Historical legacy of inclusion/exclusion

- Structural diversity

- Psychological climate

- Behavioral dimension

He also highlighted that this particular framework sought to understand the behavioral and emotional characteristics for students and faculty on campus. Next, Glenn mentioned that the Williams et al. (2005) offered the "Toward a Model of Inclusive Excellence and Change in PostSecondary Institutions." He noted that this framework builds on the other frameworks. As in Smith's model, the intent is to move beyond assessing student diversity to focusing more on the overall institutional plan (Glenn, 2014). The four elements included in this model:

- Access equity and success

- Campus climate

- Curricula excellence

- Learning and development

Smith's dimensions are similar to those in the "Model of Inclusive Excellence." While each of her four dimensions can be used to organize and assess tasks, their influence increases if they work in relation to one another (Smith, 2009). Smith further explained that with her framework each area may be negatively influenced if it operates alone and is not reinforced by the others. All four dimensions of Smith's (2009) diversity framework were used to inform the study. However, particular focus was devoted to the dimension of vitality and viability as it relates to institutions' efforts in support of increasing faculty diversity. 
When evaluating diversity initiatives, reviewing work on the program level does not necessarily bring about significant change. Instead, linking the work to an institutional mission and ensuring that a framework exists to facilitate that change encourages longer-lasting results (Perez, 2010; Smith \& Parker, 2005). Specifically, the research reveals that comprehensive institutional change in teaching methods, curriculum, campus climate, and institutional definition and culture provide educational benefits for both minority and majority students (Smith \& Parker, 2005). Moreover, research highlights that a broad campus commitment to diversity may improve recruitment and retention of students and faculty from underrepresented groups and may provide positive educational outcomes for all students (Smith, 2009).

Faculty continue to be essential for sustaining diversity efforts (Smith, 2009). For all students, colleges and universities should replicate a global society. Smith (2009) maintained that replicating a global society often improves the campus climate for minorities. Moreover, a diverse faculty affords students an opportunity to learn from different perspectives and voices. Likewise, diverse faculty help students negotiate differences and learn to think critically, preparing students to participate in a democratic society (Clayton-Pedersen et al., 2007). Besides preparing students to be productive citizens, diverse faculty can be added support when it comes to access and success by "identifying talent, enabling student achievement, and studying which students are thriving and why" (Smith, 2009, p. 77).

\section{Chapter Summary}

The purpose of this qualitative study is to explore institutional efforts to increase faculty diversity at three Christian universities and examine how these efforts relate to institutional missions. The study offers descriptions of what promotes or curtails diverse faculty as well as highlight recruitment and retention efforts at the three institutions. Chapter I highlighted the importance of this 
study to CCCU member institutions that are struggling to make gains in employing and retaining diverse faculty. The chapter also discussed Daryl G. Smith's (2009) dimensions of diversity that offered four areas for studying diversity: access and success, institutional vitality and viability, education and scholarship, and intergroup relations and campus climate. The chapter that follows contains the review of related literature on faculty diversity. The methodology and procedures used to gather data for the study are presented in Chapter III. The results of analyses and findings are contained in Chapter IV. Chapter V provides a summary of the study and findings, conclusions drawn from the findings, a discussion, and recommendations for practice and further study. 


\section{CHAPTER II}

\section{LITERATURE REVIEW}

A large part of the literature on faculty diversity highlighted the many ways faculty members are influencing the academy, shaping the classroom experience, and preparing students to work in a diverse, global society. CCCU schools have become more ethnically and racially diverse over the past 20 years, but more work needs to be done on campuses in terms of recruiting and retaining minority faculty (Rine \& LoMaglio, 2012; Nieves, 2012). Yancey (2010) agreed and further explained the societal benefits of diversity at faith-based institutions and its importance for student learning. He wrote that mainstream America has likely underestimated the potential influence of Christian colleges and universities, given the recent increase in enrollment at Protestant institutions (Yancey, 2010).

This chapter provides a review of the literature and research related to diversity efforts in higher education, especially in Christian colleges and universities. As shown in the references, I used the following key words to access several online academic databases - EBSCO Academic Search Premier, Journal Storage, ProQuest Direct, and Education Resources Information Center (ERIC). Additionally, I conducted a generic search of databases for dissertations and theses in the University of Arkansas' and John Brown University's library systems that yielded thousands of references on the topic of diversity and higher education. I conducted several more general searches before narrowing the topic and setting some parameters. I collected several studies, before I limited the range of publication dates after 2000 and specified that the search include all results, including scholarly journals and bibliographies. The literature review begins by examining the historical roots of Christianity and higher education. The chapter is divided into 
three sections that include (a) history and mission of faith-based institutions, (b) the diversity imperative, and (c) hiring diverse faculty.

\section{History and Mission of Faith-based Institutions}

In order to understand the challenges of hiring diverse faculty and changing the culture of evangelical campuses, university leaders must review history to see when problems with diversity and inclusion began in the church and in Christian institutions (Peart, 2000; Perez, 2010; Yancey, 2010). During colonial times, the American colleges were mostly religious institutions established to educate clergy and laity (Peart, 2000; Thelin, 2004; Washington, 2006; Yancey, 2010). Washington (2006) wrote that a religious commonwealth required an educated clergy, but it also needed academically sound leaders. Seeking to integrate faith, life, and learning, the Puritans established institutions such as Harvard and Yale (Washington, 2006; Yancey, 2010). Harvard, founded in 1636, was considered to be a "Christ-centered" institution (Patterson, 2001), providing a distinctively Christian education (Ringenberg, 2006). Further, Patterson (2001) explained that the colonial colleges established a narrow curriculum for the primary purpose of educating the elite and incorporating biblical and theological studies with traditional liberal arts. Their goal was to "create disciplined Christian gentlemen" (Ringenberg, 2006, p. 50). Despite the original purpose of creating institutions to bring savages to Christ (Thelin, 2004), few people of color, particularly Native Americans and slaves of Africanheritage attended such colleges.

Prior to the Civil War, few opportunities existed for African Americans to attend colleges (Peart, 2000; Washington, 2006). Ringenberg (2006) reported that early records show that two Blacks, Samuel Hopkins and Ezra Stiles, enrolled at Princeton in the mid-1770s to prepare themselves as missionaries. The two attended the institution just as a group of Philadelphia 
Quakers organized the country’s first anti-slavery campaign (Peart, 2000). The evangelical upsurge in the 1740s, called the Great Awakening, impacted colonies as writers, preachers and political leaders used religion to shape the plight of slaves. Often they discussed freeing the souls of the Negro, but ignored their physical bondage (Peart, 2000). Later in 1826, John Russwurm at Bowdoin College in Maine and Edward Jones at Amherst Collegiate Institution in Massachusetts were the first two black students to receive a college education (Ringenberg, 2006). Russwurm graduated and went to Liberia in West Africa, where he governed the country's southern Maryland colony. Years later the nation witnessed "an increasing number of colleges not only for Blacks and women but also for groups outside the Protestant mainstream, many of whom had recently come from Europe" (Ringenberg, 2006, p. 85).

Thelin (2004) supported Ringenberg's notion that the educational missions for providing access to more populations shifted early in the $20^{\text {th }}$ century. Moreover, Thelin (2004) noted that regardless of skin color or gender, several institutions committed to providing integrated and coeducational learning opportunities. Abolitionists founded institutions such as Berea in Kentucky, Lincoln in Pennsylvania, and Wilberforce in Ohio to educate African Americans. The Presbyterians built and supported Lincoln, and the Methodist Episcopal Church started Wilberforce. Two private citizens, John Fee and Cassius M. Clay, founded Berea College (Thelin, 2004). Berea College founders established that the campus would be "an anti-slavery, anti-caste, anti-tobacco, anti-sectarian school - a school under Christian influence; a school that will furnish the best possible facilities for those of small means who have energy of character that would lead them to work their way through the world" (Ringenberg, 2006, pp. 86-87).

According to Ringenberg (2006), schools such as Berea College served as early models of integration, where Blacks and Whites attended college. However, that commitment soon 
ended. In 1904, the Supreme Court upheld a school segregation case from Kentucky, forcing Berea to end the integration (Ringenberg, 2006). The Kentucky Legislature's passage of the Day Law forbid teaching black and white students together. When the U.S. Supreme Court upheld the Day Law, Berea set aside funds to assist in the establishment of Lincoln Institute, a school located near Louisville, for black students (Ringenberg, 2006). The ruling started a trend. Other denominational colleges established black-only colleges and secondary schools with the idea of schools being "separate but equal” (Ringenberg, 2006). With the exception of Quaker institutions, little historical documentation remains regarding the early efforts of today's Christian colleges and universities to make educational opportunities available for all. In their book Divided by Faith: Evangelical Religion and the Problem of Race in America, Michael Emerson and Christian Smith (2000) conducted 2,000 telephone surveys and 200 face-to-face interviews. The researchers argued that evangelicals have a theological world view that makes often prevents them from understanding the systematic injustices in communities. Emerson and Smith (2000) also provided a historical overview of the American church and diversity. Denominations often played a role in promoting or opposing slavery. The historical roots of the church still divide modern-day institutions today (Emerson \& Smith, 2000; Peart, 2000; Thelin, 2004). Emerson and Smith (2000) stressed the importance of acknowledging the past to begin the process of racial reconciliation within the church. Emerson and Smith reported that the Quakers (Friends), Methodists, Mennonites, and Baptists fought early on against slavery. The authors explained that in the period leading up to the Civil War, several denominations, as well as the American Presbyterians, split over their view of slavery. Additionally, the Southern Baptist Convention divided because one group defended slavery 
(Emerson \& Smith, 2000). Throughout history, churches and religious groups have inspired American politics.

\section{Faith Plays Both Sides}

Many Christians were antislavery activists in the early 1900s. However, when they had to choose between winning new converts and fighting for the rights of the oppressed, they neglected the justice issue (Emerson \& Smith, 2000). Emerson and Smith (2000) documented the roles some of the early church fathers played in prolonging slavery. Those same church fathers were instrumental in establishing early Christian colleges. Historians recognize George Whitfield as the founder of American evangelicalism (Emerson \& Smith, 2000; Peart, 2000). While Whitfield preached for equality between black and white Americans, he continued to support slavery (Peart, 2000; Washington, 2006). In presenting a conflicting vision of equality and slavery, Whitfield appeared to separate the spiritual from social issues (Peart, 2000; Washington, 2006). Washington explained that Whitfield believed the economic success of the colonies was directly linked to the increased productivity of slave labor. He appeared before the Georgia Legislature and made a case for the value of having slaves to maintain his orphanage, a contradiction to the gospel message he preached and what he had once published in a pamphlet (Peart, 2000).

Another minister, Charles Finney, also preached a message of abolition but changed his tune when threatened with losing church members. Emerson and Smith (2000) argued that Finney made a substantial contribution to the abolitionist movement by providing the "theological framework" for abolition. The link between history and the work of diversity is important for success (Clayton-Pedersen et al., 2007). This means acknowledging the not-so pleasant past of the institution to establish creditability prior to beginning any diversity 
initiatives, including increasing the number of diverse faculty members on campus (Yancey, 2010). Nevertheless, philosophical differences ushered in a different description of Christfollowers, evangelicals. The shift prompted Christian denominations and their leaders to start campuses now described as evangelical Christian campuses (Patterson, 2001). This in turn led to the creation of the CCCU, a group of faith-based institutions across the nation (CCCU, 2013).

In the latter half of the $19^{\text {th }}$ century, social forces in the United States jeopardized the dominion of Protestant Christianity (Marsden, 1996; Patterson, 2001). The number of Catholics increased, and Catholics gained more social and political power (Yancey, 2010). Consequently, new elite universities Stanford and Cornell developed without religious support. According to Yancey, Europe's Enlightenment movement also influenced higher education in the United States because it encouraged academics to separate church and state. As a result, he wrote that more educational institutions worked to stay clear of religious affiliations (Yancey, 2010). Similarly, Patterson (2001) suggested that many Protestant universities accepted the ideological change, began to downplay their denominational ties, and promoted more general moral values (Marsden, 1996).

\section{CCCU Promotes Christian Colleges}

The CCCU and the American Association of Bible Colleges provided struggling Christian universities support as attitudes shifted from providing Christian education (Perez, 2010). These organizations allowed member institutions a more unified way to market the value of integrating faith and learning at respective campuses (CCCU, 2013.) Moreover, the CCCU worked to rebrand member institutions, describing them as academically and theologically sound colleges and universities. In an effort to support campuses in offering quality instruction, the CCCU hosted dozens of professional development opportunities for faculty and staff (CCCU, 
2013). Faculty development opportunities proved to be critical for campuses that integrate faith and learning.

Yancey (2010) reported that more than 800,000 students attend Christian colleges, and "their influence on our larger society is consequential" (p. 5). In order to study the challenge of improving racial diversity at faith-based institutions, Yancey surveyed 406 Protestant colleges in the United States. According to Yancey (2010), given the large number of current students, along with the increasing number of incoming students, it is important to understand what shapes students' racial attitudes or perspectives. Furthermore, Yancey (2010) emphasized that the influence of Christian education on the larger society continues to grow, and diversity plays an integral part in developing productive, responsible citizens.

\section{Evangelical Defined}

American Protestants show "ideological and theological" diversity and do not represent a uniformed group (Yancey, 2010). Evangelical and mainline Protestants are the two dominant groups. While both groups adhere to the same basic tenets of faith, "there are main differences between them that help shape their ability to attract minority group members" (p. 10). Yancey (2010) wrote that the former group underscored returning to the biblical fundamentals and became known as fundamentalists; the latter group highlighted the need for social justice, including providing for the poor and other marginalized groups. He described the scenario: Protestants of color and white mainline Protestants are theologically divided on issues such as biblical inerrancy and social issues such as homosexuality. To this point, Lew (2001) suggested that some evangelicals believe the term multiculturalism or diversity includes sexual orientation. This controversial view provides another obstacle for institutional leaders who believe there is a biblical basis for diversity that does not include sexual orientation. Furthermore, the church 
patterns with managing diversity likely surface at Christian institutions and hinder university leaders' ability to attract both faculty and students of color (Yancey, 2010).

Ringenberg (2006) proclaimed that ultra conservatives, or self-described fundamentalists, continue to populate Christian colleges. The fundamentalist movement continues to influence the largest number of Protestant colleges, including the Baptist, Presbyterian, and Disciples of Christ denominations (Ringenberg, 2006; Yancey, 2010). Fundamentalists place a high emphasis on the divinity of Christ and trustworthiness of the biblical record. Ringenberg (2006) wrote that several groups strayed from the term fundamentalist and opted to be called evangelical, meaning they want to be known for Christian grace and issues other than theology. Also, Ringenberg (2006) wrote that evangelical "became the preferred one of the majority of orthodox Protestants after World War II (by the 1980s, probably no more than 10-15 percent of the estimated 40 million evangelicals) would have called themselves fundamentalists" (p. 172).

Still, evangelicals and fundamentalists tend to have more conservative views than mainline Protestants (Yancey, 2010). Emerson and Smith (2000) described conservative Protestants' view of resolving racial conflict as one that ignores institutional racism (Yancey, 2010) and other forms of discrimination and focuses on developing interracial friendships. Thus, this view discounts the experience of people of color promoting a "color-blind, individualistic perspective" as unable to meet social needs and manage the racial conflict (Yancey, 2010, p. 25).

\section{Evangelicals Struggle with Difference}

The historical patterns, theological frameworks of diversity, and the traditions or missions of Christian colleges often determine how institutions handle multiculturalism. In Kratt's (2004) study on diversity at evangelical Christian colleges, he made the case for multiculturalism by focusing on Scripture that speaks to the diversity of the body of Christ 
(Kratt, 2004). He cited Acts 9:11 in which the early church experienced unity despite the differences of culture. Kratt used a mixed-methods approach to study three CCCU institutions. In addition to interviews, the researcher spent time analyzing institutional documents and archival information to provide quantitative and qualitative data to assist him in determining what drove an institution to seek change in the area of diversity and how they were monitoring progress. Kratt (2004) determined that many evangelical institutions refused to see reconciliation as playing an integral role in campus diversity efforts. One of the claims for evangelicals is creating followers of Christ, and anything that may thwart that mission, including challenging existing social structures and institutions, gets avoided (Emerson \& Smith, 2000). Besides that, Emerson and Smith (2000) argued further that the racially homogenous nature of Protestant churches prohibit Christians from developing authentic cross-cultural relationships.

Emerson and Smith (2000) countered Kratt. They argued that many Christians see reconciliation as an important step in beginning to acknowledge the importance of diversity in the kingdom of God (Emerson \& Smith, 2000). Several other researchers have also highlighted biblical principles as they relate to diversity (Woodley, 2001). Woodley (2001) stated, "We need a plethora of perspectives and cultural worldviews if we are to see a clearer picture of the immense grandeur of our creator God" (p. 17).

\section{Campus Diversity Efforts Endure}

In order to see lasting changes in the area of diversity, an institution's history and mission must be aligned (Aleman \& Salkever, 2003). In Aleman and Salkever's (2003) qualitative study, the researchers interviewed faculty, students, and administrators at a non-Christian liberal arts college in efforts to understand the purpose of liberal education and its relevance in creating a "multicultural community" (p. 564). The researchers discovered that institutional culture can be 
shaped through leadership and change efforts. Another researcher, Perez (2010) agreed with Aleman and Salkever (2003) that institutional leadership can promote diversity efforts. Perez (2010) discussed in his dissertation what drives diversity efforts at four Christian colleges. He found that institutions that connected diversity work to their institutional work made more progress improving racial diversity on campus. CCCU Interim President Dr. Bill Robinson has encouraged member institutions to make progress in the area of diversity, particularly in the area of hiring diverse faculty. This shifts the attention from increasing the number of ethnically diverse students to faculty (Patterson, 2001).

The CCCU has not always had a clear mission on diversity. At times, leaders have taken a decentralized approach, allowing institutions to create diversity initiatives on the respective campuses (Patterson, 2010). However, Dr. Myron Augsburger, who was elected president in 1988, made diversity a priority at the CCCU by bringing together a group of Christian scholars and leaders to participate in a multicultural dialogue for developing a theology of inclusion (Patterson, 2001). As a result of that gathering, the CCCU co-published a book in 1991 that comprised essays on the topic of diversity titled Ethnic Minorities and Evangelical Christian Colleges. The book shared experiences of students and faculty of color at predominantly white Christian colleges. That same year, the CCCU created the Office of Racial/Ethnic Diversity to continue the diversity conversation. This office organized and often sponsored diversity conferences and gatherings (Patterson, 2001). Upon Dr. Augsburger's departure from CCCU, the office closed and diversity efforts were spread to individual institutions (Patterson, 2001).

In an effort to continue Dr. Augsburger's diversity work, the next CCCU President Robert Andringa set up a council to facilitate and continue diversity discussions. The council conducted training and development for faculty and staff and created an award to recognize 
diversity efforts of member-institutions. The Robert and Susan Andringa Award for Advancing Racial Harmony recognizes CCCU campuses that have made progress in the areas of diversity, racial harmony, and reconciliation (CCCU, 2013). Despite efforts to illustrate the value of diversity efforts, Perez (2010) wrote these institutions still continue to struggle to link diversity to strategic planning efforts and the general mission.

\section{Evangelicals Stand on Faith}

Becoming more mainstream brings additional problems for evangelical colleges as they struggle to keep religion at the center of their educational missions (Yancey, 2010). Among the new challenges are diversity concerns (Wolfe, 2006). As mentioned, evangelical Protestantism does not have a stellar record when it comes to managing race matters (Kratt, 2004; Peart, 2002; Yancey, 2010). Wolfe (2006) wrote that evangelicalism spread in the South supporting the "racial bigotry" common at one time in the South (p. 20). Further, Wolfe (2006) referenced the Pentecostals and how in the $20^{\text {th }}$ century the movement began as a biracial faith but eventually split into white and black congregations. Baptists, the largest Protestant denomination, also split along racial lines.

White evangelicals have made some efforts to overcome their storied past (Wolfe, 2006). According to Wolfe, mega churches and national church movements such as the Promise Keepers now celebrate multiculturalism, creating more diversity within the evangelical scene.

Despite the increased diversity within the church, Wolfe wrote:

America's evangelical colleges are not diverse institutions by any stretch of the imagination. Fuller Seminary in Pasadena, California, which trains more evangelical clergy than any other institution in the United States, is stunningly multicultural, but its success in this area has not been matched by undergraduate institutions. Only about 2 percent of Wheaton students are African American, for example, compared to 8 percent at Earlham and 7 percent at Oberlin, similar but non-evangelical Midwestern institutions. Among universities, Baylor has a relatively robust African-American percentage (6 percent), but it is still lower 
than at nearby public universities such as the University of Houston (15 percent) or the University of Tulsa (8 percent). (p. 6)

Wolfe (2006) wrote that an explanation of why evangelical colleges lag behind secular ones in their ability to attract a racially diverse student body (McMinn, 1998; Yancey, 2010) may be because of their lack of religious diversity. Wolfe cited that many institutions require faculty and students to sign statements of faith, which exclude people who are from different religious backgrounds. Wolfe (2006) noted that statements of faith are designed to prevent religious diversity. She wrote in her article: "That is one reason I object to them; they smack of religious bigotry and suggest a lack of appreciation for academic freedom. But there is something else wrong with statements of faith: they manifest a defensiveness that is one of conservative Christianity's less attractive features" (p. 6). Although such statements do not usually address race, Wolfe (2006) reported they can signal past occurrences that traditionally have been unwelcoming to diverse student and faculty populations.

\section{The Diversity Imperative}

Topics of diversity continue to fuel conversations across the United States, and currently key discussions center on the role of higher education in shaping the nation. Smith and Schonfeld (2000) wrote that as diversity efforts in higher education are under scrutiny, institutions need to find ways to measure the impact of diversity initiatives and the value of diverse populations on campuses. In recent years, scholars have said that racial diversity positively impacts students (Aleman \& Salkever, 2003; Smith \& Schonfeld, 2000; Turner, 2000). However, more quantitative and qualitative research is needed to address diversity concerns beyond students (Smith \& Schonfeld, 2000). In response to advancing the conversation, the literature offered numerous examples of how diverse faculty can facilitate positive inclusive environments for teaching and learning. For universities seeking accreditation, the Higher Learning Commission 
[HLC] (2013) recommends that "the institution understands the relationship between its mission and the diversity of society" (p. 5). The HLC recommended that universities consider their role in a culturally diverse society and create processes and activities that reflect human diversity.

\section{Scholars Talk Diversity Business}

Avery and Thomas (2004) wrote organizations are not alone in their efforts to increase employees' multicultural competencies. Researchers and educators seek to develop students' diversity management skills before they graduate (Day \& Glick, 2000; Helms, Malone, Henze, Satiani, Perry, \& Warren, 2003). One of the most common practices for creating awareness among students toward demographic shifts and cultural differences is the incorporation of diversity content in the curriculum (Schneider, 2000; Smith, Hornsby, \& Kite, 2000; Waterman, Reid, Garfield, \& Hoy, 2001). In fact, $62 \%$ of colleges, universities, and community colleges require the completion of a diversity course for graduation (Schneider, 2000).

Another way to create student awareness includes finding ways for student interaction. As campus diversity increases, so does the opportunity to interact with members of different demographic groups (Chang, 1999). If structured properly, such interaction has the potential to reduce prejudice while enhancing sensitivity toward minority groups (Dovidio, Gaertner, \& Kawakami, 2003; Smith \& Schonfeld, 2000). In short, the literature supported that through extended positive contact with diverse others in positions of equal status, individuals may become more competent at managing organizational diversity (Avery \& Thomas, 2004). According to the teaching division of the American Psychological Association, diversifying content increases sensitivity and awareness, broadens understanding of human conditions, promotes tolerance, enhances psychological mindedness, encourages personal perspectives, and shapes students' political action (Simoni, Sexton-Radek, Yescavage, Richard, \& Lundquist, 
1999). To achieve these objectives, educators incorporate different methods (Ledwith \& Seymour, 2001). An example of this is connecting diversity to business rationale (Varner, 2001). When students understand the business rationale for studying diversity and believe the course is practical and meaningful, they may retain the knowledge and material (McKendall, 1994). For instance, before taking a diversity course, $57 \%$ of students recently indicated a lack of awareness of workforce diversity as a business concern (Muller \& Parham, 1998). Therefore, although it is necessary for faculty to cover a variety of topics in particular disciplines, it helps if faculty can highlight the business relevance to students (Avery \& Thomas, 2004).

In a 1997 report titled Diversity Works: The Emerging Picture of How Students Benefit, Daryl Smith and her colleagues — a team of researchers from the Claremont Graduate University - reviewed hundreds of studies. The research concluded that institutional diversity initiatives provide students with real educational and social benefits. Daryl Smith (2009) designed a framework to assist practitioners and researchers in thinking about the components of diversity. Rather than viewing diversity as a long list of activities or identities, her framework conceptualizes diversity in higher education as four distinct but interrelated dimensions focusing on the institution: access and success, campus climate and intergroup relations, education and scholarship, and institutional viability and vitality. The sections below use Smith's framework to highlight what scholars have reported in terms of diversity work, specifically minority faculty contributions and considerations for majority administrators and faculty who want to improve campus racial diversity.

\section{Access and Success}

Diversifying the faculty is still a key factor in achieving success for diverse students 
(Astin, 1993; Smith, 1997; Umbach \& Kuh, 2006; Yancey, 2010). Faculty members from diverse backgrounds have been shown to mentor students, bring new perspectives to the curriculum and to scholarship, and enhance the institution's ability to be successful in a variety of realms (Smith, 1997; Umbach \& Kuh, 2006; Yancey, 2010). Moreover, the numbers of diverse people, or more specifically the presence of a critical mass of diverse people, create greater opportunities for social support, role models, and mentoring. The challenge of creating racial diversity at colleges and universities is one that is common across different educational institutions. Such racial inclusion can also help colleges and universities fulfill their commitment to improve the larger society by serving populations that have been traditionally marginalized or ignored throughout history (Yancey, 2010).

Another way to serve marginalized students is to make sure they are engaged on their campuses. Umbach and Wawrzynski (2005) used two national data sets to explore the relationship between faculty practices and student engagement. Their findings suggested that students reported higher levels of engagement and learning at institutions where faculty members used active and collaborative learning techniques. Students more often achieved success when they had enriching educational experiences (Umbach \& Wawryznski, 2005). Access and success of underrepresented populations remain a challenge for higher education, but researchers are changing the way they study those challenges.

Since 1989, there have been some changes in how researchers and institutions examine issues of access and success (Smith \& Wolf-Wendel, 2005). Early research focused on exploring why too often minority students were underprepared when they arrived on college campuses. The literature highlighted poor academic preparation in comparison to examining what institutions could do to improve access and success (Smith \& Wolf-Wendel, 2005). In contrast, 
research today focuses more on examining what institutions of higher education are doing to address access and success (Smith \& Wolf-Wendel, 2005).

In terms of access and success at private faith-based institutions, Christopher Confer (2011) examined the factors affecting minority student enrollment at four-year CCCU member institutions in the U.S. The quantitative study included a sample of 283 admitted minority students from eight CCCU member institutions, which participated in the ASQ PLUS survey between 2005 and 2010 years. Confer (2011) reported that demographic and background characteristics of minority students, perceived institutional characteristics, financial factors, and institutional marketing factors influenced minority students' decisions to attend CCCU institutions. Confer suggested that CCCU institutions become more strategic in how they recruit minority students, and how they deal with those students during the admissions process. Furthermore, campus interaction, including contacts with faculty and students, provided minority students with experiences that helped them with making enrollment decisions (Confer, 2011).

\section{Campus Climate and Intergroup Relations}

Carolyn Vasques-Scalera (2002) conducted a qualitative study of a group of former students who participated in Intergroup Relations, Conflict and Community (IGRCC) as peer facilitators. Through analysis of questionnaires, in-depth interviews, and student reflection papers, she examined how these students were affected by their experiences in the program. Data were gathered from 30 former facilitators one to four years after they left the program. Her study highlighted that student facilitators in a diversity program were more likely to address issues of prejudice and oppression and choose careers that allowed them to appreciate diversity. Similarly, Smith and Schonfeld (2000) argued that acknowledging faculty, staff, and student differences such as race, class, gender, sexual orientation, ethnicity, and religion — helps build community. 
Likewise, Allport's (1954) hypothesis proposed that intergroup contact reduces stereotypes and prejudice when four specific conditions are met. First, the situation must be consistent. Second, the diverse individuals must have a common interest. Third, competition among the groups must be avoided to keep from minimizing the goal. Finally, authorities must support efforts (Allport, 1954).

Yancey (2010) reported that ethnic studies departments developed at institutions to introduce culturally diverse perspectives into the curriculum. In the 1960s and 1970s, educational institutions also introduced multicultural programs. Yancey wrote that while such efforts were designed to create more diversity in the curriculum, they were also to create a more accepting atmosphere for students of color. He highlighted the data collected on Protestant campuses about how programming influenced students' attitudes:

I found evidence that whites who have not participated in any of the diversity initiatives were not very willing to recognize the racial problems on their campus. Such students were more likely than other white students $(15.6 \%$ to $7.4 \%: p=3)$ to state that their college and university should do nothing to correct racial problems. (p. 81)

Thus, the lack of participation of white students can directly influence how they relate to their minority peers. Yancey (2010) noted that it also may represent majority students' unwillingness to acknowledge racial concerns.

\section{Education and Scholarship}

Christian, non-religious, private and public universities all offer programming efforts to promote racial diversity. Similarly, scholars suggest that the classroom is also an effective way to deal with issues of racial diversity. Yancey (2010) found that white students enrolled in diversity courses or courses taught by professors of color were more likely to reshape their viewpoints on race issues and were also more likely to develop a deeper understanding of multiculturalism and 
the dilemma of the nation's minority residents. Furthermore, Yancey (2010) noted in the quantitative analysis that course curriculum is a relevant factor in producing more diversity on Christian campuses, and minority faculty can enhance the curriculum by infusing information not covered in traditional courses. Generally, research supports that many white or majority students acknowledge that they count on diversity or cross-cultural courses to help them become more racially aware (Chang, 2005). Yancey (2010) suggested that if minority professors are viewed as competent and diversity courses are truthful, they can have a huge impact on evangelical campuses. Yancey's conclusions mirror Chang's (2005) previous research on diversity courses and Umbach's (2007) study on minority faculty. Using data from a national study of 13,499 faculty at 134 colleges and universities Umbach's study explored the impact of faculty of color on undergraduate education. The study offered evidence suggesting that faculty of color benefit undergraduate education in two ways (Umbach, 2007). First, faculty of color provide varied teaching techniques and interacted more frequently with students than white faculty. Second, increased structural diversity among faculty leads to better use of educational practices.

In terms of scholarship, Smith and Schonfeld (2000) wrote that it is critical for faculty to engage with diversity issues. When considering diversity beyond what can be viewed on campus, Smith and Schonfeld said faculty members are eager to "explore how the presence of diversity enhances thinking skills, exposes people to diverse viewpoints, and prompts reexamination of academic and scholarly topics and areas of inquiry" (p. 10). Conversely, Yancey (2010) and Wong and Polite (1991) argued that at Christian universities faculty members are often less eager to discuss topics on race or adopt a research agenda that focuses on minority issues. None of the researchers refuted the merit in increasing the number of diverse faculty and their ability to 
impact students, enhance curricula, and offer scholarly contributions. Yancey (2010) wrote that diversity in faculty and courses "enabled educational institutions to send socially acceptable messages of racial inclusiveness" (p. 87).

Avery and Thomas (2004) also reported that current research has important educational implications. Despite an increase in diversity curriculum, there remains a discrepancy between the typical college graduate's ability to manage diversity in the workplace (Day \& Glick, 2000). One potential means of closing this gap is to identify a number of instructional techniques that help with teaching students to manage diversity. In their study, Avery and Thomas (2004) provided assistance for educators hoping to strategically enhance their students' diversity education. Designing diversity management education to include information from varied perspectives as well as structured opportunities for contact should create environments that are positive to student learning (Avery \& Thomas, 2004).

Often students arrive at college without ever having been exposed to significant diversity (Hurtado, 1999; Milem, 2000). Consequently, they are clueless when it comes to understanding group differences. Generally, they are intolerant of others, viewing their way as right and different ways as wrong (Avery \& Thomas, 2004). Recognizing this, Schneider (2000) proposed that "a single course, or even two, on diversity is at best a down payment on the kinds of knowledge citizens need both as members of a democratic society still riven by traditions of segregation and hierarchy and as participants in an ever more connected global community" ( $p$. 3). These "down payments" can pay significant dividends in terms of promoting a more harmonious society. For instance, a study examining students' pre-and post-semester diversity tolerance levels noted a statistically significant decline in diversity tolerance among white 
students unless they had been enrolled in a diversity course or participated in a diversityconscious student organization (Henderson-King \& Kaleta, 2000).

Chang (2005) discovered that white students had more positive attitudes toward African Americans upon completing diversity course requirements. Other reviews offer support for diversity content. For instance, Smith et al. (2000) found that students were more positive toward international issues following a 3-hour presentation on cultural diversity. Similarly, participating in a racial or cultural awareness workshop or enrolling in a diversity class appears to increase students' openness to diversity and sensitivity and decrease stereotypes and prejudice (Whitt, Edison, Pascarella, Terenzini, \& Nora, 2001; Yancey, 2010). Whitt et al. (2010) conducted a longitudinal study and investigated relationships between various experiences in students' sophomore and junior year and their openness to diversity. The researchers found that students were most open to diversity precollege. Diversity content may also influence tolerance and empathy (Avery \& Thomas, 2004). Furthermore, a study of 237 communication students revealed an increase in empathy resulting from taking a diversity course (Carrell, 1997). Thus, it was evident that diversity content can exhibit beneficial effects on students' attitudes and beliefs.

\section{Institutional Viability and Vitality}

The literature is consistent that campus diversity efforts directly influence students. Yancey (2010) reported that Christian colleges and universities may have more difficulty obtaining racial diversity than other institutions, and they continue to lag behind nonreligious schools in racial diversity on their campuses (Wolfe, 2006). Yancey showed concern that "students who attend these colleges often do not gain the advantages of racial diversity, and these colleges may be failing to provide the best education possible" (p. 28). Yancey conducted a quantitative study in which he examined the correlation between diversity initiatives and 
curriculum and the level of racial diversity in Protestant colleges and universities. He (2010) concluded that promoting color-blindness prevented a college or university from discovering institutional solutions to racial problems; it also dismissed some of the concerns that students voiced about race relations.

Researchers offered institutional solutions to improving campus diversity. Smith and Schonfeld (2000) wrote increasing diversity leads to a more enhanced and appealing academic environment, where greater learning and skill development is possible. Moreover, Smith and Parker (2005) co-authored a chapter that proposed using organizational learning along with a framework for diversity to help campuses that wanted to see institutional changes in the area of diversity. The authors wrote that hiring issues, curricular changes, event planning and many other diversity efforts rest with "a broad and disparate group of individuals on a campus" ( $p$. 115). Organizational culture and diversity work go hand in hand.

In order for campuses to reach their goals, diversity initiatives must be linked to the institutional mission (Aleman \& Salkever, 2003; Ibarra, 2001; Kezar \& Eckel, 2002). Moreover, Smith and Parker (2005) concluded that higher education institutions should use the learning organization evaluation to achieve their goals. The researchers discussed a three-step process of institutional diversity assessment, evaluation, and monitoring. Campus leaders were also encouraged to take a holistic approach, collecting evidence or information from learners in multiple ways, to assess their efforts (Smith \& Parker, 2005.) Several findings suggested that students benefit from schooling in more diverse environments (Chang, 1999; Gurin, 1999; Hurtado, 1999; Milem, 2000; Smith \& Schonfeld, 2000; Terenzini, Cabrera, Colbeck, Bjorklund, \& Parente, 2001; Whitt et al., 2001). In fact, Smith and Schonfeld (2000) noted that "critical thinking, problem-solving capacities, and cognitive complexity increase for all students exposed 
to diversity on the campus and in the classroom" (p. 19). Similarly, others have reported that diversity encourages learning, critical thinking, problem-solving, and group skills on campuses (Terenzini et al., 2001). The pressure for universities to produce diversity-competent graduates is unlikely to dwindle, given that employers want people who can thrive in a diverse organization (Avery \& Thomas, 2004). Consequently, educators are obligated to do a better job of facilitating diversity to prepare students for the workplace (Day \& Glick, 2000).

\section{Challenges for Diversity in Higher Education}

The past two decades have offered several legal and political challenges to affirmative action, making it difficult to diversify the student body as well as staff and faculty (Smith \& Wolf-Wendel, 2005). For example, the University of California Board of Regents implemented a policy in 1995 that removed the use of race and ethnicity in admissions. A year later, California voters approved Proposition 209, which amended the state constitution to ban race conscious admissions decisions in the state's public education system. In 1996, the Fifth Circuit Court ordered Texas to eliminate all race-conscious affirmative action in university admissions decisions (Hopwood v. Texas, 2000). In 1999, Florida then-Governor Bush had the state board of education ban consideration of race in admissions decisions for the state's higher education institutions. However, the Florida postsecondary system was allowed to consider race and ethnicity in awarding scholarships and other financial aid.

In 2003, the high court upheld the University of Michigan Law School's affirmative action policy (Smith \& Wolf-Wendel, 2005). This meant the University of Michigan could continue to use race in admissions decisions under a narrow set of circumstances. A number of the Supreme Court Justices wrote dissenting opinions. Former Justice Sandra Day O'Connor, who supported the use of race in admissions, suggested that the use of race/ethnicity in college 
admissions should be a temporary remedy until such time that equity of access has been achieved. The next day, opponents of affirmative action launched a referendum campaign to bar such programs. In 2006, voters overwhelmingly approved a ballot initiative amending the state constitution to ban affirmative action programs in higher education. Afterward, Michigan's state colleges and universities abandoned any use of race or ethnicity to promote diversity, and minority enrollment plummeted. In 2012, a federal appeals court ruled that the referendum itself was discriminatory, and the U.S. Supreme Court stepped in to decide the issue. The Michigan decision was important because it showed the importance of race and how it fits with the educational mission and role higher education fills in society (Smith \& Wolf-Wendel, 2005). Moreover, it facilitated a research agenda on the impact and benefits of diversity (Bowen \& Bok, 1998; Chang, 1999).

In June 2013, the Supreme Court decided not to rule on race-conscious school admission policies on the criteria at the University of Texas and whether they violate the equal protection rights of some white applicants. The justices sent the case back to the lower courts for further review. In Fisher v. University of Texas at Austin (2013) the court affirmed the use of race in the admissions process but made it more difficult for institutions to use such policies to achieve diversity. Justice Anthony Kennedy, who wrote the opinion for the majority, said lower courts may defer to a university's judgment that student diversity provides educational benefits, but should strictly scrutinize any race-conscious methods they invoke to attain it. Because racial classifications are "odious to a free people," universities must provide evidence showing that measures "to attain diversity are narrowly tailored to that goal" (Fisher v. University of Texas at Austin, 2013, p. 10). Moreover, Chief Justice John Roberts wrote in a 2007 opinion, people must stop discriminating on the basis of race (Parents Involved v. Seattle School District, 2007). The 
discrimination goes beyond admissions for students, and historically has impacted the hiring of ethnic minority faculty.

\section{Hiring Diverse Faculty}

Responding to internal and external pressures, campus leaders have increased their efforts to ethnically/racially diversify their faculty. Smith et al. (2004) reported that several empirical studies make the case for increasing campus diversity; however, the least successful diversity initiatives on campuses include faculty diversity. Despite decades of affirmative action policies, faculty of color continue to be underrepresented in higher education (Harvey, 2001; Trower \& Chait, 2002; Turner \& Myers, 2000). In response to this reality, the current literature offers several explanations for the low numbers of diverse faculty and offers some suggestions for improvement. Smith et al. (2004) examined whether specific interventions facilitated the hiring of diverse faculty beyond those engaged in teaching courses specifically on race and ethnicity. Using data from estimated 700 searches, they investigated the hypothesis that at institutions with predominantly white populations, hiring of faculty from underrepresented groups (AfricanAmericans, Latinos, and American Indians) occurred when at least one of three following conditions existed:

1. The job description used to recruit faculty members explicitly engages diversity at the department or subfield level; 2. An institutional "special hire" strategy, such as waiver of a search, target of opportunity hire, or spousal hire, is used; and 3. The search is conducted by an ethnically/racially diverse search committee. (p. 2)

Smith et al. (2004) also expressed that while Asian-American faculty were an increasing concern, the majority of research focused on historically underrepresented African-American, Latino, and American Indian faculty. 


\section{Discussing the Broken Pipeline}

Hiring minority professors is a prevalent problem for colleges and universities (Yancey, 2007b). A large part of the literature on faculty diversity suggests that the lack of faculty of color comes from the fact that few are earning doctorates (Myers \& Turner, 1995; Snyder, 1992; Thurgood \& Clarke, 1995; Yancey, 2010). Aguirre (2000) examined data from 1980 to 1993 and suggested that the relationship between doctoral attainment pools and faculty hiring numbers were in some cases positively related. Additionally, Aguirre (2000) noted that the two populations most likely to define diversity in colleges and universities in the 21 st century were women and minorities. At a time when it appears that faculty pools are shrinking as the demand for new faculty is increasing, minority faculty have an opportunity to really diversify faculty ranks (Aguirre, 2000). Still, too often at faith-based institutions, administrators use the pool argument to explain the lack of diverse faculty (Yancey, 2010). According to Yancey (2010), this aggravated the situation since many of the Protestant campuses are located in areas that are not racially diverse. Furthermore, some of them have membership or denominational or theological traditions that deter minority faculty from applying (Yancey, 2010; Wolfe, 2006).

\section{Challenges for Diverse Faculty}

Antonio (2002) indicated that while the research offers much on issues of recruitment and retention, the value or benefits of diverse faculty to higher education has a limited amount of research. Antonio questioned how faculty of color influenced higher education. Some scholars maintained that diverse faculty are essential to higher education because they provide students with diverse role models, assist in providing more effective mentoring to minority students, are supportive of minority-related and other nontraditional areas of scholarship, and give minorities a greater voice in the governance of the nation's colleges and universities (Smith \& Parker, 
2005). Others view the full representation and participation of faculty of color in the academy as essential to creating diverse and pluralistic colleges and universities (Turner \& Myers, Jr., 2000). Antonio (2002) found that documenting contributions such as mentoring, role modeling, and governance play a part in promoting diversity; however, "faculty-life" scholarship should be a top priority as higher education continues to experience slow growth in the representation of diverse faculty and the lack of support for race-based affirmative action.

Another challenge for faculty of color is navigating the recruitment and the evaluation process. The term "collegiality" has made its way into more faculty recruitment and evaluation processes. Quezada and Louque (2004) found that collegiality can be a code word for favoring candidates with backgrounds, political and social perspectives, and interests similar to members of the search committee. Often committees hire people who resemble the majority of faculty at the institution (Alger, 1998). Thus, creating an unwelcoming and unsupportive work environment for diverse faculty who happened to get hired (Turner \& Myers, 2000).

Another factor complicating the recruitment of faculty of color is the problem of "leaks" in the pipeline between the availability of faculty of color, the training of minority graduate students, and the accessibility of undergraduate education for minority students at the elementary and secondary school levels. This creates a problem of supply, which means more doctoral recipients of color are needed (Turner \& Myers, 2000). Turner and Myers (2000) interviewed 55 faculty of color, provoking discussions on the perceptions and assessments of institutional practices associated with recruitment and retention of faculty of color. Their study mirrored previous research and indicated the following as barriers: (a) Experience of isolation was the most common problem; (b) Occupational stress as a result of participation in too many committees and concern that their scholarship is perceived to have less merit was a concern; (c) 
At times, faculty felt as though they were the token hires and were not hired for their expertise but only to increase numbers; and (d) There was perceived ethnic and racial bias in the recruitment and hiring process.

Quezada and Louque (2004) found that much evidence suggested that the organizational culture of institutions can hinder faculty of color. More specifically, in colleges where the structure and process of recruitment, retention and the evaluation process are sometimes less supportive of diverse faculty, those seeking tenure can be placed at a disadvantage. Often diverse faculty left schools because of the campus environment. Schools and departments with high rates of attrition among faculty of color need to self-assess and review their own practices for answers and solutions. Quezada and Louque (2004) reported that university leaders recognize that likely there is a problem worth investigating in order to build a diverse faculty in higher education institutions. Moreover, diversity within the faculty impact students' multicultural understanding (Smith, 2009) and can help to ensure that students can succeed in ethnically, culturally, and linguistically diverse settings (Quezada \& Louque, 2004). The researchers concluded that administration preparation programs that assess programs for cultural proficiency, particularly when considering faculty of color, will be better prepared in developing a diverse faculty than those who do not evaluate.

\section{Professors of Color Make a Difference}

Yancey (2010) maintained that having minority faculty improved racial diversity on Christian campuses. Yancey (2007b) suggested there is a correlation between the presence of faculty of color on campus and the racial diversity in the student body. Ethnically diverse professors and those who teach diversity efforts can have lasting effects on the campus community and students. Moreover, minority faculty play an important role in facilitating the 
racial diversity that can exist on Christian campuses. However, Yancey reported that students recognized that faculty of non-diversity courses often did not deal with diversity issues in classes and were perceived as not shaping racial diversity on campus. Thus, having professors of color does not automatically lead to a change in racial perspectives. In order to have an effect, faculty members have to engage with their students on diversity issues (Smith, 2009). Whether or not diverse faculty increase understanding on campuses is an ongoing conversation. For many researchers, determining how institutions hire minority faculty members is a more obtainable goal.

Maher and Tetreault (2009) examined efforts over four decades to diversify the faculty of three universities: Rutgers University-Newark, Stanford University, and the University of Michigan. Maher documented in the 2007 book Privilege and Diversity in the Academy that the terms excellence and diversity were in opposition. The researchers found that a few exceptional men of color and women joined university faculty. Universities developed affirmative action policies and provided hiring incentives for minorities and women. But in the academic departments where actual hiring decisions occurred, resistance to having more than a few women colleagues or faculty of color remained deep (Maher \& Tetreault, 2009). Maher and Tetreault (2009) wrote that newcomers spoke of their isolation and pressure to conform.

Law professor Kenji Yoshino discussed such conditions for minorities in his book Covering: The Hidden Assault on Our Civil Rights. Yoshino (2006) wrote faculty members "need not be white, male, straight, Protestant, and able-bodied" (p.22). However, employees do need to act like straight, white, male, able-bodied Protestants. Yoshino reported this may signal progress, but "it was not equality" (p. 22). Additionally, he explored what happened to racial minorities "who breached the social contract of assimilation" such as African-Americans who 
wear ethnic hairstyles or non-English speaking employees who address each other in their native tongue (p.138). He argued that differences should be encouraged not downplayed in the workplace. Individual differences should add to the organization's value (Yoshino, 2006).

\section{Shaping the Scholarship}

As the number of diverse faculty slowly grew during the 1970s and early 1980s, minority faculty began to question scholarly norms (Maher \& Tetreault, 2009). African American, Latino and Native American studies, women's studies, and general ethnic studies programs began to transform scholarship offering new standards, methodologies, and research topics. This scholarship gradually began to affect the mainstream disciplines (Antonio, 2002; Maher \& Tetreault, 2009). Women and minority faculty also steered the curriculum toward multicultural approaches.

At the same time, Maher and Tetreault (2009) reported that university and departmental attention moved from affirmative action mandates and discrimination complaints to debates about "the legitimacy of feminist and multicultural research" (para. 7). For example, Stanford historian Estelle Freedman filed a grievance asserting that she had been discriminated against because her research on women had been characterized as a fleeting fad. She was granted tenure in 1983 (Maher \& Tetreault, 2009). The researchers found that allies among white men emerged. Terrence McDonald, a historian and dean of the University of Michigan's College of Literature, Science, and the Arts noted that his diverse colleagues taught him about the theory and practice of race and gender: "It has had a huge impact on my teaching and my own work. It is at the core of everything now" (Maher \& Tetreault, 2009, para. 9). More and more faculty members, administrators and students at public and private institutions began to understand the value of hiring diverse faculty. 


\section{Faculty Diversity at Evangelical Campuses}

Yancey (2010) joined several scholars in identifying strategies to help Christian campuses advance in the area of diversity. Scholars reported results that intentional hiring strategies are a successful way to promote hiring of underrepresented faculty outside of diversity courses. In the study, such hiring strategies were labeled: exceptional hires, search waivers, spousal hires, special-hires, and interventions (Smith et al., 2004; Wong \& Polite, 1991; Yancey, 2010). Wong and Polite (1991) suggested encouraging fellowship with minority faculty; providing mentorship and development opportunities for early-career minority faculty; seeking minority faculty members' input on institutional policy and other issues; and providing opportunities for minority faculty to develop administrative power. In Yancey's (2010) study, some of the qualitative data suggested that special hires were made with enthusiastic support from department and division chairs; however, he noted that such support may not always be the case and could endanger faculty success.

While minority students have historically been underrepresented in Christian colleges, Wong and Polite (1991) described the lack of diverse faculty as "even more acute" (p. 241). Wong and Polite provided anecdotal and empirical evidence that described the experience of minority faculty at evangelical Christian colleges. The researchers found that because of the small number of ethnically diverse faculty on the campus, the faculty of color were more vulnerable to subtle prejudice factors that prevented their longtime success as academics and hindered them from being influential role models for minority students (Wong \& Polite, 1991; Yancey, 2010).

Wong and Polite (1991) mentioned that at the time of their study no systematic studies had been attempted to offer insight on the plight of minority faculty at evangelical Christian 
campuses. While more scholars are writing about race and religion, few are focusing on the academy and more specifically on trends and development of diverse faculty. To better understand the experience of minority faculty at Christian colleges and universities, Wong and Polite (1991) used three social psychology concepts. Wong and Polite wrote that the concepts: “the ultimate attribution error, illusory correlations, and self-fulfilling prophecies" (p. 251) are interconnected and can prevent faculty from progressing socially and professionally on such campuses. First, the ultimate attribution error occurs when social roles and other situational factors are ignored that may influence or direct behaviors. Wong and Polite (1991) wrote that the ultimate attribution error may be reflected in minority professors' student evaluations. Second, illusory correlations deal with the bases of stereotypes. Yancey (2010) conducted an Internet survey that asked students at Protestant campuses about their experiences with diverse faculty members. Often students expressed that these professors lacked verbal communication skills. Third, self-fulfilling prophecies stem from the lack of campus diversity. With few minority professors in evangelical Christian colleges, Wong and Polite (1991) wrote it would be difficult to become more diverse and inclusive and improve multicultural understanding. Professors need to incorporate lessons that address institutional racism and the importance of social structures in shaping the current racial situation. Yancey (2010) found that students' responses indicated that the majority of them had no idea of the effects of institutional racism.

Another way minority faculty can help with diversity efforts on Christian campuses is to help students develop an appreciation for different cultures. Faculty racial identity can also produce an atmosphere in which students are more open to new ways of thinking. On the other hand, in Yancey's (2010) study some students complained that professors were too quick to show their anger or to overly focus on racial problems. Such actions possibly hindered 
improving campus climate for minorities. Furthermore, Antonio (2000) pointed out that while there had been a good deal of research on the recruitment and retention of minority faculty, there had not been much academic attention paid to the pedagogical contributions of faculty of color. Antonio also found that faculty of color were more likely to teach from a holistic perspective. They were more concerned with the moral, civic, and emotional wellness of students.

\section{Strategies that Work}

Universities in the 21 st century are striving to close the gap between diversity of the student body and the diversity of faculty. Within the last decade, many colleges and universities have created a variety of programs and strategies to increase the number of underrepresented minority group faculty in predominantly white institutions (Harvey, 2001; Trower \& Chait, 2002; Turner \& Myers, 2000). Statistics supported the need for progress in hiring more diverse faculty. In the fall of 2010, faculty of color comprised $17.5 \%$ of all full-time faculty members in higher education (Gasman, Kim, \& Nguyen, 2011). During Fall 2005, Marshall University Multicultural Affairs designed a survey to determine what types of programs have been established to address the lack of faculty diversity and to identify the strategies and strengths of these programs as well as the obstacles they face. The study provided a descriptive report of the practices of higher education institutions in increasing underrepresented group faculty. One suggestion that came from the study included hiring post-doctoral candidates as "fellows" and offering low teaching loads to give the student-instructors time to finish a dissertation. Researchers also pointed out that providing supplemental resources to colleges and academic units to hire and retain diverse faculty helped in the adjustment of candidates (Marshall University Multicultural Affairs, 2005). Other successful strategies reported involved ways to improve the curriculum for developing faculty. 
For example, Allan and Estler (2005) studied eight faculty members who were of Christian or Jewish heritage and involved with the educational leadership program within the College of Education and Human Development at the University of Maine. At $97 \%$ white, the 2000 Census documented the state among the least racially diverse in the nation (Allan \& Estler, 2005). Besides that, the state struggled with high unemployment and poverty rates. Maine's Native American population represented four federally recognized tribes, two of which occupied sovereign reservations, one within 5 miles of the campus. According to Allan and Estler (2005), the University community in many ways reflected the demographics of the state with $4 \%$ of both the student body and professional/faculty workforce self-reporting as racial minorities. People of color comprised $2 \%$ of hourly staff.

Faculty members who participated in the case study at the University of Maine agreed to participate in the Diversity Across the Curriculum (DAC) reading grant. In response to a request for faculty development, the University awarded the grant (Allan \& Estler, 2005). The grant provided each faculty member with funding for the purchase of books related to diversity. The DAC grant provided a total of $\$ 1,500$ to be divided among all faculty members in the group for the purchase of books related to diversity. From October 2000 to June 2001, faculty participated in four 2-hour sessions centered on the topic of diversity and leadership. At these meetings, the faculty engaged in focused readings, discussions, and dialogue with students of color and Gay Lesbian Bisexual Transgendered-identified students who were invited to provide their perspectives on classroom climates at the university (Allan \& Estler, 2005). Concepts of privilege and whiteness emerged as the primary themes of monthly discussions during the spring semester when faculty discussed texts, including Johnson's (2001) Privilege, Power and Difference, Tatum's (2003) Why are all the Black Kids Sitting Together in the Cafeteria? and 
Rothenberg's (2004) Race, Class and Gender in the United States: An Integrated Study. Allan and Estler (2005) discovered that the participants were willing to create a curriculum that addressed issues of diversity and privilege. Additionally, the researchers reported that participants gained a deeper understating of leadership for social justice as a moral obligation.

Diggs, Garrison-Wade, Estrada, and Galindo (2009) wrote that traditionally the academy has been described as being open and progressive, despite the fact that it often fails to recognize injustice (Jones, 2004) and subtle acts of racism (Solorazano, 1998) minority faculty suffer through. These issues are significant for minority faculty who enter the tenure track at majority institutions (Diggs et al., 2009). Diggs et al.'s literature review highlighted the work of scholars who wrote about minority faculty navigating the tenure process and faculty mentoring. Mentoring, opportunities for leadership, participating in campus program efforts, and creating a supportive community provide diverse faculty with needed support (Piercy, Giddings, Allen, Dixon, Meszaros, \& Joest, 2005). Institutions that touted higher retention rates for minority faculty offered more structured mentoring relationships.

Mentoring made a difference for diverse faculty and was particularly important for minority faculty members working in predominantly white institutions (Wong \& Polite, 1991; Yancey, 2010). Faculty of color have reported that mentoring facilitates their emotional, cultural, and social adjustment to institutions in which they often face alienation and isolation (Tillman, 2001). Moreover, Yancey (2010) noted that faculty success is dependent on support and mentoring that often occurs at the departmental level. Moreover, he suggested that continued research is needed to explore if such interventions improve success for faculty (Tillman, 2001; Yancey, 2010). 
Another way to increase success for diverse faculty is to support scholarly activity on ethnic minority issues (Tillman, 2001). Christian campuses that do not currently have faculty to teach diversity courses and have a limited interest in research that appeals to minorities should identify faculty attracted to both improving the literature and adding to the body of scholarship (Wolfe, 2006; Wong \& Polite, 1991; Yancey, 2010). Furthermore, faculty of color have reported that race and ethnicity influenced their reception in the academy (Bower, 2002). This may be visible when diverse faculty teach courses with multicultural content or reference racial issues in non-diverse content. When majority students challenge the validity of the content, it may be reflected in student evaluations of courses and teachers (Delgado-Romero et al., 2007; McGowan, 2000; Yancey, 2010). Thus, Tillman (2001) wrote that such interests, values, and knowledge of minority faculty can work against them as they pursue tenure and promotion.

\section{Minority Faculty Seek Community}

Faculty of color often struggled with issues of developing personal and professional identity within the academy (Tillman, 2001). Whether male or female, diverse faculty often experience isolation. Hence, social marginalization (Wirth, 1945) occurs when groups of people, with similar physical or cultural characteristics, are identified as different from the dominant or traditional culture. Consequently, this designation of difference can result in unequal treatment including discrimination, exclusion and silenced voices for the subordinated groups (Tillman, 2001). When differences are not equally valued, individuals and groups are marginalized. Nonetheless, minority faculty members bring unique perspectives from their personal and social histories to the academy (McCombs, 1989). Yet, it is difficult for them to contribute to institutional change as they face being viewed as tokens, which threatens their personal and collective identities (Wong \& Polite, 1991). Unlike the privileged experience that white males 
can generally expect in the workplace, many of the conditions faculty of color can take for granted include low numbers of students of color (Wilson, 2002), few role models (Valadez, 1998), and less support for their research interests (Turner \& Thompson, 1993). In addition, diverse professors should not count on having many colleagues of color on campuses (Tillman, 2001). So, what should faculty of color expect?

Diverse faculty can look forward to challenges from students, administrators and other faculty, questions about their credentials or qualifications, and doubts about their ability to teach (Cleveland, 2004). According to King and Watts (2004), African American faculty members face myriad challenges within predominantly white settings. Consequently, the message for these faculty is to blend in, and this request "requires such a degree of assimilation that African American faculty may find it intolerable. The alternate options are to assimilate or struggle to transform the culture so that it is less hostile for oneself and for future faculty of color"' (King \& Watts, 2004, p. 118). Undoubtedly, alienation and marginalization are part of the AfricanAmerican experience in majority institutions (Alfred, 2001). Verugo (2003, as cited in DelgadoRomero et al., 2007) reported similar challenges related to recruiting and retaining Latino faculty, including discrimination, low numbers of faculty, marginalization and a lack of status or power. Granted, the experience of minority faculty at Christian institutions mirrors those at larger majority campuses.

\section{Diversity Still Eludes Evangelicals}

The research provides bleak statistics on the progress of improving student and faculty diversity in higher education. Scholars found that the challenge is even more profound for Christian colleges and universities. Meanwhile, the demographics are constantly changing in the United States. Yancey (2010) reported one of the important changes focuses on the racial 
dynamics happening as students of different races interact more. Similarly, Emerson (2006) suggested that such students would be called "sixth" Americans. The term is a person who intentionally does not fit into the five basic racial groups: American Indian, Asian, African American, Hispanic, and White American (Emerson, 2006). As a result, the person freely flows between racially diverse groups and does not ascribe to any racial identity (Emerson, 2006). Consequently, such individuals are more likely to interracially date, have racially diverse social networks, attend multiracial religious institutions, and work in diverse career fields (Yancey, 2010). According to Emerson (2006), this sixth American is becoming more common in the younger cohorts that colleges and universities continue to serve. They may also be the next group to join the ranks of faculty. Such students expect to learn in educational atmospheres that are racially diverse since they experience such diversity in all of their other social environments. In order to stay relevant, Protestant colleges are going to have to adjust to the changing racial dynamics to compete for this pool of students and faculty (McMinn, 1998; Yancey, 2010).

\section{Chapter Summary}

The goal of reviewing the literature was to provide historical context of evangelical Christian higher education, to discuss the diversity imperative, and to highlight the practice of hiring diverse faculty. The literature offered observations that the emphasis of diversity appears to be centered on access and success and to an extent on educational and scholarly mission, two of Smith's (2009) dimensions of diversity. However, few reports mentioned the other two: institutional viability and vitality, and campus climate/intergroup relations. Limited research discussed the importance of diverse faculty in influencing and shaping diversity on campus, particularly when it comes to improving the overall institutions' diversity efforts and climate. Additionally, research is limited on how diversity efforts are progressing at evangelical 
campuses, and if there are concerted efforts to improve faculty diversity on such campuses.

Although institutions strive to facilitate change, the literature showed that creating separate and distinct programs does not always promote change. Instead, diversity content and the presence of talented diverse faculty have an impact on creating better campus environments. 


\section{CHAPTER III}

\section{METHODOLOGY}

The study uses Daryl Smith's (2009) dimensions of diversity as a conceptual framework to explore institutional efforts to increase faculty diversity at three Christian colleges and universities. Additionally, the study provides insight into what tenets of faith may be shaping the diversity conversation on the respective campuses. Using Smith's dimensions of diversity to guide the discussion, this study explores the following five questions:

1. What diversity efforts exist at three Christian universities in the South?

2. What aspects within the history of evangelicalism promote or deter the hiring of diverse faculty at these three Christian universities in the South?

3. What are Christian universities doing to recruit and retain diverse faculty?

4. What is the climate for minority faculty at Christian universities?

5. How does faculty diversity or the lack of it impact Christian universities' educational and scholarly missions?

\section{Research Design}

I selected the case study, an in-depth exploration of a situation, group or a sequence of activities (Creswell, 2007). The case study allows the researcher to explore individuals or organizations through interventions, relationships, communities, or programs (Yin, 2009). Moreover, the qualitative case study approach allows the researcher to explore "a phenomenon within its context using a variety of data sources" (Baxter \& Jack, 2008, p. 544). According to Baxter and Jack (2008), using different data sources ensures that the phenomenon is examined from multiple perspectives. Robert Stake (1995) and Robert Yin (2009; 2006) offer two key approaches to case study methods. Both researchers advocate for making certain topics are well 
explored and the phenomenon is understood (Baxter \& Jack, 2008). According to Yin, (2009) a case study design should be used when: (a) the study answers "how" and "why" questions; (b) behaviors of participants in the study cannot be manipulated; (c) contexts are critical for understanding the phenomenon explored; or (d) the boundaries are murky or difficult to determine between the phenomenon and context. However, Stake (1995) suggested that researchers consider the case as an object of the study, and Merriam (1998) proposed that the case study be a process of inquiry.

While case study frameworks vary, several researchers agree the multiple-case study design, also called the collective case study, produces more valid, and transferrable results when compared to the single-case design. The collective case study offers the researcher multiple results from different cases (Merriam, 2009; Stake, 2000; Yin, 2009). Additionally, a multiple or collective case study allows the researcher the opportunity to analyze within each setting and across settings, opposed to a single holistic case study where the researcher is seeking to understand only a particular case (Baxter \& Jack, 2008). Equally important, in a multiple case study researchers are evaluating several cases to understand the similarities and differences between the cases (Baxter \& Jack, 2008).

Yin (2009) described how multiple case studies can "(a) predict similar results (a literal replication) or (b) predict contrasting results but for predictable reasons (a theoretical replication)" (p. 47). The collective or multiple case study design is suitable for helping to develop an in-depth understanding of how universities manage faculty diversity efforts at CCCU member institutions. According to Kezar (2002), the complexities of colleges and universities support the notion of selecting a case study methodology because the method better facilitates 
the comprehension of research questions. Again, in this study the multiple case studies offered a closer review of the diversity work at institutions, particularly regarding faculty diversity.

\section{Case Institution Selection}

Qualitative designs require a sampling strategy to help the researcher decide what questions to ask and whom to ask (Lindolf \& Taylor, 2002). For this study, purposeful sampling was used to select case sites. Purposeful sampling is "selecting information-rich cases for study in depth" (Patton, 1990, p. 169) in order to understand some phenomenon about those cases. Types of purposeful sampling include criterion selection, comprehensive sampling, maximum variation sampling, network sampling, and sampling by case type (Patton, 1990). I selected three Christian institutions located in the South for the study.

According to the CCCU, the campuses located in Mississippi, Oklahoma, and Texas are in the Southwest and Southeast regions. Besides the geographic locations, Grace Elizabeth Hale offered deeper rationale for why the selected states are considered southern. Hale (2010) highlighted that after the Civil War, when faced with granting active citizenship for their exslaves, white southerners in states created structures promoting white privilege and society reestablished positions of power for Whites by creating cultural systems based on physical violence and segregation. Furthermore, Hale discussed origins of segregation, disfranchisement, and questioned how people in the Jim Crow South articulated the meanings of being White (Hale, 2010). Based on the CCCU's regional divisions and Hale's (2010) observations that each case institution operates in environments where Jim Crow segregation laws were enacted and enforced, all three case settings are geographically located in the south. Once I determined the geographical validity of case institutions, I then used criterion sampling. The institutions selected as case sites: 
- Shared the Council for Christian Colleges and Universities' vision. As stated in Chapter II, requirements for membership in the CCCU include a strong commitment to Christcentered four-year education, full regional accreditation, and a liberal arts curriculum (Council for Christian College and Universities, 2013).

- Won awards in the areas of diversity. The Robert and Susan Andringa Award for Advancing Racial Harmony highlights the achievements of CCCU campuses in making progress in the areas of diversity, racial harmony and reconciliation.

- Located in the southern region of the nation. Limited research exists on diversity efforts in this region. Perez (2010) focused on what drives diversity efforts at four CCCU campuses located in Northwest, Southwest, Midwest, and East Coast. Kratt (2004) focused on student body diversity on Christian campuses in the West. Initially, I reviewed the websites of 46 southern CCCU institutions to determine if they had distinctive diversity statements or pages. The review of university websites showed that 22 or $48 \%$ offered multicultural references or diversity links. Universities and colleges selected for the CCCU Racial Harmony award generally had success in at least two of Smith's (2009) dimensions of diversity. Since 2000, 17 CCCU universities have claimed the Racial Harmony award. The researcher selected four Racial Harmony award winners operating in the South for potential case studies. Three agreed to participate. Further research confirmed that at least two of the institutions promoted diversity initiatives within Smith's conceptual framework's dimension of institutional vitality and viability, specifically addressing faculty needs. Again, my study focuses on institutions that have shown progress in improving overall campus diversity.

The CCCU honored one university, called Faith, with the Racial Harmony award in 2002 after campus leaders submitted 30 web pages produced by students in a technical writing course 
highlighting multicultural activities such as missions, athletics, Black History Month and Multicultural Week. The CCCU awarded the institution called Peace University the Racial Harmony Award in 2004 for creating a long-term vision for celebrating campus diversity. A third case study site, a university called Love, received the Racial Harmony Award in 2006 for making diversity progress among the student body, faculty and curricular development.

In closing, the three institutions each offer different perspectives on how diversity efforts influence faculty diversity. One of the common pitfalls associated with case study is that researchers too often attempt to answer a question that is too broad (Baxter \& Jack, 2008). In order to avoid such pitfalls, authors Yin (2009) and Stake (1995) suggested placing boundaries on a case to prevent information overload. Ways to bind a case include: (a) by time and place (Creswell, 2009); (b) activity and time (Stake, 1995); and (c) by context and definition (Miles \& Huberman, 1994). Moreover, Baxter and Jack (2008) wrote that binding the case helped researchers keep studies in a realistic scope. Time and place and activity (Stake, 1995) bind this diversity study.

\section{Participant Selection}

Marshall (1996) wrote that a suitable sample size for a qualitative study is one "that adequately answers the research question" (p. 523). For simple questions or less complicated studies, the sample may be in single digits; for more complex questions large samples and a variety of sampling strategies may be needed (Marshall, 1996). In practice, Marshall (1996) indicated that the number of required participants can become clearer as the study ensues and as new themes or explanations stop emerging from the data.

The sample of my study included 20 total participants, 19 from the three case institutions and one CCCU administrator. To be eligible, study participants had to be full-time employees or 
students at case institutions. At Faith University, I interviewed three faculty members and three administrators; I interviewed two administrators, three faculty members, and a student at Peace University; and at Love University, I interviewed a student, an administrator, and four faculty members. In total, including the CCCU administrator, the participants comprised of $12(60 \%)$ males and $8(40 \%)$ females; $11(55 \%)$ faculty members, 7 (35\%) administrators, $2(10 \%)$ students. I contacted each institution's Institutional Review Board chair via email (see Appendix A - email to IRB representative and Appendix B - institutional consent form) to solicit participation. After the University of Arkansas Institutional Review Board approved the study (see Appendices C and D - IRB approval and modification), I began recruiting participants via email (see Appendix E, sample e-mail letter to participants). The electronic letters were sent to minority faculty, diversity officers, administrators and those identified as other possible participants. Since the total population of possible key informants or campus leaders were small, I used a convenience sample. Still, there was also a purposeful approach.

Two types of purposeful sampling used included intensity sampling and maximum variation sampling (Patton, 1990). An example of maximum variation sampling, involves purposefully making efforts to ensure that participants came from ethnically diverse, academic ranks, and political backgrounds. Intensity sampling was used for information that reflects the phenomenon intensely (Patton, 1990), such as the only faculty member of color at a majority institution. I selected the most productive sample or participants who were well suited or in a position to answer the research questions. Daryl Smith's (2009) dimensions of diversity provided a framework of the variables that might influence an individual's contribution (Marshall, 1996). Participants had some knowledge of the four dimensions: access and success, campus climate and intergroup relations, education and scholarly mission, and institutional vitality and viability. 


\section{Data Collection}

The suitability of the case-study approach lies in the possibility of multi-perspectival

analyses (Morrow \& Smith, 2000), which means the researcher should consider not just the voice of administrators, but use different sources. I collected multiple forms of data from three Christian universities. Using a combination of personal interviews, observations, field notes, documents and textual analysis, I explored what promotes or deters faculty diversity at different institutions.

\section{Personal Interviews}

The use of personal interviews provides researchers with insights and understanding of the phenomenon under study through engagement. They allow for extensive probing, follow-up questions, discussion, and observation of emotional reaction not possible in a quantitative study such as a telephone or mail survey (Babbie, 2001). Personal interviews allow analyses of thoughts, attitudes, and behaviors that provide greater content validity (Babbie, 2001; Creswell, 2007; Patton, 2002). For this study, I mostly relied on single face-to-face interviews with participants. Due to scheduling and technical issues, three interviews were conducted over the phone (see Appendix F, interview protocol). Included are sample questions from the interview protocol in my study. 1. Tell me about your relationship with [CASE INSTITUTION]. Probes: Current position at [CASE INSTITUTION]? Please share how your institution describes diversity? 2. What relationships, if any, exist between the [CASE INSTITUTION] mission and diversity initiatives? 3. What statements, if any, about cultural diversity are key components of the educational priorities for the [CASE INSTITUTION]? Each interview lasted between 30 and 60 minutes. The interviews were recorded with an iPad and a digital audio recording devise and transcribed using https://transcribe.wreally.com/. 
Patton (2002) described an interview as: “open-ended questions and probes yield indepth responses about people's experiences, perceptions, opinions, feelings and knowledge. Data consist of verbatim quotations with sufficient context to be interpretable" (p. 4). In a semistructured interview, the same open-ended questions are asked to all participants. The somewhat standardized interview is efficient and can be more easily investigated and compared (Creswell, 2007). I used semi-structured interviews that began with defined questions, but questions often changed based on the source's experience (Patton, 2002). Moreover, the qualitative research interview seeks to describe the central themes in each of the cases. The main task in interviewing is to understand the meaning of what participants discuss (Creswell, 2008).

\section{Observations and Field Notes}

Another way of collecting data involves observation. Patton describes the process of observation as “descriptions of activities, behaviors, actions, conversations, interpersonal interactions, organization or community processes or any other aspect of observable human experience" (Patton, 2002, p. 4). DeWalt and DeWalt (2002) noted that using participant observation as a method helps the researcher develop a "holistic understanding of the phenomena under study that is as objective and accurate as possible given the limitations of the method" (p. 92). They suggested that participant observation be used as a way to increase the validity of the study, as observations may help the researcher have a better understanding of the context and phenomenon under study. Validity is stronger with the use of additional strategies used with observation, such as interviewing, document analysis (Kohlbacher, 2006). Merriam (1998) added that the researcher should:

- $\quad$ pay attention, shifting from a broad look to a more narrow review, 
- focusing on a single person, activity, interaction, then returning to a larger view of the situation;

- look for key words in conversations to recall a particular conversation;

- concentrate on the first and last statements of a conversation, making it easier to remember specifics;

- during breaks in conversations, reflect on scenes one has observed. (p. 53)

Kohlbacher (2006) wrote that documentation of participant observation data consists of field notes recorded in field notebooks. These data are records of what the researcher experienced, learned through interaction with other people, and observed. Field notes should highlight events, including details of how people reacted, where participants were positioned, their comings and goings, physical observations, and all other details relevant to the experience (Kohlbacher, 2006). Field notes may be written subtly during participant observation or following the activity. Kohlbacher (2006) suggested notes be expanded as soon as possible before memory of the details fades. Furthermore, in this study field notes were completed for all interviews, even those that were audio recorded. Field notes create a continuous or sequential, record of what was observed (Creswell, 2007). During two-day visits at each institution, I observed the natural happenings or institutional cultures on the different campuses. Additionally, my field notes captured specific events, including people's reactions, participants' ins and outs, how they interacted with others, and physical observations.

\section{Documents and Textual Analysis}

Patton (2002) explained qualitative data consist of excerpts from recorded, well preserved documents. Patton further explained:

The quality of qualitative data depends to a great extent on the methodological skill, sensitivity, and integrity of the researcher. Systematic and rigorous 
observation involves more than just being present and looking around. Skillful interviewing involves much more than just asking questions. Content analysis requires considerably more than just reading to see what's there. Generating useful and credible qualitative findings through observation, interviewing, and content analysis requires discipline, knowledge, training, practice, creativity, and hard work. (p. 5)

For this study, internet sites were reviewed, capturing diversity websites of the institutions. Besides that, campus diversity statements were also copied electronically. I was mindful of Patton and the other researchers' directives when collecting the data, and I used several strategies to ensure trustworthiness and credibility.

Once the documents were collected and stored, the researcher determined how to best understand the information. Babbie (2001) defined content analysis as "the study of recorded human communications" (p. 304). Content analysis is an action where coding is "the process of transforming raw data into a standardized form” (Babbie, 2001, p. 309). Further, Ryan and Bernard (2000) suggested that "coding forces the researcher to make judgments about the meanings of contiguous blocks" and that coding is "the heart and soul" of text analysis. According to Titscher, Meyer, Wodak, and Vetter (2000), the content analysis is "the longest established method of text analysis among the set of empirical methods of social investigation" (p. 55).

\section{Research Rigor}

Qualitative research embraces multiple standards of quality, known as validity, reliability, rigor, or trustworthiness (Morrow \& Smith, 2000). Books are filled with varied descriptions of procedures for qualitative research (e.g., Lincoln \& Guba, 1985; Maxwell, 1996; Merriam, 1998; Schwandt, 1997). In these books, validity is described as adequacy, authenticity, credibility, goodness, plausibility, and trustworthiness (Creswell \& Miller, 2009). 
In efforts to promote seriousness and validity in qualitative research, Guba and Lincoln (1994) proposed four criteria for judging the soundness of qualitative research and offered those as an alternative to quantitative criteria. Guba and Lincoln (1994) called their alternatives parallel criteria and explained that they loosely achieve the same purposes as internal validity, external validity, reliability, and objectivity in quantitative research. In my study of diversity and faculty at southern evangelical Christian institutions, several strategies helped to ensure trustworthiness and credibility of the findings and conclusions in the study. These strategies included: peer debriefers; researcher reflexivity; triangulation, and participant member checks.

Peer debriefing. When someone who is familiar with the research or the phenomenon reviews the data and research process, a peer debriefing occurs. A peer reviewer provides support, plays devil's advocate, challenges the researchers' assumptions, and questions the methods (Lincoln \& Guba, 1985). Moreover, Peer debriefers can provide written feedback to researchers or simply serve as a sounding board for ideas. Peer debriefers also help researchers add credibility to a study (Creswell \& Miller, 2000). A university colleague, a leadership and business professor, served as the peer debriefer for the study.

Researcher reflexivity. Researcher reflexivity provides another validity procedure to selfdisclose the researcher's assumptions, beliefs, and biases (Creswell \& Miller, 2000). According to Creswell and Miller (2000), it is particularly important for researchers to acknowledge and detail potential biases early in the research process to allow readers to understand their positions, and then to suspend those biases as the study evolves. Researchers may choose from several options for using the reflexivity to create a narrative (Riessman, 2007). They could include a separate section on the researcher's role, provide an epilogue, write a commentary throughout the discussion of the findings, or bracket themselves out (Flowers, \& Larkin, 2009). In this study, 
I included a separate section on the researcher's personal experiences as used in phenomenological methods (Moustakas, 1994) on the researcher's role, as well as used opportunities to bracket my own assumptions.

Triangulation. Triangulation is a validity procedure where researchers search for merging multiple and different sources of information to form themes in a study (Creswell \& Miller, 2000). Denzin and Lincoln (2000) identified four types of triangulation: across data sources, theories, methods, and among different participants or investigators. Qualitative researchers often produce "corroborating evidence collected through multiple methods, such as observations, interviews, and documents to locate major and minor themes" (Creswell \& Miller, 2000 p. 127). The narrative is valid when the researcher has consistent processes and relies on multiple forms of data (Creswell, 2000; Denzin \& Lincoln, 2000). In this study, triangulation occurred through multiple methods including interviewing students, faculty and administrations, observations, and reviewing of documents.

Participant member checks. With member checking, the validity procedure shifts from the researchers to participants in the study. Lincoln and Guba (1985) label member checks as "the most crucial technique for establishing credibility" (p. 314) in a study. Member checking consists of taking data and interpretations back to the participants and allowing them to review the data to determine if the narrative is factual and an accurate account. Participants received a copy of their transcribed interview.

\section{Additional Strategies for Ensuring Research Validity}

Credibility. According to Guba and Lincoln (1994), credibility (vs. internal validity) refers to the idea of internal consistency, where the concern is "how we ensure rigor in the research process, and how we communicate to others that we have done so" (Gasson, 2004, p. 
95; Guba \& Lincoln, 1994). To increase credibility, I used thorough, thick descriptions of source data and the emerging analysis (Geertz, 1983). To further ensure candor, I offered subjects confidentiality. Additionally, I used a password-protected computer to house all interviews until the report's release, and at that point I deleted all interview materials.

Transferability. The parallel criterion transferability (vs. external validity or generalizability) refers to the level to which the reader is able to generalize the findings of a study to his or her own context and addresses "how far a researcher may make claims for a general application of their [sic] theory" (Gasson, 2004, p. 98). Again, I achieved this by providing relevant information about myself, since I was the instrument in this study. In addition, I provided research context, processes, participants, and researcher-participant relationships to enable the reader to decide how the findings may transfer.

Dependability. The parallel criterion dependability (vs. reliability) deals with "the way in which a study is conducted should be consistent across time, researchers, and analysis techniques" (Gasson, 2004, p. 94). Thus, the process through which findings are derived should be explicit and repeatable as much as possible (Guba \& Lincoln, 1994). I accomplished this through keeping a journal of research activities and processes; influences on the data collection and analysis; emerging themes and categories.

\section{Confirmability and Researcher's Role}

Confirmability (vs. objectivity) is based on the acknowledgement that research is never objective (Guba \& Lincoln, 1994). It addresses the fact that "findings should represent, as far as is (humanly) possible, the situation being researched rather than the beliefs, pet theories, or biases of the researcher" (Gasson, 2004, p. 93). I am an assistant professor of journalism at John Brown University in Siloam Springs, AR. I joined the faculty in fall 2010. Prior to moving to the 
classroom full time, I worked as The Virginia Beach and North Carolina editor at the VirginianPilot in Norfolk, VA. I arrived there as a local government editor in 2001. In 2008, I took leave from The Pilot to complete a Knight International Journalism Fellowship in Liberia. During my year in West Africa, I created a judicial and justice reporting network and helped journalists develop skills to cover the post-war nation's poverty reduction efforts. Ghanaians elected a new president in 2008, and I also worked in that country to prepare journalists to cover the highly contested 2008 race.

In the summer 2010, I returned to West Africa and launched a new website for a newspaper that I created during my stay in Liberia. That newspaper was the first owned and operated by a Liberian woman. Before moving to Virginia, I worked as an assistant metro editor at the Montgomery Advertiser. I also worked as a reporter at the Lexington Herald- Leader, the (Biloxi) Sun Herald and in Knight Ridder's Washington bureau.

I hold a bachelor's of science degree in communications from the University of Tennessee at Knoxville and a master's of arts degree in journalism (public affairs) from the University of Maryland, College Park. I have taught at Norfolk State and Hampton universities. I am a past president of the Hampton Roads Black Media Professionals, and a lifetime member of Delta Sigma Theta Sorority, Inc. Additionally, I am a 2005 graduate of the inaugural Maynard Media Academy at Harvard University. In 2006, I received one of the Pilot's top honors, the Joyce Ingram in Lime Green Leadership award, for my leadership and role in shaping newsroom diversity efforts.

For two decades, I have worked on projects related to diversity efforts on campuses, in newsrooms and in West Africa. As an editor at The Virginian-Pilot, I helped to create a database of talented journalists of color, in order to increase the pool of candidates for jobs at the 
newspaper. Additionally, I served as a diversity facilitator, conducting trainings called "Fault Lines" at various newspapers. Robert C. Maynard designed the training program to help businesses reach culturally diverse audiences. In West Africa, I designed and conducted diversity training to bridge gaps between various ethnic tribes in order to facilitate peace among the different people groups. Currently, I serve on the diversity committee at John Brown University. I also serve as the faculty sponsor for the campus multicultural student organization. In both campus roles, I often advocate for students and faculty of color. I am passionate about the value of diverse employees, students and faculty and the benefits for the workplace and institution.

In order to keep my personal biases and attitudes from the study, I used the technique referred to as "bracketing" throughout the research process (Creswell, 2008). I used two different bracketing methods. One method of bracketing is writing memos throughout data collection and analysis as a means of examining and reflecting upon my involvement with the data (Cutcliffe, 2003). According to Tufford and Newman (2012), memos can take the form of theoretical notes, which clarify the researcher's thought process while conducting the study; methodological notes that explain the procedural aspects of the study, and observational comments that allow the researcher to explore personal thoughts and feelings about the endeavor. I used the latter and crafted memos addressing my personal thoughts and feelings. Glaser (1998) described the process of memoing as freeing for the researcher, allowing him or her to not be constrained by preconceptions. Another method of bracketing included engaging in interviews with an outside source to uncover and bring into awareness preconceptions and biases (Rolls \& Relf, 2006). Tufford and Newman (2012) wrote that bracketing interviews conducted prior to, during, and following data collection may uncover themes that may hinder the researcher's ability to listen to participants. Moreover, bracketing interviews can increase the researcher's understanding and 
connection with participants' experiences by highlighting personal experiences (Rolls \& Relf, 2006). Interviewing with my peer debriefer and writing memos helped me to make sure the study remained credible.

Data protocol. Yin (2009) suggested that theory plays a significant role in guiding case study research. With that in mind, I developed a data protocol which resulted from the review of relevant literature (Yin, 2009). Moreover, I took a note from Stake (1995) and gathered peers to help develop, review, and revise the data collection protocol before utilizing it. The data collection protocol focused on collecting information that describes the institutional mission; faculty experiences with diversity efforts; and the role administrators play in shaping those experiences. Over a two-month period, I visited and conducted interviews with administrators, faculty, and students (see Appendix G, copy of the case study protocol).

\section{Data Analysis}

Creswell (2008) described qualitative data analysis as inductive, iterative, and intensive. Researchers use an inductive process when they gather large amounts of information and eventually reduce it to a more narrow detailed report, using patterns, themes or overlapping information (Creswell, 2008; Patton, 2002). The research process is an iterative one where researchers repeatedly return to the data source making certain the findings are accurate and complete (Polkinghorne, 2005). A successful case study offers readers a complete, intensive report filled with rich details from multiple data points (Merriam, 2009; Patton, 2002). As Merriam (2009) observed, in qualitative data analysis the researcher takes collected data to develop themes that emerge from the interviews and conversations centered on the study's research questions. 
This process generally evolves at two levels in a multiple-case study: within case and cross case (Merriam, 2009). The first is the descriptive phase, which includes transcribing, organizing, and coding. The second called the interpretative phase, ensues when the researcher investigates the patterns in the data and makes general conclusions about the research questions resulting in the findings (Patton, 2002; Sandelowski \& Barroso, 2003). To analyze the data, I created a case study electronic file system to organize all information collected. The system includes the audio and transcriptions from the three site visits, data from institutional documents, and observations. Data from observations and institutional documents were used to triangulate the interview data (Creswell, 2007).

Patton (2002) described content analysis as the most popular form of reviewing the qualitative data. To assist with coding and compiling data into categories, I searched for emerging and overlapping themes from the research questions. Stake (1995) recommended that researchers keep an open mind when it comes to new thoughts, ideas, and opportunities that emerge during the case study. Moreover, I used four techniques for discovering themes in texts. These techniques provided by Creswell (2008) are based on: (1) an analysis of words (word repetitions and key-words-in contexts); (2) a careful reading of larger blocks of texts (compare and contrast, social science queries, and searching for missing information); (3) an intentional analysis of linguistic features (metaphors, transitions, connectors); and (4) the physical manipulation of texts (unmarked texts).

\section{Chapter Summary}

In conclusion, this chapter highlighted the research design, multiple or collective case study, outlined the research protocol for the study, explained how I respected the emerging process that is characteristic of qualitative research, and adjusted the study based on participant 
feedback. First, the chapter reviewed the nature and design of qualitative research and discussed the rationale for selecting the collective or multiple case study. The chapter also covered how to design a qualitative study, including problem formation and sample selection. A purposeful sample focused the study so that the information collected was relevant and in depth. The case study sites were selected based on specific criteria, including location and recognition for diversity awards. Second, the chapter covered the collection of qualitative data; sections covered conducting effective interviews, being a careful observer, mining data from documents, and the interactive nature of data collection in case studies. Third, the chapter reviewed the analysis and reporting of qualitative data, and discussed analytic techniques and data management, and strategies for dealing with validity, reliability, and ethics. The next chapter provides results of data analyses and findings of the study. 


\section{CHAPTER IV}

\section{FINDINGS}

The purpose of this qualitative study was to explore institutional efforts to increase faculty diversity at three Christian universities and examine how these efforts related to institutional missions. Additionally, the study used the following research questions to offer descriptions of what promoted or curtailed the hiring of diverse faculty, as well as highlighted recruitment and retention efforts at the institutions.

\section{Research Questions}

With Daryl G. Smith's (2009) dimensions of diversity as the conceptual framework this study examined the following five questions:

1. What diversity efforts exist at three Christian universities in the South?

2. What aspects within the history of evangelicalism promote or deter the hiring of diverse faculty at these three Christian universities in the South?

3. What are Christian colleges doing to recruit and retain diverse faculty?

4. What is the climate for minority faculty at Christian universities?

5. How does faculty diversity or the lack of it impact Christian universities' educational and scholarly missions?

First, this chapter provides discussion on the data collection and analysis. Second, the chapter offers a brief institutional profile of each case, including descriptive statistics, as well as highlights the themes or patterns at each location. Third, the chapter presents major themes across case institutions as they relate to the study's research questions.

\section{Data Collection}

This study was guided by two research goals that had not been satisfactorily addressed by 
existing literature. The first focused on the exploration of what promoted or deterred diverse faculty at Christian colleges and universities. The second focused on how faith shaped the diversity conversation on the selected campuses. I selected the multiple-case study design, also called the collective case study, in order to produce more valid and transferable results. When compared to the single-case design, the multiple case study offers the researcher various results from different cases (Merriam, 2009; Stake, 2000; Yin, 2009).

During a 6-month span, I reviewed institutional documents on mission and diversity efforts. The site visits at three campuses took place in February and March of 2014. In total, I interviewed 20 participants. I interviewed six participants at Faith University; six participants at Peace University; and seven participants at Love University. Both Peace and Love Universities had a student participant. I also interviewed a CCCU administrator. I contacted participants directly; however, at Peace University the president recruited faculty and administrators.

During each interview, I asked participants 10 open-ended questions listed in the interview protocol (see Appendix F). When necessary, I asked follow-up questions or probes. Interviews were transcribed immediately following site visits. However, three participants' interviews at Faith University were lost when transferring the data from my digital recording device. This was my first case site. In an effort to replace the recordings, I re-interviewed one participant over the phone. For the second and third interviews, I relied on field notes, observations, and institutional data provided by these participants. All interview transcripts were provided to participants for review and approval. In order to conceal participants' identities, I assigned them biblical pseudonyms. In conclusion, the two-day campus visits gave me the opportunity to explore the campus, conduct interviews, collect institutional documents, generally observe campus life, and attend chapel services. My time at each case site helped me to create an 
in-depth profile of each institution, while highlighting the faculty diversity concerns taking place there. Table 1 introduces the study's participants.

Table 1

Participants for the Study $(N=20)$

\begin{tabular}{|c|c|c|c|}
\hline Name & University & Position & $\begin{array}{c}\text { Years at } \\
\text { University }\end{array}$ \\
\hline Ruth & Faith & Administrator & 25 \\
\hline Isaac & Faith & Administrator & 24 \\
\hline Josiah & Faith & Administrator & 18 \\
\hline Paul & Faith & Faculty & 32 \\
\hline Deborah & Faith & Faculty & 11 \\
\hline Hannah & Faith & Faculty & 6 \\
\hline Matthew & Peace & Administrator & 19 \\
\hline Abraham & Peace & Administrator & 18 \\
\hline Jeremiah & Peace & Faculty & 25 \\
\hline Sarah & Peace & Faculty & 15 \\
\hline Esther & Peace & Faculty & 8 \\
\hline Rachel & Peace & Student & Junior \\
\hline David & Love & Administrator & 7 \\
\hline Jacob & Love & Faculty & 23 \\
\hline John & Love & Faculty & 11 \\
\hline Martha & Love & Faculty & 7 \\
\hline Mary & Love & Faculty & 6 \\
\hline Luke & Love & Faculty & 5 \\
\hline Elijah & Love & Student & Junior \\
\hline Aaron & $\mathrm{CCCU}$ & Administrator & 28 \\
\hline
\end{tabular}

Note. Participants comprised of $12(60 \%)$ males and $8(40 \%)$ females; $11(55 \%)$ faculty, $7(35 \%)$ administrators, $2(10 \%)$ students. 


\section{Data Analysis}

As Merriam (2009) recommends, I analyzed data to develop themes that emerged from the interviews and conversations centered on the study's research questions. This process generally evolves at two levels in a multiple-case study: within case and cross case (Merriam, 2009). Both levels refer to two distinctive phases. The first is the descriptive phase, which included transcription, organization, and coding. The second called the interpretative phase, happened as I investigated the patterns in the data and made general conclusions using the research questions (Patton, 2002; Sandelowski \& Barroso, 2003).

To analyze the data, I created an electronic folder to organize all information collected. The system included the transcriptions from the three site visits, all recorded interviews, data from institutional documents, and observations. Reflective notes, institutional documents, and observations were used to triangulate the interview data (Creswell, 2007). Additionally, I used four techniques for discovering themes in texts. These techniques provided by Creswell (2008) are based on: (1) an analysis of words (word repetitions, key indigenous terms, and main words in contexts); (2) a careful reading of larger blocks of texts; (3) an intentional analysis of linguistic features (metaphors, transitions, connectors); and (4) the physical manipulation of texts (unmarked texts, and cut and sort procedures). Also, I advanced codes for themes within each case, and reported the differences and similarities for themes in the cross-case analysis (Creswell, 2012). Lastly, all of the data analysis efforts helped me to shape a rich detailed report from various data points.

\section{Faith University}

\section{Institutional Profile}

Built in 1963, Faith University boasts of a futuristic look with architecture resembling the 
popular Baby Boomer cartoon of the Jetsons. Besides the gold reflective buildings, the campus spanning 263 acres offers visitors much to see. A 200-foot tower stands in the middle of campus, flames rise from the top representing the spirit of prayer. A large bronzed sculpture of praying hands can be found on campus, and 60 country flags line the main street representing the homelands of students. The campus is open, minimal security, where visitors may also enjoy a peaceful walk along the meticulously maintained landscape. Gardens around campus offer students a quiet place to reflect.

Faith University is a four-year, coeducational, private Christian university. Currently, enrollment is at about 2,700 students. Within evangelical circles, Faith University describes itself as inter-denominational, not affiliated with any particular denomination. As reported in institutional documents, students enrolled come from more than 60 different denominational backgrounds. A typical chapel service highlighted students praying in different languages, including a student who prayed for his home country, Myanmar. Flag praise dancers performed in the aisles. The hour-long service seemed to offer more than $32 \%$ ethnic minority and $7 \%$ international students diversity in worship.

Once plagued with millions of dollar in debt, Faith University almost closed its doors. Of the \$62 million given to Faith University, about half went toward eliminating the university's $\$ 52$ million debt. The remaining $\$ 32$ million was allocated to upgrade technology, renovate the campus, increase financial aid for all students, and improve marketing, according to the university website. In January 2009, the University laid off 53 employees and cut about 40 unfilled positions. The layoffs came as the administration and Board of Trustees worked for long-term financial viability for the university. According to institutional reports from September 2009, the new president announced that the school was debt free. A private donor provided 
millions to support the University. Currently, the total annual costs estimated for students to attend this institution are $\$ 41,000$. (This estimate includes tuition, fees, room, board, and supplies.)

The endowment offers some insight on the financial health of the school. Despite the huge financial crisis, Faith University reports just over \$40 million in its endowment. In 2012, the University earned $\$ 1$ million in income and recorded $\$ 2.5$ million in assets. A national financial review organization gave the institution a B grade for financial health. In 2012, the average salaries of full-time, non-medical faculty was $\$ 55,746$. At Faith, specific resources were set aside to promote ethnic diversity. The institution has teamed up with the National Hispanic Christian Leadership Conference and operates a year-round Hispanic Center on campus, which helps students transition to university life and persist to graduation. Staff at the center also work to minimize other barriers such as language and health care, according to institutional documents. This campus has one of the most diverse student populations within the CCCU. However, with more than $79 \%$ of full-time faculty being White, the statistics do not reflect the racial composition of the student body, which is $41 \%$ non-white. Tables 2 and 3 include data on student and faculty diversity in Fall 2013. 
Table 2

Fall 2013 Student Diversity at Faith University $(N=3,110)$

\begin{tabular}{lcc} 
Diversity & $N$ & $\%$ \\
\hline Caucasian & 1731 & 50.87 \\
African-American & 563 & 16.54 \\
Asian- American & 80 & 2.35 \\
Hispanic-American & 236 & 6.93 \\
Native American & 111 & 4.12 \\
Two or more races & 120 & 3.53 \\
International students & 236 & 7.02 \\
Other & 33 & 0.98
\end{tabular}

Note. Student body comprised of 1497 (43.99\%) males and $1906(56.01 \%)$ females

Table 3 below presents full-time faculty numbers as reported for Fall 2013.

Table 3

2013 Faculty Diversity at Faith University $(N=170)$

\begin{tabular}{lcc} 
Diversity & $N$ & $\%$ \\
\hline Caucasian & 135 & 79.41 \\
African-American & 11 & 6.5 \\
Asian & 7 & 4.12 \\
Hispanic-American & 7 & 4.12 \\
Native American & 2 & 1.17 \\
Two or more races & 5 & 2.94 \\
Unreported or 'other' & 3 & 1.76
\end{tabular}

Note. Faculty comprised of 105 (61.76\%) males and 65 (38.24\%) females. 
In a 2007 review of the racial demographics of CCCU faculty, $91.3 \%$ of faculty at CCCU member institutions identified as White non-Hispanic. Although the faculty employed at Faith University are more diverse than the CCCU average, they continue to lag behind their student population.

Faith University offers faculty and students a structured approach to engaging on the topic of diversity. At Faith University common themes emerged during interviews with faculty members and administrators. The interviews, internal document reviews, and web site analysis of national college data collection organizations generally support the findings. Moreover, the patterns shaping the campus diversity conversation and efforts include: diversity rhetoric, intentionality, environmental dynamics, globalization, and top-down approach. The following sections will discuss those five themes.

\section{Diversity Rhetoric}

Faith University expresses its interest in diversity on the institution's website, in strategic planning documents, and in accreditation self-reports. Administrators have clear views and a clear definition of diversity. However, that definition gets lost within faculty ranks. While faculty members are capable of giving definitions for diversity, most have no knowledge of a formal institutional definition as written in the University's self-report for the Higher Learning Commission. Deborah indicated that “...In terms of how they define diversity, I can’t answer that because I'm not sure I know how they define it, if it's defined at all." All of the faculty interviewed echoed those sentiments.

Although diversity concerns involving gender emerged, the conversation at Faith University mostly centered on race and ethnicity. More specifically, the emphasis on diversity efforts tended to shift more towards international diversity. Isaac, an administrator, discussed 
that efforts were made to ensure that international students feel welcome. For example, the administrator mentioned detailed plans, such as offering Korean food in the cafeteria to accommodate 100 new Korean students who would be attending campus through a particular new partnership. The meal planning for diverse student populations, on a small level, highlights the deliberate attitude of the administration.

\section{Intentional Diversity}

Over and over, when discussing how to increase the number of minority faculty at Faith University, participants discussed the need for intentionality. Hannah another faculty member explained that while the diversity definitions remain unclear, more intentional conversations about diversity are taking place on campus. Diversity concerns are now discussed during faculty meetings, and those on campus can see more of a celebration of diversity. Faculty member Deborah promotes and organizes a campus institutional diversity celebration annually. The institution also has a multicultural committee, made up of faculty and students, who help with programming efforts. However, Faculty member Paul said efforts are much more planned on the undergraduate level, but may be less noticeable at the graduate level. Paul also explained:

I don't see there is enough effort being put forth, and to me, it's less now than before... Although we do have certain key positions being filled with ethnic persons, minority persons...I feel that at one time we were more diversified, and there was perhaps more intentionality.

While faculty members at Faith University continued to discuss the need for planned strategic efforts to make progress in the overall institutional progress in diversity work, administrators described intentional efforts to help with recruiting and hiring more faculty of color. Participants mentioned that Faith University desires to create a faculty body that more closely resembles the student body. Administrator Isaac explained that the institution has intentional policies in place for hiring. While the institution does not seek to achieve quotas, 
Isaac added that every faculty search should include a diverse pool of candidates.

Faith University leaders reported that they are intentional and strategic about pursuing minority faculty. Jobs are posted in the employer section of HigherEdJobs.com, and the institution pays a higher rate to advertise in the Affirmative Action E-mail list of HigherEdJobs.com. This upgrade reaches more than 250,000 candidates. Isaac reported that although it would be unpopular with many, "I would be willing to go as far as waiting two years to fill a position in order to ensure that the candidate pool is diverse." Additionally, all three administrators interviewed discussed efforts to ensure that all hiring teams include minorities. For example, each search committee should have five members and one of those should be from an ethnically diverse background.

\section{Environmental Dynamics}

According to the U.S. Department of Education, CCCU schools increased student enrollment over 70\% from 1990 to 2004 (Vescovi, 2013). During that same period of time, all independent four-year schools increased $28 \%$, while public four-year institutions grew about $13 \%$. These statistics reviewed from institutional documents highlighted a positive trend for CCCU institutions. Moreover, leaders at Faith University attributed the increase in enrollment to Christian college environments. Ruth, who is also an administrator, expressed that the college experience goes beyond tacking Christian beliefs onto different course work, and it goes beyond chapel and religious services. The Christian values can be seen in the student center, campus eateries, and sporting events. Conversely, the same Christian environment that serves as a recruiting tool for students, those same faith-based values can create obstacles for prospective minority faculty members. Furthermore, Christian campuses may send those potential employees unintentional negative messages about diversity and the general campus climate. 
Faith. When asked what prevents or promotes the hiring of diverse faculty, the common reply from faculty and administrators included the spiritual or religious fit. Although the University is not connected to a particular denomination, but is rooted in Pentecostalism, faculty applicants are expected to be "spirit filled" and to have a "prayer language" or to be "actively seeking" to release the prayer language. Administrators discussed challenges with getting minority applicants in the pipeline. Josiah, an administrator, explained that more charismatic Christians have not always promoted or required higher education, and this narrows an already limited pipeline of potential hires further, particularly when seeking minorities.

Climate. Generally, faculty and administrators reported that the campus was not overtly unfriendly; however, there are instances where situations can be perceived as unwelcoming. Deborah, a faculty member, talked about how a different interpretation of the faith affects the campus climate. She also mentioned that she often questioned colleagues at other universities:

If we are people of God, and we really are who we say we are, and we believe what we say we believe, then why do I still feel invisible on this campus? Why do people still not know who I am, or inquire, or reach out to try to improve relations ... if we're filled with the Holy Spirit like we say... And the response, I got from this Caucasian gentleman, who is culturally competent in my opinion, he looked at me dead in the eye and said, 'well don't you know ...? They all believe the Holy Spirit is white.' And I honestly, as much as I run my mouth, I was actually speechless for a few minutes. There's no way I could have ever dreamt I'd ever hear such things....I honestly never defined ethnicity to the Holy Spirit. I know with us being Western, we tend to think that God is American, and He speaks English.

White administrators interviewed at Faith University were often reluctant to discuss the campus climate for minorities. However, one administrator reported occasionally hearing comments that would be unwelcoming for people of color.

Both faculty and administrators mentioned that politics can also divide campus, creating an unwelcoming environment for minority faculty. For instance, several participants pointed out 
that following the 2008 election, campus leaders did not acknowledge the victory of the nation's first African-American president. A week later, administrators apologized for the oversight, announcing President Barack Obama as the nation's $44^{\text {th }}$ commander in chief. Ruth, an administrator, said that often Christian institutions tend to be politically conservative and not as friendly or open to many of the nation's issues and challenges. As it relates to diversity, Ruth expressed:

I think that it might be challenging sometimes for minority faculty members to feel at home, to feel free to be able to express concerns, express who they are, and to express even their political beliefs. And, unfortunately I don't think that's unique to Faith University.

While the politics may divide at Faith, the Christian mission continues to unite faculty and administrators.

\section{Expanding the Globe}

Faith University, like most Christian institutions, promotes globalization. One of the main components of the mission is preparing students to serve and work in varied capacities around the world. As a result, faculty and administrators often discussed the direct link of the mission to the efforts for improving campus diversity. Paul, a faculty member, reported that while some departments are more diverse than others, still "we are a globalized world, and we need to respect that in all departments in the school."

Participants also reiterated how Faith University takes seriously the call - the Great Commission - to go into every nation sharing the Gospel. However, both faculty and administrators also stressed the need for getting to know local diverse people groups. Before tackling the world, Faculty member Hannah explained: "You have people groups that are here and that you're going to encounter. And, we'll have to be intentional about learning about how they live, how they view the world, so that you can better serve them." 


\section{Diversity Top-down}

Overall, Faith University wants to see lasting change or improvements in general diversity efforts, specifically as it relates to hiring more faculty of color. Countless conversations focused on the importance of having senior leadership onboard with diversity work. Participants noted that success mostly comes when initiatives are top down. In fact, administrators and faculty noted that leadership changes at times stemmed diversity efforts. However, the institution began a faculty diversity initiative in 2000, in response to the Board of Trustees. Institutional records report that the Board asked that serious improvements be made in faculty hiring because then $8 \%$ of the faculty were minorities, compared with $20 \%$ in 2013 . Although administrators have made progress in hiring faculty of color, they still mention the challenges. First, administrators discuss the limited number of faculty of color in the pipeline who fit the institution's faith culture. Second, administrators suggested that the salary demands of minority

faculty are too high. Consequently, the University cannot compete for the limited pool of faculty. The majority of faculty expressed frustration with both scenarios, lack of financial resources and the challenges of finding minority candidates. Still, all participants at Faith University agreed that diversity efforts must go beyond programming events and be integrated into strategic plans and curriculum conversations.

\section{Peace University}

\section{Institutional Profile}

Peace University designates itself as a Christian liberal arts institution dedicated to helping students tackle the ever-changing demands of society. Institutional leaders believe that only the Christian liberal arts institution can produce purpose-driven women and men. The school's mission focuses on preparing students for career and personal relationships. The 
University, accredited by the Southern Association of Colleges and Schools, awards Associate, Baccalaureate, and Master's degrees. Peace University maintains satellite campuses for graduate and undergraduate studies in Texas, Tennessee, and Florida. Additionally, the institution also offers online programs.

Located in a historic residential neighborhood, the campus provides a quiet setting for learning. At first glance, visitors cannot help but notice the traditional southern architecture, some renovated with contemporary office space. Live Oak trees line the walking pathways and a paved walkway of bricks bear the names of special people who shaped the University's history. A highlight of the 42-acre campus is the lake. Walking trails surround the water. On a cool March day, students and fishermen enjoy the lake.

The residential campus, located in an urban area in Mississippi, dates back to the 1800s. The institution has a longtime off-and-on relationship with the Presbyterian Church. A Board of Trustees have independently run the institution since 1972. Faculty and staff members represent various denominations, but the institution continues to draw from its Presbyterian roots, the Presbyterian Church (U.S.A.), the Presbyterian Church in America, and the Evangelical Presbyterian Church. Peace University receives both financial support and students from these three denominations. In 2012, the average salaries of full-time, non-medical faculty all ranks was $\$ 37,791$.

The financial health of the school can be assessed by evaluating the institution's endowment. Peace University reports on an institutional website just under $\$ 5$ million in its endowment. In 2012, the University earned \$50 million in income and recorded $\$ 47.3$ million in assets. An organization known nationally for providing financial reviews gave the institution a "C" Grade for financial health. 
Peace University offers prospective students racial and ethnic diversity within the student body. Of the 1,200 undergraduates, about a third are racial or ethnic minorities. Table 4 provides data on Fall 2012 student and faculty demographics.

Table 4

Fall 2012 Student and Faculty Diversity at Peace University $(N=3,531 ; 80)$

\begin{tabular}{lrccc}
\hline Diversity & Student $n$ & $\%$ & Faculty $n$ & $\%$ \\
\hline African-American & 1765 & 50 & 6 & 7 \\
$\begin{array}{l}\text { Asian/Asian } \\
\text { American }\end{array}$ & 35 & 1 & 1 & 1 \\
Hispanic & 177 & 5 & 0 & 0 \\
Two or more races & 71 & 2 & 0 & 0 \\
Native American & 0 & 0 & 0 & 0 \\
White & 1236 & 35 & 73 & 91 \\
Unknown & 212 & 6 & 0 & 0 \\
\hline
\end{tabular}

Note. Gender of faculty $42 \%$ female, $58 \%$ male

Similar to the CCCU statistics, the faculty representation at Peace University continues to lag behind their student population.

At Peace University, faith comes first. This institution offers an unconventional approach to diversity work on campus. Several common themes emerged during interviews with faculty members and administrators. The interviews, internal and external document reviews, and web site analysis of national college data collection organizations helped to triangulate the findings. Moreover, the patterns shaping the institutional diversity conversations and efforts include: the diversity rhetoric, spirit-led initiatives, environmental dynamics, and a top-heavy approach. The following sections will discuss those four themes. 


\section{Diversity Rhetoric}

Administrators, faculty, and students all expressed that Peace University has not set a specific diversity goal. However, there is a desire and heart for diversity. The participants interviewed agreed the University's Christian mission encourages the institution to be welcoming, accepting, and respectful of diverse people. Most mentioned that scripture calls for acceptance, "one body of Christ." Furthermore, Abraham, a senior administrator, discussed the importance of creating that body through racial reconciliation: "There's probably not many, not any other issue in the history of the world that divided people as much as race. And so, if you can't deal with race as a Christian, you can't deal with reconciliation.” To answer the diversity charge, rather than setting objectives and goals, administrators and faculty at Peace University search for deeper indicators that show progress in diversity works.

For instance, Rachel, a junior, placed extra emphasis on the hospitality given to international students attending campus. Rachel also commented on the faculty diversity. While the numbers may not be impressive, the student mentioned that professors come from different backgrounds and offer different perspectives, which is often displayed in the classroom. Rachel has not participated in any class taught by minority faculty. Meanwhile, Administrator Abraham explained that defining diversity is complex and has gone beyond issues of black and white at Peace University. The administrator added: “God didn't make us all the same, and I'm thankful for it."

\section{Spirit-led Initiatives}

Peace University does not have a strategic plan. This point offered much insight to the inter-workings of the institution. Matthew, another administrator, explained "we believe in following the leading of the Spirit, and where God opens the opportunities, that's where we want 
to go." When reviewing the institutional website, few documents express future projects. The University does not highlight a diversity statement or offer any diversity statistics. In order to operate without a strategic plan, administrators discussed having a "culture of comfort."

Abraham elaborated on the University's philosophy:

Strategic plans are security blankets to colleges. Everybody feels good about them, we've got this document, look where we're headed. Presidents feel good about them because look how productive I am. I created this plan. I'm really leading. Faculty and staff feel good about it because we've had our chance to have input in this thing.

In contrast to a methodical or systematic approach, diversity conversations at Peace University are organic. They come up as they come up. The school uses a "sailboat" model to planning. How it works, Administrator Abraham explained, is that the sailboat catches the wind of God, and He directs the path. For example, administrators described the University's latest project, a new nursing school. For the nursing school, administrators have hired five new faculty members, four of whom are African American, including the new chair of the department.

\section{Environmental Dynamics}

The campus student center offers residents an informal setting to relax in. Diverse groups of students eat lunch together and share couches for napping or studying between classes. Participants all mentioned the warmth of the campus in general, and said they thought students and faculty of color were in a welcoming environment that generally appreciates diversity. In a Wednesday morning chapel, students performed an urban dance routine. The chapel offered students varied forms of worship.

Campus climate. Participants mentioned that respect of all persons is important on campus. The Bible calls for respect of persons. To that end, faculty member Esther noted that racist jokes and behavior in general are not tolerated. Administrators said the University 
president deals with individuals directly who have problems respecting and valuing diversity on campus. Still, the campus, like most southern campuses has not always been a friendly place for minorities. Jeremiah, a faculty member, presented a scenario in 1963 involving Alabama churches in the presbytery that had African-American members since slavery. He explained:

In other words, when slavery was abolished, the same families continued. But this is almost too incredible; it's terribly embarrassing. It's awfully painful, but... some of those families were asked to leave the predominantly white churches at that time because there was such a negative reaction on the part of some against integration.

Of course, not all southern Presbyterian churches were like that, but some were, and that affected Peace University. Participants reported that those kinds of influences have not been seen on campus for years. However, Sarah, another faculty member, recalled being an anomaly on campus: "I had students who would come by and they would never say what they wanted but they would just kind of come by and look at me, and I thought, Okay." Still, Sarah reported that the campus climate was fine.

Denomination. Faculty working at Peace University must be Christian. Denominational and theological distinctions do not exist. However, the Biblical Studies Department is the exception on campus. Historically a Presbyterian institution, the Department requires that faculty teach certain courses from a theological perspective called reformed theology.

Jeremiah expressed that there are "not as many ethnic minorities who have a reformed theological perspective, as there are Caucasian. In other words, there are not a lot of reformed theologians numerically and even less in minority groups." Presbyterian and reformed denominations generally require a three-year seminary degree after four years of college.

Racially charged. Historically, the state is known for white citizens and government officials who harassed, persecuted, tortured and killed African Americans who questioned Jim 
Crow laws, the segregationist order. The racial tensions lurk beneath the surface. Administrator Abraham said, “on the surface we act like it's great, no problem, everything's fine. Scratch it a little bit, and it comes right out." University leaders walk gently when discussing the topic of diversity. Administrators were very leery of participating in the study, citing that they did not hope for any agitation.

For those reasons, Peace University does not program diversity. There is no diversity officer and few clubs and diversity activities. Administrator Abraham replied that diversity lowlevel program efforts "people see through it in a hurry in.... It has to be at the heart. It has to be genuine, and it has to be lasting. Diversity for us is proven over time, not proven by any specific effort." Participants agreed that in some cases institutional diversity initiatives work, but they have found that such models may appear insincere, patronizing and unrealistic in their environment.

\section{Diversity Top-heavy Approach}

Despite not having a written policy or specific diversity hiring objectives, the president of Peace University definitely sends a clear message that diversity is a value. However, the diversity message comes from above. More than 25 years ago, Peace University made three big decisions, which shaped the institution's commitment to diversity. First, the institution returned to its evangelical roots. Second, leaders raised the educational quality. Third, administrators became more purposeful about student selection. All three things helped start the campus diversity discussion.

Administrators stressed over and over that diversity efforts of any kind often fail without buy-in from the top. Why? At Peace University the president and the provost make all hires. Although candidates can apply on the institutional websites, the hiring process is primarily 
referrals-based. Faculty and staff often provide recommendations. Abraham, a senior administrator, offered the following hiring explanation:

I'm not convinced that faculty or administrators or anybody else is so pure in their desire that they're going to hire somebody dramatically better than they are. And, so every time we hire, I want to upgrade. And, so we're always pushing for the very best people we can find and afford, and who God's called here obviously.

Nonetheless, faculty expressed some frustration with the referral system, highlighting that often recommendations are vetoed.

Business case. At Peace University, and most institutions, money is a motivator when it comes to diversity work. Abraham reported that if universities want to be successful and compete in the state you have to reach the "African-American community, or you're not going to survive. So, that's not a bad thing. God uses practical things to get us to do what we need to do." In that same way, most participants understood the solid business case for diversity. Finances and the lack thereof can also hinder hiring and retention efforts. Administrators talked about losing talented faculty of color to competitors because they could not compete with a $\$ 20,000$ salary increase. Abraham also mentioned the struggle to retain talented minority faculty: "if you got a $\mathrm{PhD}$, and you're African American, those are popular people." Participants also discussed the limited pool of applicants, mostly due to competition. Still, participants reported the University needs to make progress in terms of hiring more faculty of color. Progress has been made in terms of student diversity, said Sarah, a faculty member, and "it would be good to have a nurturing or some kind of mechanism in place that would encourage more faculty diversity." In conclusion, all participants acknowledged the leadership has a heart for diversity and influences the overall campus commitment, despite not having any systematic approach to diversity work. 


\section{Love University}

\section{Institutional Profile}

Love University offers students a Christ-centered education. University leaders boast of preparing more than 3,600 undergraduates to become global leaders. The University, founded in 1906, is in an urban setting on 208 acres. The institution offers 71 baccalaureate majors in more than 125 areas of undergraduate study in addition to its graduate programs. Affiliated with the Churches of Christ, Love University requires students to attend chapel daily and take several Bible courses before graduation. At 150 feet tall, a tower rings a signal every 15 minutes and the top of the hour calls students to chapel.

The tan-brick buildings offer the campus some uniformity. However, the spurts of purple and white signage help to point visitors in specific directions. On a March day, facility workers washed down sidewalks and attempted to water some of the browning campus lawn. This is West Texas. Flat. Dry. Few trees offered students shade on campus. Still, students found time to enjoy the 80-degree weather. Early morning, students walked or jogged trails. At the start of a trail stands a bronze sculpture depicting Christ ascending into heaven. In limestone blocks, scriptures remind visitors of "The Good News" of God's plan to redeem mankind.

Since the beginning, a board of trustees, made up of the Churches of Christ, have governed Love University. Students' tuition and fee costs are about $\$ 29,000$. Including estimates for room board, supplies and travel, that price tops out at about $\$ 44,000$. An endowment of over $\$ 307$ million and an athletics endowment of more than \$9 million are major contributors to the school's financial stability. Again, the financial health of the school can be assessed by evaluating the institution's endowment. In 2012, the University earned \$112.4 million in income and recorded $\$ 501$ million in total assets. The revenue and income amounts come from a report 
of independent auditors. A national college financial review gave the institution an "A" grade for financial health. In 2012, the average salaries of full-time, non-medical faculty for all ranks was $\$ 63,855$.

Love University offers prospective students racial and ethnic diversity within the student body. Faculty and administrators reported that the 2013-2014 freshman class was the most diverse in the institution's history. The multicultural office reported more than 900 students came from diverse cultures, and eight different student organizations served that population. Table 5 provides a glance at student and faculty diversity at Love in Fall 2012.

Table 5

Fall 2012 Student and Faculty Diversity at Love University $(N=4,367 ; 240)$

\begin{tabular}{lcccc}
\hline Diversity & Student $n$ & $\%$ & Faculty & $\%$ \\
\hline African-American & 306 & 7 & 14 & 6 \\
$\begin{array}{l}\text { Asian/Asian } \\
\text { American }\end{array}$ & 46 & 1 & 2 & 2 \\
Hispanic & 393 & 9 & 5 & 0 \\
International & 218 & 5 & 0 & 0 \\
Native American & 0 & 0 & 0 & 94 \\
White & 3232 & 74 & 219 & 0 \\
Unknown & 46 & 1 & 0 & \\
\hline
\end{tabular}

Note. Gender of faculty $33 \%$ female, $67 \%$ male

In a 2007 review of the racial demographics of CCCU faculty, $91.3 \%$ of faculty at CCCU member institutions identified as White non-Hispanic. In-terms of White non-Hispanic faculty, Love University shows statistics $1 \%$ below that of the CCCU. At Love, minorities among the 
estimated 250 faculty do not reflect the diversity within the student population, as reported in institutional documents.

In comparison to Peace University, Love University offers a more systematic approach to campus diversity efforts. Although the latest strategic plan is not available and still in progress, diversity ranked as a high priority in the conversations. A diversity committee worked to create an institutional diversity definition as well as to provide a framework for engaging in racial dialogues. In the context of strategic planning, this diversity committee also conducted campus wide interviews with faculty and recommended hiring a chief diversity officer. At this point the committee is not certain what will actually remain in the completed strategic plan. Despite a recent shift in leadership, participants are hopeful that diversity will remain high on the institution's agenda. At Love University, several common themes emerged during interviews with students, faculty and former administrators, who now teach. The personal interviews, internal documents, and external web site analysis of national college data collection organizations helped to triangulate the findings. Moreover, the patterns shaping institutional diversity work include: diversity rhetoric, intentionality, power and access, environmental subtleties, and a ground-up approach. The following sections will discuss those five themes.

\section{Diversity Rhetoric}

Love University talks the diversity talk. When reviewing the institution's website, it is easy to find a biblical mandate for diversity, cultural experience essays from faculty and information about the multicultural office. Likewise, the University's intercultural team, which includes several minority faculty, outlines the campus vision for cultural diversity and inclusion. The majority of faculty members interviewed agreed that rhetorically, the University excelled in terms of diversity, but in actuality the efforts continued to be status quo. Luke, a faculty 
member, expressed that Love "applauds diversity in public and says that it wants to recruit, maintain, and foster the scholarship of non-Anglo... faculty members. But it doesn't necessarily have all the mechanisms, vehicles or programs in place to help faculty members." Still, every participant acknowledged the institution does well with achieving student diversity. However, the efforts were different when evaluating diversity in faculty and administration.

While the University has a clear mission to diversify the student population, that message did not necessarily translate to faculty. Faculty member Mary used fingers to count the number of faculty of color on campus and then created a short list. Thereafter, Mary explained that faith alone may be driving "our desire to have more students and faculty and staff of color, though. I think that's more about being a good society, being good citizens and recognizing the need." Luke agreed; "theology is rarely ever evoked" when publicly discussing faculty diversity. To this end, the institution's history played a greater role in diversity conversations.

Like many southern institutions, Love University had an official policy of not enrolling minorities. Participants described the University as being in a state of "perpetual repentance" for excluding persons of color and being slow to change directions. As a result, a former president issued a public apology in efforts to create reconciliation. Several faculty members reported the institution continues to try and correct those past wrongs. Luke, a faculty member, maintained that "shame, though never named," seems to drive the faculty hiring efforts and the desire to increase the ethnic diversity in the student body. Conversely, the majority of participants referenced the institution's mission as facilitating diversity work. What drives the diversity efforts at Love University may be debated, however, all interviews expressed the institution's efforts are deliberate. 


\section{Promoting Intentionality}

Despite the motivation, Love University highlighted several intentional efforts to increase student and faculty diversity. To increase the number of African-American students on campus, a board member donated $\$ 4$ million. That helped. Similarly, the University offered potential faculty of color fellowships to earn a terminal degree. That program once worked to increase the number of minority faculty, but is no longer funded. Those intentional efforts led to some gains in achieving the diversity goals, but have since slowed.

Still, the University has some intrinsic motivators for hiring more faculty of color. David, an administrator, explained with nearly $30 \%$ minority student population on campus, the University definitely has an interest in increasing the number of minority faculty. The students, David said, are "naturally going to gravitate towards people who would probably have a greater understanding of their background. And so, we have a burden for our faculty of color on campus." Faculty of color interviewed echoed those concerns. The participants discussed advising minority students outside of their discipline and the increased request for writing recommendation letters. Additionally, Elijah, a junior, shared concerns about having limited access to professors and staff of color. The student expressed the desire to have experienced a class with a non-white faculty member. The student also said his campus experience is in some ways unique because he lives in a fraternity house with students who are ethnically diverse. The student suggested personal growth came as a result of his housemates. Participants noted the importance of people becoming more culturally competent and learning from diverse populations on campus. For this purpose, faculty who had served as administrators commented that while in those roles they always considered ways to improve diversity among faculty. 
At Love University, the hiring process communicates to potential faculty and staff that diversity matters. Each potential hire meets with a group of individuals concerned about increasing diversity among the faculty. Martha, a faculty member, shared some potential questions: "What could you do to bring greater diversity to the faculty? And what could you do to promote, to help students of color?" The questions often puzzled prospective faculty. She explained:

They might have spent the whole day with the physics faculty and then suddenly we have this mixed group of faculty asking questions about how do you relate to minority students, and sometimes people were puzzled about it. I always believed strongly that just the existence of that interview communicated something important.

Besides the interview process for prospective faculty, various departments were intentional about hiring faculty of color. Participants said if it came down between two potentials of equal credentials, the person of color would prevail, but all candidates go through the same hiring process, regardless of ethnicity.

On campus, a group of faculty and students have been intentional about understanding diversity issues. This small group has been vocal and visible on campus for 12 years. Although many of the members of the multi-ethnic fellowship work and attend Love University, the group is not formally affiliated with the institution. The organization has supported University diversity efforts with providing national speakers, serving on various committees and panels, and engaging the community on topics of racial reconciliation. Equally important, participants, who are also fellowship members, stressed that the University needs to more clearly define diversity and place more of an emphasis on racial diversity. 


\section{Power and Access}

Minority faculty conversations focused on access, specifically gaining access to knowledge. When discussing the campus climate, Mary pronounced that open discrimination is not the problem, but "key information is passed along informally, and it's really who you know." Mary further explained if black faculty mostly talk with one another and the same for white faculty, then information remains within certain circles. Subsequently, hints about tenure and promotion and publishing often do not trickle down to faculty of color. Beyond concerns about access, participants discussed the need for a better distribution of power. John, a faculty member, referenced the book of Acts and talked about how Jesus asked His apostles to wait in Jerusalem until they had been given power from on high. Hence, John elaborated that positions of leadership and influence can occur at any administrative, faculty or student level. He questioned:

Are we willing to allow all human beings, regardless of gender or race to share in the power of the institution? I think as a Christian institution we would admit that the power we operate with is not political power or racial power, but it is spiritual power, and if that is the case, then everybody, regardless of what they look like on the outside should be given the opportunity to participate in the sharing of that power, which we need in order to do ministry.

White privilege. A subtheme of "white privilege" surfaced within the conversation of access and power. Several participants depicted the privileges that can come with being a part of the dominant culture. During 50\% of the participant interviews, the term "white privilege" was used to illustrate an ongoing problem in the nation and on campus. Faculty member Jacob further explained "that diversity meant being much more aware of, and conscious of the deeply embedded, although sometimes unknown and sometimes even denied, white privilege of the existing system." At Love University, white privilege prohibits many members of the community from understanding the necessity of minority faculty recruitment efforts, and at times students' concerns. 


\section{Environmental Dynamics}

Another major diversity concern expressed at Love University was campus and community climate. Participants discussed the challenges of living in the community. In addition to the concerns about the minority faculty living and working environment, came issues of faith and how religious convictions manipulated the racial and ethnic diversity on campus.

Participants were open and candid when discussing the campus climate for minority faculty and concerns about the University's Churches of Christ roots affecting the culture.

Denomination. Consistently, the topic of religious diversity came up in discussions. Again, Love University comes from the Churches of Christ tradition. The denomination gave "lip service at some levels to equality, but the reality of it, we just reflected the same kind of segregationist racism that was in most predominantly white religious groups in America," said Jacob. In addition to the University's slowness to integrate, participants communicated how the Churches of Christ - black and white - basically operate separately. When explaining how white Churches of Christ have evolved because of higher education, Jacob said "AfricanAmerican Churches of Christ tend to be like white Churches of Christ were 50 years ago, and this is very, very sectarian." This creates a challenge for hiring faculty and further narrows the pool of applicants. In an effort to make sure potential hires are a religious fit, the University mostly posts open positions in the denomination's publications.

Presently, faculty and administrators are in an ongoing debate of whether or not the University should continue to require full-time, tenure-track faculty to be "a faithful member of the local Church of Christ," as cited in the hiring literature. According to participants, occasional exceptions are made when it comes to hiring. However, most of the participants maintained that 
to increase faculty diversity the policy needs to change. Mary wanted a policy change to better serve the student body:

If we have so many students that are not from the Church of Christ -- more than half our students are not Church of Christ now -- then as Christians we're not being hospitable if we are not hiring people outside of the Church of Christ.

For as many faculty who want to allow non- Church of Christ faculty, others oppose the idea and want to stay with tradition, linking the University to the denomination.

Climate. Love University is a nice place to work. Faculty of color mentioned that they did not see or experience open discrimination. Moreover, the University works to promote an open and welcoming community. The website literature supports that. Nonetheless, Jacob expressed that on campus:

Many people have a good will to try to make inclusion in the diversity and richness, and not just tolerance of other people. I mean tolerance is better than intolerance, I suppose, but it's the lowest of the virtues. It doesn't honor. It doesn't embrace. It doesn't celebrate.

Participants noted a group of campus leaders want to change the climate, while the faculty and administrators want to create an environment where diversity is valued and celebrated.

Mentioning climate can spark lots of conversation. The majority of participants believe climate concerns drive institutional diversity efforts. A few years ago, five or six faculty of color left about the same time. Publicly, the faculty left for reasons such as better pay and family concerns. However, participants close to individuals who departed said the climate played a role. Luke described the climate for some minority faculty: "they feel alienated, particularly as Democrats or supporters of Barack Obama, and that is an ethnic-political-religious division. ...My sense is when minority faculty members get a chance to leave, they do." Whatever the reason, David, an administrator, shared that he wants to be one of the people on campus who can 
stand in the gap for faculty of color. He wants to correct those who offend and support those who feel offended. David gave this example:

The University is like a house, you know. And, there are some rooms in the house where you can go and some you can't. I've heard minority faculty say they don't even feel that they're always getting to go in the house. And, that hurts.

Similarly, the community poses challenges for Love University. The city is majority white, but the children coming up through the school system are majority Hispanic. Luke, a faculty member, stated the institution has no plan for responding to changing demographics. “The university doesn't always do a good job of thinking through the way in which those families would integrate" into the campus community. Consequently, the University has also been slow to respond to other racial concerns. A few years ago, the Ku Klux Klan left recruitment pamphlets in residential mailboxes and in different neighborhoods. Participants mentioned the University had no response to the recruitment campaign. Participants mentioned the incident was mostly dismissed as the ignorance on the part of the Klan, but the University tended to overlook that the campaign sent a much different message to minority faculty, striking a chord of fear that needed to be addressed.

Participants reiterated that the city provides a challenge for diverse faculty. While waiting in the pharmacy line, Luke's then 3-year-old son was playing, fiddling with something a few feet away. He offered this illustration: A lady in the line "did a quick scan around and saw no one that matched the skin complexion of my son. And, so announced to everyone that why can't niggers keep track of their kids? She called my son the n-bomb." Luke described that two things happened in that moment: the lady stereotyped an entire ethnic group in terms of their ability to parent and included Luke in that group. In contrast, faculty described the University as mostly welcoming, but described the community as unfriendly. 


\section{Diversity Ground-Up}

While diversity documents and policies help, participants explained that having people on campus committed and passionate about the work makes the difference. Faculty member Martha expressed worry over the fact that faculty often drive the campus efforts. On one hand, Martha said it is great having key people driving efforts, but on the other hand it can be worrisome "because some of the people who push us to think about matters of diversity, well let's say they retire or go somewhere else. ...If it weren't for certain key folks, that emphasis could certainly be muted, and quickly." Again, several of the participants interviewed are a part of a passionate group committed to diversity and inclusion.

Like the other case sites, faculty noted that administrative buy-in and support is important to increasing campus diversity. To be successful, the University must be positioned to hire faculty when the opportunity comes. Martha elaborated and reported "it takes a lot of creativity. And it takes some real determination and daring in that there are always a need for more positions than we have money." Again, this institution offers much goodwill. However, it is unclear overall how diversity fits into Love University's day-to-day operations. Perhaps, Jacob summed it up best: the University "has so much good potential."

\section{Cross-Case Analysis and Synthesis}

In this study, I analyzed data across all of the cases in order to identify similarities and differences in how Christian universities approach diversity efforts, particularly in regard to faculty. By identifying similarities and differences, I hope to provide further insight into issues concerning the hiring of minority faculty by analytically generalizing the case study results. If researchers want to build a logical chain of evidence, studying multiple cases affords the researcher the possibility (Yin, 2009). In the same way, I used the cross-case analysis to seek 
evidence for the relationships studied. The remainder of this chapter describes the themes that emerged across case institutions and proceeds as follows: a discussion of how universities define diversity; faith versus diversity work; culture and climate; and administrative commitment.

\section{Diversity Defined}

All three institutions believed that diversity is important to the growth of the academy, but few participants could articulate how the institution defined diversity. While several faculty members offered definitions of diversity, none of the participants referenced an institutional definition. Faith University was the only institution that provided a written definition. There, diversity was discussed at length in documents used for accreditation purposes. Still, administrators on that campus seemed more aware of the diversity definition than faculty, who all reported having no knowledge of a formal definition. At Love University the diversity committee drafted a working definition, but the draft had not yet been approved. Peace University offered nothing in writing. To this end, the majority of faculty at the three universities desired to have more written documents, outlining definitions of diversity.

Finding a clear published definition of diversity was a challenge, but participants at each institution verbalized race/ethnicity, religion, and gender as considerations included in conversations about diversity. Moreover, participants implied that more attention should be given to race. Across the cases, participants also noted that sexual orientation is a slippery slope and for the most part should not be included in institutional definitions of diversity. Notwithstanding, differences began to surface as participants discussed theological perspectives and how faith influenced diversity efforts.

\section{Faith versus Diversity Work}

A dichotomy between the faith and mission exists at the three institutions. First, 
participants at each campus commented that the institutional mission, directly or indirectly, drives the diversity efforts. Each institution had a common Christian mission. If universities want to prepare students to serve in various capacities globally, leaders must ensure that those students are culturally competent. But when faith is considered another dynamic surfaces. That dynamic is called spiritual fit.

Although referenced differently at each case site, spiritual fit or religious belief system came up over and over. Each university, with different denominational roots, described its belief systems as, at times, creating hurdles for increasing diversity among faculty. However, the institutions differed on what determined the spiritual fit. At Faith University, spiritual fit entailed having or seeking a prayer language. While at Peace University, spiritual fit centered on prospective faculty feeling comfortable working in an environment where the Holy Spirit directs most of the initiatives. At Love University, prospective faculty members being actively involved with the Church of Christ defined the spiritual fit. Despite the varied interpretations of spiritual fit, participants attributed their belief systems for further narrowing the pool of minority faculty candidates, who are already statistically a smaller group.

Alternatively, those same hurdles do not exist for students at those universities. None of the institutions require students to belong to a particular denomination or church. In fact, not every student is Christian. When it comes to the student body, all three institutions have made considerable gains in enrolling students of color. Within the CCCU, these campuses serve as models for student diversity and possess awards for racial reconciliation work. The institutions all tout different reasons for the increased student diversity. At Peace, the campus is in a diverse community and it makes good business sense to recruit and retain students of color. At Love, specific efforts were made to increase the African-American student population. Moreover, the 
shifting demographics of the community to majority Latino youth in the public school system have encouraged leaders to reflect greater diversity among students. At Faith, the legacy drives those student diversity efforts. Historically, this University admitted minority students when other institutions refused. The participants sincerely wanted to better serve students on their respective campuses.

\section{Culture and Climate}

Culture and climate provide the backdrop for diversity efforts at the institutions. The majority of participants described campuses as welcoming, intentional and deliberate about creating an inclusive environment for faculty and students. A smaller group of participants, however, highlighted diversity of thought and religion in cases where institutions were described as inter-denominational. Despite most participants reporting that they work in campus environments that are both open and welcoming to diverse people, faculty of color often added a caveat expressing elements of tension.

Tension further exists between institutions wanting to increase faculty diversity, and actually changing the climate to be more inclusive once they arrive. Across the cases, minority faculty expressed that too often faculty of color are ignored, discounted and left out of the loop. That friction also surfaced within the student body. Both student participants expressed that while they never experienced the classroom with a faculty member of color, their campuses appeared to go beyond and above in accommodating and welcoming international students. At Love University, the student participant mentioned being sad to report hearing negative comments and seeing negative behaviors on campus. At that same campus, a faculty member shared that during a recent meeting with administrators and African-American students, the students expressed a "bait and switch," meaning that the students felt like there was a real 
interest in recruiting them, but not much effort in retaining them. Students characterized the campus community as unfriendly.

Besides concerns about the campus climates, other factors helped to shape the culture at institutions. As mentioned earlier, denominational ties and institutional history often influenced the culture on the campuses. For instance, Peace University is geographically located in a racially charged community. Administrators expressed that dynamic called for careful consideration and what may be considered a loose diversity effort compared to others, with few documents and diversity initiatives in place. Still, the University strives for a more natural and deeper commitment to longer lasting changes that do not include programmatic efforts.

\section{Administrative Commitment}

Campus diversity efforts are only as strong as the commitment of the senior leadership. An overwhelming majority of all the participants mentioned that if an institution wants to make progress in increasing diversity, specifically when it involves hiring minority faculty, top administrators need to lend support. Without buy-in from the top, participants reported diversity work often stalls or fails. While efforts have been stop and go, in some way the three universities are moving forward. First, the strategic planning diversity committee at Love University now is pushing to legislate diversity, making it one of five key components in the latest strategic plan. Second, the message of diversity comes directly from the president at Peace University - an executive approach. Third, Faith University also provides more of a legislative approach, making sure that diverse faculty sit on search committees and that documents exist to guide institutional diversity efforts. Despite the framework and polices on diversity, resources are necessary.

The most cited reason for slow hiring and countless failed retention efforts is lack of money. Although the case institutions are ranked differently in terms of financial health, they all 
mentioned a limited amount of positions and financial resources as reasons for stalled efforts to hire more minority faculty. Within the finance conversation, two subthemes always emerged: competition and a limited pipeline. Moreover, competition is too great for institutions to hire minorities with terminal degrees, and the limited number of minorities further exacerbates the situation. As a result of such competition, several administrators reported losing faculty to higher-paying positions or unsuccessful recruiting efforts due to low-paying salaries.

Recruiting and retention efforts for faculty of color are limited at Faith, Peace and Love Universities. Generally, recruiting occurs through informal networks. Only Faith University strategically posts advertisements specifically directed toward minority faculty. The other institutions post open positions on institutional websites and in denominational publications. Participants at two universities discussed that posting jobs with national organizations often resulted in a pool of candidates that too often were not good mission fits for the institutions. Besides limited recruiting efforts, none of the institutions have specific practices for retaining minority faculty. All reported the "same treatment" for faculty. Beyond first-year new faculty mentoring, no additional support was afforded to any faculty members. Unanimously, faculty members reported the mentors did not play a significant role in their success. Often participants described the meetings as an occasional lunch or coffee conversations. The limited conversations offered little direction for new faculty.

When discussing tenure and promotion, faculty often mentioned the importance of informal networks and the desire for help navigating the process. In terms of the level of support for faculty seeking some form of tenure, the responses varied. About $10 \%$ of faculty participants received exceptional coaching and guidance during the tenure process, while others reported adequate or limited support. Only $1 \%$ of minority faculty reported exceptional guidance. 


\section{Chapter Summary}

This chapter displayed the data analysis and findings. The findings of the study were presented using a two-pronged approach: descriptive and theme-analysis phases. First, the descriptive phase included an in-depth profile of each case institution. Second, the themeanalysis phases offered the themes that emerged within each case. Third, an across-case look at the themes created an overview of the multi-case study of Faith, Peace, and Love universities. All three institutions were described as southern evangelical Christian institutions. The current study's research questions provided the framework for the emerging themes, including diversity rhetoric, intentionality, environmental dynamics, and diversity approaches. For as many common threads shared between the three institutions, the patchwork for diversity still varied from campus to campus. The motivation existed for increasing the number of minority faculty across cases, but the organizational or systemic approach for how to do it differed. Next, Chapter V offers discussion and conclusions of the study. 


\section{CHAPTER V}

\section{Discussion}

\section{Overview}

During the 21 st century, university leaders can expect the faces of the college population to continue to change. In an increasingly diverse nation, researchers forecast that by 2020 , students of color will encompass $46 \%$ of the nation's total student population (Passel \& Cohn, 2008). As a result of the shifting demographics, all institutions of higher education should take seriously ethnic diversity, not only in numbers but also in the overall institutional approach to diversity (Perez, 2010). At the CCCU's 2014 Engaged Community conference, leaders highlighted reasons and ways Christian higher education can get on board with embracing diversity and changing operations to support and celebrate the increased student diversity. One way to prepare for the growing diversity within the student population is to offer them a diverse professoriate. Hiring more faculty of color can improve campus diversity (Armstrong, 2011). In Rine and LoMaglio's report, (2012) Duane Litfin, former president of Wheaton College, said:

[Christian colleges seek] to engage any and all ideas from every perspective, but they attempt to do so from a particular intellectual location, that of the sponsoring Christian tradition. They draw their faculty exclusively from those who know what it means to live and work from that tradition - indeed, from those who embody it. (p. 35)

CCCU leaders must understand that they need diverse faculty as the minority student populations continue to grow. Equally important, secular and Christian academies will have to compete for students. Faith alone may not help leaders at the Christian campuses serve a larger number of students from culturally diverse backgrounds.

As mentioned previously, the purpose of this qualitative study was to explore institutional efforts to increase faculty diversity at three southern Christian universities and examine how 
those efforts relate to institutional missions. Additionally, the study described what promoted or prevented the hiring of diverse faculty. I used Daryl G. Smith's (2009) dimensions of diversity to evaluate the role of institutional missions, and how they are connected to overall diversity efforts. Smith's conceptual framework offers four areas for studying diversity: access and success, institutional vitality and viability, education and scholarship, and intergroup relations and campus climate. Moreover, the study provides insight on how tenets of faith shape diversity conversation on each of the three campuses. This study should be of great value to leaders at CCCU institutions who desire to increase faculty diversity and add to the literature on diversity.

\section{Conceptual Framework}

Daryl G. Smith, a professor of education and psychology at The Claremont Graduate School, developed a conceptual framework for discussing dimensions of diversity. Scholars suggested using the dimensions to capture and evaluate campus diversity work and reported that the framework may be helpful for organizing the discussion of such efforts. For example, Glenn (2014) discussed that in order for chief diversity officers to evaluate diversity efforts at universities they needed to have a framework for determining what areas should be reviewed and for discussing those findings. Listed below are Smith's (2009) four dimensions:

- Access and Success. Generally, this dimension relates to an institution's undergraduate and graduate student populations and evaluates the achievement of previously underrepresented or minority groups (e.g., graduation rates, persistence, and retention) (Clayton-Pedersen et al., 2007). In the context of the study, this dimension refers to the access and success of minority faculty.

- Campus Climate and Intergroup Relations. This dimension incorporates the type and quality of campus relations among students, faculty, and staff. Additionally, it focuses on 
the question of whether the campus celebrates and acknowledges diversity

(Clayton-Pedersen et al., 2007).

- Educational and Scholarly Mission. This dimension involves faculty engagement with diversity issues, and student-learning outcomes related to diversity (Clayton-Pedersen et al., 2007). The dimension also contains curriculum development and scholarly research projects.

- Institutional Vitality and Viability. The final dimension asked the question: How can administrators, faculty, and staff make sure diversity becomes a part of the campus ethos? This dimension is all-encompassing and addresses the overall university commitment to diversity, including policies, strategic plans, and missions (Smith \& Parker, 2005).

Besides using the research questions to guide the general conversation, the themes are also discussed within Smith's (2009) framework.

\section{Methods}

As discussed earlier, I selected the multiple or collective case study design to explore what promotes or curtails diverse faculty at three southern Christian universities. I visited three Christian universities. Again, Faith, Peace, and Love are pseudonyms for the universities. While interviewing participants, I respected the emerging process which is characteristic of qualitative research. Moreover, I explored several intrinsic cases that illustrated some unique interests (Creswell, 2010; Stake, 1995). The goal of the study is not to generalize the results to all universities. However, my goal is to identify strategies that may increase the number of faculty of color at CCCU institutions. I used a purposeful sample to focus the study so that the information collected would be relevant to diversity concerns. 
After being invited to participate, students, faculty, and administrators at each case institution volunteered for the study. However, the president of the third case institution helped to recruit participants. I purposively chose Faith, Peace and Love universities because they are CCCU-member institutions. The case sites were each selected based on specific criteria, including location and recognition for CCCU diversity efforts. I visited each university for two days. There, I conducted interviews, worked as an observer, and reviewed data from institutional documents to create case descriptions. As suggested by Stake (1995), prior to campus visits I developed a data collection protocol. The data collection protocols focused on describing institutional mission, culture, education and scholarship in terms of faculty diversity. In the study, I also compared the within-case themes across the multiple geographic sites. The next section of the chapter will provide a summary of the study's results and findings.

As explained in Chapter IV, the findings of the study were presented using a two-pronged approach: descriptive and interpretative phases. Earlier, I produced a "narrative description" or an in-depth profile of the case institutions (Stake, 1995, p. 123). In describing the cases, I gave the context of each one, highlighting the physical location and giving a time reference. Then, I created a holistic analysis (Yin, 2003) and offered themes and assertions contained in each individual case. After developing the individual case records for institutions, I studied transcripts, coded participant interview data, reviewed observational notes, and then identified the overall themes of the study. Next, I looked across the cases to see what common themes emerged. The themes are summarized first in the context of the study's conceptual framework and are discussed later in response to the research questions. Table 6 provides the summary of the themes in relation to the four dimensions of the conceptual framework. 
Table 6

Conceptual Framework Outlines Themes

\begin{tabular}{lll}
\hline \multicolumn{1}{c}{ Framework } & Themes & Sub-themes \\
\hline Access and Success & Diversity Defined & \\
Education and Scholarship & Faith Versus Diversity Work & \\
Climate/Intergroup Relations & Culture and Climate & \\
Institutional Vitality and Viability & Administrative Commitment & Intentionality \\
\hline
\end{tabular}

\section{Summary of Themes}

\section{Access and Success}

Diversity defined. Without a structure to frame and define, diversity conversations can quickly become contentious and less productive (Smith \& Parker, 2005). The majority of the participants had no idea how their institutions defined diversity. While many participants offered definitions, they were generally not communicated as the official version. This occurred whether or not the universities actually had a written statement, and posed a problem when describing student and faculty retention. For example, the minority group of concern often varied from person to person, with participants placing emphasis on their particular demographic. When I spoke with women, they made sure to discuss the need for more women faculty. For AfricanAmerican males, the first thing that came to mind when defining diversity was ethnic/racial diversity. In efforts to provide clarity, Faith University had a written definition. However, faculty members were unaware of the definition. At the time of the study, Love University had a working definition that was being considered for the institution's new strategic plan. Peace University had nothing in terms of a published definition of diversity. 
Despite the varied and limited diversity statements or definitions, participants from each university announced the importance of diversity on their respective campuses. An implicit goal was to increase diversity among the student bodies and to better serve those students. According to Smith and Parker (2005) many campuses continue to work on creating access at the undergraduate and graduate level to increase the racial/ethnic diversity through summer programs, admission strategies and partnerships. Universities also have specific strategies to help retain those students. In at least one case, the need for creating a more diverse professoriate arose from the nudging of an accreditation organization. For those purposes, the universities recognized the need to have faculty who reflect the diversity within the student population. But the monetary support and management systems were generally not in place to facilitate the desired changes.

\section{Education and Scholarship}

Faith versus diversity work. Smith and Parker (2005) referenced in several different components of her framework the relationship between organizational culture and diversity work (Ibarra, 2000; Kezar \& Eckel, 2002; Aleman \& Salkever, 2003). Participants at every institution connected their universities' Christian missions to campus diversity efforts. The mission, in most cases, contributed to the energy and commitment to diversity in terms of education and programmatic efforts. Moreover, the campus commitments directly affected the education of students and the scholarship of faculty. Participants at two universities discussed efforts to make sure students were enrolled in at least one diversity course. At both places, the courses were supposed to be provided at the department level. One student described the courses as a joke and mentioned that too often unprepared faculty teach the classes and that the diversity highlighted was often geared more toward international efforts as opposed to domestic. On the contrary, the 
third university offered no specific diversity courses, and participants mentioned that they worked at a teaching institution, which did not place a huge emphasis on research. Still, when participants expressed the role faith played in driving diversity efforts, tensions between the two emerged.

The same faith which suggests that institutions better reflect Christ's kingdom often excluded the very potential faculty institutions hoped to recruit. Either denominational requirements or spiritual fit limited the general pool of applicants. Participants at each university communicated that belief systems were hindering efforts to recruit faculty of color. An already small supply of $\mathrm{PhD}$ candidates became even smaller when religious qualifications entered the hiring process. To that end, at the time of the study, administrators and faculty at Love University were debating whether to remove policies requiring faculty to attend Churches of Christ. Historically and presently the rigidity of the denominational ties and theological traditions are stalling efforts for CCCU institutions to increase faculty diversity (Yancey, 2010; Wolfe 2006). Furthermore, such requirements may deter minority faculty from applying to particular Christian schools.

\section{Climate/ Intergroup Relations}

Culture and climate. The majority of participants described campuses as welcoming, and discussed how intentional they were about making sure their campus was inclusive. Participants expressed the desire for community as Gasman, Kim and Nguyen (2011) described: a culture where differences were embraced and heterogeneity was deliberately sought. No one labelled the environment as hostile for minorities or reported discriminatory practices. However, participants expressed concerns about limited access to knowledge and how faculty of color at times were 
left out of informal networks. Faculty of color echoed sentiments of being left out of informal networks, and several discussed feeling isolated and ignored.

All the universities appeared to strive for a deeper understanding of how to create a better educational environment. At Love University, participants discussed the need to learn to celebrate diversity and how white privilege threatened that goal. Participants also mentioned that often the community influenced the climate. At Love University, participants labeled the community as unfriendly. Similarly, Peace University participants described the geographic location of their community as racially charged. Institutional culture and climate played a significant role in administrators' ability to recruit, hire, and retain minority faculty. When considering the framework of climate/intergroup relations, Smith and Parker (2005) suggested that it takes time for "cross-institutional teams" to come together and design "manageable and beneficial collaborations" (p. 123). Consequently, turnover of faculty and administrators interested in diversity work can hinder institutional efforts.

\section{Institutional Vitality and Viability}

Administrative commitment. Smith (2009) underscores that for diversity efforts to be successful leaders on many different levels must be involved. Participants all agreed that in order for diversity to be treated as a priority, senior leaders need to promote the issue, particularly if a change in institutional culture was desired. In terms of institutional vitality and viability, Smith and Parker (2005) pronounced that a diversity coordinator would play a key role in keeping senior leadership focused on diversity progress, especially in hiring. Although two institutions used search committees in the hiring process, all participants expressed the importance of having administrative support when it came to creating plans to recruit and retain faculty of color. From an administrative perspective, two challenges came up at each institution: money and the 
pipeline. During the years 2009-2010, the U.S. percentage of doctoral degrees conferred by ethnicity comprised of 74.3\% White; 7.4\% Black; 5.8\% Hispanic; $11.8 \%$ Asian/Pacific Islander; and American Indian/Alaska Native 0.7\% (U.S. Department of Education, NCES, 2012).

The approach to the conversation varied at the universities, but the general concern was that hiring minority faculty can be costly due to the limited number of diverse candidates on the market. Administrators discussed losing faculty to higher paying jobs and reported inflexible hiring practices as obstacles to recruiting talented faculty.

Overall, the goal was to increase the number of minority faculty on campuses. Though this may be, the approaches to the institutional diversity efforts differed. At Peace University, where the president and provost made all the hires, it was a top-down approach. Faith and Love Universities relied on a more collective process, involving a hiring administrator and a search committee. Both institutions had a systematic approach, which encouraged and communicated diversity in different ways. At Faith, minority candidates were directly targeted through job announcements. Alternatively, Love University provided an internal committee the opportunity to gauge prospective faculty's commitment to diversity in the curriculum, research, and classroom management.

\section{Discussion and Conclusions}

Generally, history and the history of higher education serve as the backdrop for having a rich diversity discussion. On stage, the Civil Rights Movement and President Lyndon B. Johnson's War on Poverty in the mid-1960s exposed many inequities for minorities. Then, people of color did not have equal access to housing, jobs, or education. Through new laws and amid protests for equality in schools, administrators at predominantly white institutions had to respond and reshape their institutions. The landmark 1954 Supreme Court decision, Brown v. 
Board of Education, changed the demographics at public schools. Moreover, those education policies called for integrating public school systems and encouraged universities' leaders to begin to recruit minority students and faculty.

When white institutions first reached out to students and faculty of color, they did so in the belief that they would be the primary beneficiaries of the traditional education the schools offered. Only slowly did white educators begin to discover that they had as much to learn as to teach; that their historical constituencywhite Americans - also secured unexpected benefits from education in a multicultural environment; and that the Socratic model of learning by dialogue across similarities and differences of belief, theory, and experience could be expanded to include race and ethnicity as valued forms of difference. (Maruyama, Moreno, Gudeman, \& Marin, 2000, p. 1)

Like their counterparts at secular universities, CCCU leaders are discussing the benefits and value of diversity on campuses. While leaders understand the educational value and the advantages of linking diversity efforts to institutional missions, they continue to struggle to increase the number of faculty of color, who they know help to create a better teaching and learning environment. Again using Daryl G. Smith's (2009) dimensions of diversity as the conceptual framework, I will discuss the five research questions. In the discussion, I introduce another participant CCCU Administrator called Aaron, who although not affiliated with any case institution, offers a broad perspective to the research questions.

\section{Institutional Vitality and Viability}

\section{Q1 What diversity efforts exist at three Christian universities in the South?}

Across all three cases, institutional mission influenced diversity efforts. Participants at each case site illustrated how they prepare students to work in a global society. Generally, diversity efforts included events, student support efforts and curricula changes. However, CCCU Aaron brought up an interesting point. The administrator communicated that without diverse students and faculty, students are not truly prepared to enter the workforce. Aaron elaborated: 
"We can prepare them theoretically; we can import diversity so that they see it, but we can't give them the kind of experiences they'll need after college." The administrator described the situation as the difference between learning about Italy from a textbook and actually going to Italy.

The concerns of Aaron also showed up often in the literature. Researchers Day and Glick (2000) discussed the challenge for graduates in transitioning to the workplace. Despite an increase in diversity courses, students continue to struggle with managing the diversity on the job (Day \& Glick, 2000). A participant at Faith University highlighted another concern with preparing students to serve globally. The participant noted that domestic diversity often gets short shrift, meaning not much attention was given to understanding the different ethnicities on a local level. Moreover, the two students interviewed for the study discussed not ever experiencing a faculty member of color, and one mentioned diversity courses lacked relevance. After visiting the three universities, it was clear that institutional missions were linked to individual campus diversity efforts. However, how that mission played out varied from site to site. Smith and Parker (2005) reported that event planning, hiring concerns, curricular changes, and other diversity efforts fall to "a broad and disparate group of individuals on a campus" (p. 115). Their description held true at Faith, Peace, and Love universities, where key groups or individuals promoted diversity efforts.

Faith and Love universities highlighted having an official multicultural presence. Faith promoted a multicultural committee, which mostly functioned in terms of student development. At Love, a director managed a multicultural office that served students from more than eight different cultural groups. Still, none of the universities had a chief diversity officer or someone in a senior leadership position charged with managing campus diversity efforts. CCCU Aaron also 
noted that across the CCCU, some institutions have made progress, but few are where they

should be. He attributed institutional diversity success to having presidents in favor of diversity efforts. In order for institutions to see measurable progress, the campuses will need an empowered diversity champion, whether it be a chief diversity officer or a president.

A diversity champion may also help the institutional challenge of defining diversity and creating a clear message for students, faculty, and staff. Again, across all the cases, faculty had no inkling of the universities' definitions of diversity. In cases where institutions actually had a definition, faculty were unaware. If campuses hope to improve diversity efforts, a general definition of diversity would serve as the framework leading discussions and efforts. Thus, the framework would provide a process for evaluating diversity hiring efforts and initiatives in general.

\section{Q2 What aspects within the history of evangelicalism promote or deter the hiring of}

\section{diverse faculty at these three Christian universities in the South?}

Christian universities that take Scripture seriously should show a commitment to not only educating a diverse study body, but also hiring diversity. CCCU Administrator Aaron explained:

The diversity and the life of Christ, and then the teachings of Christ in the epistles require us to work towards a oneness in Christ, and the no Jew, nor Greek; male, nor female, are very inclusive understanding of the Gospel. And so I think our Christian missions require us to have a higher-level commitment to diversity, not only for the sake of justice, but for the sake of the kingdom,

Participants at each site all mentioned working toward that oneness.

Still, two universities blamed history and past wrongs for slowing diversity efforts, including hiring minority faculty. Emerson and Smith (2000) wrote in Divided by Faith: Evangelical Religion and the Problem of Race in America that denominations often promoted or opposed slavery. Several historians explained how church roots continue to divide modern-day 
institutions today (Emerson \& Smith, 2000; Peart, 2000; Thelin, 2004). Participants at each case institution and the CCCU administrator offered insight on those current divisions. Aaron detailed his concerns:

The evangelical historic association with conservative politics systematically raises cultural barriers for ethnic and racial minorities and women. Past evangelicals have been guilty of feeling that emphasis on multiculturalism, on feminism, on any 'ism' is a part of a liberal agenda that's trying to mess up America.

Similarly, participants at Love and Faith universities described how the politics can be divisive and foster an appearance of unwelcomeness for faculty of color.

Politics aside, history remains history. Two of the southern campuses acknowledged operating under segregation and having admission policies that excluded minorities. Love University offered an apology for slow integration efforts. Faith University welcomed students of color and faculty during the 1960s.

Another problem participants noted centered on faith. This issue of denominations and how they influence institutional efforts are detailed later in the discussion on climate and intergroup relations. Still, Yancey (2010) reported that given missions and history, Christian colleges and universities may struggle more to obtain racial diversity than other institutions. While achieving progress in student diversity, these three institutions are struggling to improve in terms of faculty diversity. No matter how well-intended, participants highlighted how the institution's past may continue to present current recruiting challenges.

\section{Access and Success}

\section{Q3 What are Christian colleges doing to recruit and retain diverse faculty?}

Recruitment and retention efforts of diverse faculty in most cases were limited or nonexistent at the three universities. Participants at each case site discussed how faculty of color 
mentored students, brought new perspectives to the curriculum, and created diverse scholarship. While participants recognized that faculty diversity served as a key factor in achieving success for minority students (Astin, 1993; Smith, 1997; Umbach \& Kuh, 2006; Yancey, 2010), they all reported not having any particular recruiting strategies for hiring faculty. Likewise, participants commented on no special efforts for reaching potential candidates of color. Only Faith University posted jobs on national hiring sites and used direct marketing strategies for reaching a diverse pool of candidates. The other two universities had a more insular approach, posting job openings in denominational publications and on institutional websites. This contradicted the pervasive thought of intentionality in terms of diversity efforts. If university leaders want to recruit and hire more diverse faculty, then they should be in active pursuit.

Smith et al. (2004) reported that several empirical studies show that faculty diversity is the least successful diversity initiative. The researchers examined whether specific interventions facilitated the hiring of diverse faculty beyond those who taught diversity courses. The researchers cited:

1. The job description used to recruit faculty members explicitly engages diversity at the department or subfield level; 2 . An institutional "special hire" strategy, such as waiver of a search, target of opportunity hire, or spousal hire, is used; and 3. The search is conducted by an ethnically/racially diverse search committee. (p. 2)

Nonetheless, institutional approaches to facilitating diverse hires varied. For instance, at Peace University two senior leaders made hires without a search committee. Alternatively, both Faith and Love Universities had a more collaborative system for hiring. The third hiring strategy could be seen at these two universities. The two universities reported forming search or hiring teams 
and implementing efforts to make sure they were racially/ethnically diverse or included some minority representation. Also, Faith University had an administrator who supervised faculty hiring. No matter the approach, all three cases expressed the desire to do more in terms of hiring.

Pipeline. A large part of the literature on faculty diversity maintained that few faculty of color are earning doctorates, limiting the amount of qualified faculty (Myers \& Turner, 1995; Snyder, 1992; Thurgood \& Clarke, 1995; Yancey, 2010). An overwhelming majority of the participants in the study pointed out the shrinking pool of candidates based on "spiritual fit" or the missing educational credentials. Moreover, Aguirre (2000) explained that as faculty pools began to shrink and the demand increased for new faculty, minority faculty should have more opportunities for jobs. This, however, was not occurring at the case sites.

Administrators discussed limited funding for positions and the challenges of getting minority candidates in position pools. An administrator at Faith University stated he would be willing to wait two years to ensure he had a diverse applicant in a pool. Although financial pressures may curb the enthusiasm to wait, it was refreshing to hear such commitment. Yancey (2010) wrote that, too often at faith-based institutions, administrators use the pool argument to explain the lack of diverse faculty, and I agree. Another challenge referenced throughout the literature: rural versus urban. Participants also noted that location made a difference; some minority faculty are hesitant to live in rural areas (Yancey, 2010; Wolfe, 2006). However, all three case cities were labeled as urban environments. Although the case institutions recognized the benefits of diverse faculty, the actual hiring effort lacked enthusiasm. Slow progress in terms of hiring resulted in participants expressing concerns about faculty access and success in their campus environments. Aaron, a CCCU administrator, discussed minority faculty access:

Groups of people are not known for doling out power willingly. Mainstream evangelicalism has been pretty much a male white thing. We just love similarity. We love 
people like us. When you have the power to surround yourself with people similar in their views - that is not something you tend to give up.

At Love University, power and access was a noted theme. Participants talked about limited access to knowledge and mentioned limited opportunities existed for advancement in terms of more senior positions. Authors Wong and Polite (1991) recommended ways to give more access to faculty of color. Universities should seek minority faculty members' input on institutional policy and other issues and provide opportunities for minority faculty to develop administrative power (Wong \& Polite, 1991).

\section{Climate/Intergroup Relations}

\section{Q4 What is the climate for minority faculty at Christian universities?}

When it came to discussing campus climate for faculty members, there were few surprises. No participants of color mentioned unequal treatment or open discrimination. Their concerns were more subtleties, exclusion and silenced voices. Aaron expressed that Christian institutions continue to have problems dealing with race. The administrator discussed where the tension may lie:

I think most of the white males on our campuses look at race and gender and say, 'yes, women and racial minorities have been disadvantaged.' They will admit that, and they will be sympathetic. I do not think that most of the white males on our campuses feel that they have been privileged.

Surprisingly, participants at one campus openly discussed how white privilege shapes thoughts and decision making on campus and generally in the nation. This particular institution was aware of the terminology and understood the implications of not discussing white privilege and managing how it played out at the university.

Additionally, faculty of color expressed fatigue from extra responsibilities, including advising minority students and writing recommendations for those students. Other participants 
also mentioned that due to the small number of faculty of color, at times they are overworked because students of color often seek them out for support and understanding. CCCU's Aaron further described the situation: The culture is one where our people from underrepresented groups get crushed in our small institutions." He talked about how faculty of color often serve on more committees because people want diversity.

The literature offers great insight on everyday life for minority faculty at predominantly white institutions. As mentioned earlier, Tillman (2001) wrote that faculty of color often struggled with issues of developing personal and professional identity within the academy, and whether male or female, they often experienced isolation. Similarly, Maher and Tetreault (2009) reported that newer faculty spoke of their isolation and pressure to conform. At the three universities, I listened to several accounts of faculty feeling ignored; a few discussed feeling silenced. Participants at Love University referenced Claude Steele's book Whistling Vivaldi: And Other Clues to How Stereotypes Affect Us, in describing that often minorities work to accommodate the white majority. A participant mentioned that minorities' success at the universities can depend on their abilities to assimilate or to whistle, meaning to reduce the fear factor for Whites.

Despite working at the three Christian universities, participants of color often verbalized that beyond their faith, they worked on uncommon ground. Why? Aaron aforementioned that evangelicals have been slow to recognize diversity as a quality issue and instead consider it a term addressing equality issues. He held that when it is an equality issue:

Then you hear noise about quotas and political correctness and those kinds of things as opposed to when it's a quality issue and you begin to recognize, we're just better when we are behind all the complexities of our institutions and of our culture from diverse perspectives rather than single lens points of view.

A common phrase uttered from white participants: colorblindness. Yancey (2010) alleged that 
the term colorblind signals to faculty of color that they are unnoticeable, when clearly there are differences. Creating environments where faculty are celebrated for who they are and their contributions is important to changing the overall climate for minorities.

At Love University participants found common ground. Here, faculty members engage in a diversity fellowship. This fellowship offered minority faculty and whites the opportunity to work with the community and to get to know each other on a personal level. Members of this group openly discussed racial concerns and had a genuine interest in diversity. This was an interesting model because the group had loose ties to the University. Consequently, members could often times be much more effective with programming efforts and responding to different situations. Participants who were also members of the fellowship expressed having deep friendships with faculty and staff of different racial and ethnic backgrounds. I believe this kind of organization can drastically change the experience for minority faculty at Christian universities. However, at least one participant articulated that despite having supportive friends on campus, the desire for deeper connections and understanding remained.

\section{Education and Scholarship}

\section{Q5 How does faculty diversity or the lack of it impact Christian universities' educational and scholarly missions?}

Participants at Faith, Peace, and Love universities definitely understood the value of faculty diversity, and how it shaped their institutions' educational and scholarly missions. In fact none of the participants debated the merit in increasing the number of diverse faculty and their ability to influence students, enhance curricula, and create scholarly works. However, the insignificant number of minorities left only small footprints on their campuses. In several cases, departments at the institutions were more diverse than others. As a result, few students pursuing 
other courses of study encountered faculty of color. I found it interesting that the two student participants highlighted not ever being taught by any minority faculty. On campuses with only a handful of diverse faculty, a greater number of students are graduating without ever learning from someone from a different cultural or ethnic background. Again, this poses a problem for students when attempting to manage diversity in the workplace.

Attending a class with minority faculty does not automatically translate into students having conversations about diversity. Christian university faculty members are less eager to discuss topics on race or adopt a research agenda that focuses on minority issues (Wong \& Polite, 1991). A distinctive group of faculty at the three universities regularly engaged in conversations about race, and two of those groups were not connected to the institutions. None of the participants disclosed working on any research projects dealing with minority issues. Regardless of the limited diversity scholarship produced, Aaron believes that Christian colleges love diverse faculty members. However, he stated: “I don’t think every Christian college takes race and culture into consideration as an asset, and the institutions may not understand how important faculty diversity is to students." In conclusion, these particular case institutions understood the value of having a diverse professoriate; the problem arose with hiring and retention. I have used Smith's (2009) framework to discuss the findings. The next sections of the chapter will reveal limitations, express recommendations for future research, and describe implications for practice.

\section{Limitations}

\section{Methodological Limitations}

This qualitative study provided much insight on diversity efforts, particularly in terms of hiring minority faculty at three CCCU institutions. However, the study did so with several 
methodological limitations. First, the study included a sample size of 20 participants from the three institutions. The small sample size may not be representative of all faculty of color at CCCU institutions and does not convey the thoughts of students, staff, faculty and administrators on CCCU campuses to whom results will be generalized or transferred (Gasson, 2004).

Nonetheless, the sample highlighted institutional diversity efforts and illustrated challenges for hiring and retaining faculty of color.

Second, limited prior research exists on faculty diversity within the context of Christian universities. While the lack of research presents an opportunity for me to add to the body of knowledge, the limited information made it difficult for me to understand the research problem in the context of Christian higher education institutions. Citing prior research studies forms the basis for the literature review and provides a foundation for the entire study. Reports offer descriptive statistics on the ethnic/racial diversity across CCCU schools, but few provide a narrative to explain any phenomenon. Researchers have more often focused on student diversity. Faculty diversity was a caveat in the conversations. Still the lack of literature on faculty diversity at $\mathrm{CCCU}$ institutions provides an opportunity to continue to explore the challenges of hiring and monitoring the progress.

Third, I visited the three campuses and gathered the data. The self-reported data are limited because I did not independently verify information obtained in each interview. The interviews were taken at face value. Still, I understand the self-reported data provide potential opportunities for biases to appear and should be noted as limitations: (a) selective memory (remembering or not remembering past experiences or events); (b) telescoping (recalling events that occurred at one time as if they occurred at another time); (c) attribution (crediting self or one's organization for positive outcomes as opposed to negative outcomes); and, (d) 
exaggeration (the act of embellishing circumstances and happenings) (Creswell, 2008; Merriam, 2009).

\section{Researcher Limitations}

I am a part of the small demographic of faculty of color teaching at CCCU institutions, and in my past profession of journalism I served as a diversity trainer and advocate in the newsroom. Consequently, my passion and commitment may have showed up as a cultural bias. I often had to bracket impartial or critical thoughts. Another way to minimize the potential for bias was to make sure I followed the study protocol. Additionally, I proofread the chapters reviewing how I stated the problem, selected the cases and participants, and ordered events.

My study depended heavily on having access to people at the three case sites. When recruiting, I requested participants who had a heart for diversity work. This gave me a narrower pool of faculty, administrators, and students to draw from. Out of that group, subjects from Faith and Love universities volunteered to participate. At Peace University, the president helped recruit the selected participants. In this scenario, access was limited. Those who were requested to participate may not have been as open or candid. Moreover, data collection occurred over two months. This limited the possibilities for longitudinal effects. I had limited time available to investigate the research problem and no time at all to measure change of the period of the study. Given more time, there are more angles and possibilities to pursue in the study.

\section{Recommendations for Future Research}

External demands are encouraging higher education leaders to seriously consider the benefits and value of diversity. Universities are competing for students who are more and more ethnically/racially diverse and who come from varied cultural backgrounds. The literature on diversity within organizations, businesses, and higher education is fairly robust. However, 
limited research exists for faith-based institutions. In the Rhine and LoMaglio (2012) study,

CCCU former President Paul Corts discussed the diversity within the CCCU membership:

I cannot overly emphasize the tremendous diversity of our membership. We vary by geographic region, size, programmatic scope, theological heritage, political and economic realities, and a myriad of other distinguishing characteristics ...When I became president of the Council... [I witnessed firsthand] the enormity of the diversity among so many different characteristics and that helped me to gain a new appreciation for the incredible strength of what unites us - a common commitment to Christ-centered higher education. (p. 9)

Corts highlighted the diversity of the CCCU and those differences surfaced throughout this study, among the three case sites. This study only begins to explore challenges and concerns of increasing diversity efforts, specifically in terms of hiring faculty of color at CCCU institutions. If CCCU leaders value diversity, they must continue to encourage faculty to adopt research agendas that focus on diversity topics. This section seeks to provide recommendations for future faculty diversity research within the CCCU.

I will discuss four future research projects. First, a research study exploring the institutional viability for recruiting and competing for faculty of color will allow universities to take an honest look at their general commitment and resources allocated for diversity efforts. Historically, the case institutions have struggled with past attitudes that showed up in the form of policies, resisting desegregation. The resistance is related to fear of losing privileges, and the belief that affirmative action policies prevent white males from excelling in the academy. Researchers continue to explain that in order to attract faculty of color, institutions need to communicate a clear commitment to value diversity (Hurtado, 1999).

Second, a research project could examine the gender implications within the professoriate at CCCU institutions. Originally, I hoped to include women in the study. However, after reviewing the literature I determined that both were huge topics worthy of their own 
conversation. When defining diversity, participants almost always included women. As a result, conversations about increasing faculty of color generally segued into conversations about the need for more women faculty. In recent years, researchers have discussed concerns with gender imbalances within the faculty ranks in the CCCU. In the fall of 2009, in the United States $42.9 \%$ of university faculty were women. At CCCU member institutions, women represented $38.4 \%$ of faculty (Rhine \& LeMaglio, 2012).

Third, further research is needed on the implications of the lack of diversity among senior leadership at CCCU institutions. Again, across all cases participants referenced that at the time of our conversations, their cabinets were predominantly white males. Few articles were published on the lack of diversity in the top ranks of member schools. However, Longman and Anderson (2011) collected data over a 12-year period (1998-2010) to document the growth in the gender composition of CCCU institutions' senior-level leadership teams. Over that period, the average number of individuals filling the roles of vice president or higher levels increased from 5.3 to 5.9. The percent of men grew $20 \%$ over the period, while the percent of women serving on those leadership teams grew $161 \%$ - from $8.4 \%$ to $17 \%$ of the total serving in these senior leadership positions. Still, there is room to look at administrators of color.

Fourth, another future research project could provide deeper exploration of how cultural differences or barriers impede diversity efforts at the CCCU institutions. Turner and Myers (2000) interviewed 55 faculty of color, and discussed institutional practices associated with recruitment and retention of faculty of color. Studies on institutional climate find that a large group of minority faculty members feel that the institutional environment is unwelcoming and that problems with racial/ethnic bias exist at the academies (Trower \& Chait, 2000; Myers \& 
Turner 2001, 2000). My study focused on small southern universities; however, this may be a richer discussion at West and East coast universities, which may have more faculty diversity.

\section{Implications for Practice}

I propose the following set of best practices to increase the recruitment and retention of faculty of color at CCCU institutions. The practices have been developed using the following sources: Survey of the literature and web-based organizational documents on best practices in the recruitment and retention of faculty of color, including (a) the American Association of University Professors (AAUP); (b) a survey of faculty diversity initiatives at Faith, Peace, and Love - the case institutions; (c) ideas generated at the CCCU Engaged Conference 2014. (A group of chief diversity officers met at the conference to discuss diversity efforts within the $\mathrm{CCCU}) ;(\mathrm{d})$ previous experience working with diversity initiatives in the media industry; and (e) in Damon A. Williams and Katrina C. Wade-Golden's book, “The Chief Diversity Officer (CDO): Strategy, Structure, and Change Management. This list does not represent an exhaustive set of best practices, but it is intended to generate discussion and create a starting place for those interested in achieving greater diversity among faculty.

\section{Recommendations for Recruitment}

- Develop a recruitment strategy. (a) Involve faculty and other stakeholders in the development and implementation of a strategic plan to diversify faculty in recruitment and retention, including creating goals and measureable outcomes (Williams \& WadeGolden, 2013); (b) Ensure that diversity-related goals are part of the overall institutional mission and vision (Smith \& Parker, 2005); (c) Educate the faculty about the institution's stated commitment to diversity, and its educational benefits. Consider providing 
departments with a recruitment document (Smith et al., 2004; Turner, 2002). Make sure to clearly define diversity on your campus and articulate that meaning to the stakeholders.

- Adopt a conceptual framework. (a) Assessing and evaluating diversity efforts requires institutions to judiciously examine the campus culture, routines, and practices that may support increasing or sustaining faculty diversity (Smith, 2009; Smith \& Parker, 2005). (b) Establish a community of collegiality that encourages open dialogue about issues of race, ethnicity, culture, and other dimensions of difference. (c) Establish a culture of inclusiveness and model respect of others, and value of difference as a resource in research, teaching, and service (Niemann, 1999).

- Active Pursuit. (a) Review the recruitment process with university stakeholders and discuss practices for increasing diversity (Williams \& Wade-Golden, 2013; Irazábal, Thomas, \& Umemoto, 2011). (b) Establish hiring criteria that consider the candidates' cultural competence and willingness to work in and with minority students/communities, and/or ability to develop or integrate diversity components in the course work or curriculum. (c) Whenever possible, ensure that search committees have minority representation or those who are willing to stand in the gap and articulate the rationale for faculty diversity. (d) Make the recruitment process transparent. Smith et al. referred to this effort as "interrupting the usual" (2004, p. 153).

- Financial Strategy. (a) Establish incentives to encourage departments to recruit and hire minorities; funding can include research support, salary bonuses, or stipends.

- Feeder Systems. (a) Given particular spiritual fit concerns, it makes sense for institutions to become more aggressive with growing their own faculty. Institutions should work to increase the recruitment and graduation of underrepresented doctoral students of color. 
(b) Create research fellows and post-doctoral programs to recruit underrepresented minority faculty to the university. Consider the benefits of targeted hiring programs such as "target of opportunity" hires (programs designed to create the flexibility to hire in particular areas of expertise, experience, and diversity) when a candidate becomes available.

\section{Recommendations for Retention}

- Promotion and Tenure. (a) Have clear expectations and make certain minority faculty fully understand the criteria for promotion and tenure. (b) Regularly give constructive feedback on their work and progress (Irazábal et al., 2011). As part of the review process, help faculty identify their areas of strengths and challenges and encourage them to develop a plan. (c) Avoid subtle forms of discrimination in promotion criteria (Irazábal et al., 2011). For instance, when reviewing service commitments, are minority faculty receiving ample credit for the service (minority faculty members often have extra demands placed on them to advise other faculty and students of color, and to serve on university diversity or multicultural committees)? Are they given reduced teaching loads to compensate for increased service activities?

- Mentoring. Regardless of race, mentorship programs have helped to retain faculty. (a) Evaluate and increase formal and informal efforts to mentor new hires. (b) Find possible ways to make mentors accountable, such as asking for yearly reports from them. (c) Mentoring should include helping new faculty transition into the social and professional life of the university community; providing guidance on research, teaching, and the evaluation and promotion process (Trower, 2008). 
- Professional Development. (a) Provide adequate professional development support for faculty of color, including reduced teaching loads, research start-up funds, and opportunities to attend teaching seminars.

- Chief Diversity Officer or a dedicated diversity leadership position. (a) Diversity officers lower employee turnover. When there is a poor perception of opportunity, minorities and women will leave the university to pursue positions where they can flourish (Wilson, 2013). They may even be drawn to the other institution's diversity leadership or diversity initiatives. (b) Chief diversity officers play a key leadership role in recruiting, mentoring, and maintaining diversity and inclusion on campus (Williams \& Wade-Golden, 2013). (c) Besides creating a system of accountability, diversity officers understand public policy and implications for campus business (Wilson, 2013).

\section{Conclusion}

Without a doubt Faith, Peace, and Love universities all have a heart for diversity. Each institution has a committed group who are concerned about the institution's overall diversity efforts. In terms of creating a more institutionalized diversity vision, all campuses were not created equal. Two universities either included diversity in strategic plans or were in the process of adding it. Still, my concern is despite good-faith efforts, institutions lack the depth and intensity to truly be effective in hiring more faculty of color. Similarly, limited marketing and recruitment strategies in several instances did not scream out intentionality. In order to actively recruit, institutional leaders must go beyond posting jobs (Williams \& Wade-Golden, 2013). The institutions also need to create and communicate a clear definition of diversity so that students, faculty, staff, and administrators are speaking the same language. Daryl Smith's (2009) 
conceptual framework creates an outline and perhaps a way of discussing the diversity work at each campus.

The framework can also provide institutions a way of monitoring progress in diversity. First, institutional vitality and viability provided university leaders a way of reviewing diversity events, curricula concerns, and strategic planning efforts. This study highlighted strategic planning efforts and illustrated how diversity emerged as a key component at Faith and Love Universities. The study also illustrated the informal nature of diversity planning at Peace University. There, the Holy Spirit guides diversity efforts. Theologically, this seems like a remarkable model. However, when asked who determines when the Holy Spirit is moving and the direction of the movement, participants implied that it was the president.

Second, beyond student access and success, this study revealed that universities have no real hiring strategies for minority faculty and that few efforts were made to retain them. Third, when looking at climate/intergroup relations, participants across all cases directly discussed the climate for minority faculty on the respective campuses. Generally, participants described their campuses as friendly for minorities. However, minorities often provided varied descriptions, including feeling isolated and silenced. Fourth, the study imparted that a high value was placed on diversity in education and scholarship at Faith, Peace, and Love universities. Though this may be, the three case sites did not have enough critical mass to really influence the entire campus. As minorities find ways and spaces to grow and thrive as underrepresented populations, university administrators must develop strong and intentional efforts to recruit and maintain faculty of color. Likewise, faculty of color must persist. At Love University, John, a faculty member, simply stated:

My task is to stay as closely connected to Him as I can, and observe how He works and moves events, in life and how He orchestrates things that no human 
being can take credit for. But I have to spend a significant amount of time in that place of spirit, and it is in the place of the spirit where the soul becomes rejuvenated, revived, encouraged, and inspired to face, I mean the most insurmountable odds when it comes to dealing with race and racism and racist human beings.

I hope this study helps CCCU member institutions to appreciate the role race/ethnicity plays in the institutional experiences of faculty of color. Additionally, I seek to help institutional leaders develop a better understanding of the benefits of diverse hiring. In order for students to excel in a global, pluralistic, multicultural society, at the very least they need to be introduced to minority faculty, and given the opportunity for those professors to teach and influence them. Consequently, the absence of minority faculty underprepares graduates for living, serving, and working in diverse communities. I have outlined specific recommendations for what CCCU institutions can do to increase the number of minority faculty and to create a welcoming environment for all faculty. My only hope is that institutions will consider the consequences and start changing how they do diversity work, making certain faculty of color mirror student populations. 


\section{REFERENCES}

Abilene Christian University. (2005). CCCU to honor ACU for racial harmony [Press release]. Retrieved from http://www.acu.edu/events/news/archives2005/051017_racial_harmony.html

Aguirre, A. (2000). Women and minority faculty in the academic workplace: Recruitment, retention, and academic culture. San Francisco, CA: Jossey-Bass.

Albelda, R., Drago, R., \& Shulman, S. (2010). Unlevel playing fields: Understanding wage inequality and discrimination (3rd ed.). Boston, MA: Economic Affairs Bureau, Inc.

Aleman, A. M., \& Salkever, K. (2003). Mission, multiculturalism, and the liberal arts college: A qualitative investigation. The Journal of Higher Education, 74(5), 563-596. doi:10.1353/jhe.2003.0034

Alfred, M. (2001). Expanding theories of career development: Adding the voices of African American women in the white academy. Adult Education Quarterly, 51(2), 108127. doi:10.1177/07417130122087179

Alger, R. J. (1998, July-August). Minority faculty and measuring merit: Start by playing fair. Academe, 84(4), 71. doi:10.2307/40252320

Allan, E. (2005). Diversity, privilege, and us: Collaborative curriculum transformation among educational leadership faculty. Innovative Higher Education, 29(3), 209-232. doi: 10.1007/s10755-005-1937-y

Allport, G. W. (1954). The nature of prejudice. Reading, MA: Addison-Wesley.

American Federation of Teachers in Higher Education. (2011). Promoting gender diversity in the faculty: What higher education unions can do. Retrieved from http://www.aft.org/pdfs/highered/genderdiversity0511.pdf

Antonio, A. L. (2000). Faculty of color and scholarship transformed: New arguments for diversifying faculty. Diverse Digest, 3(2), 6-7.

Antonio, A. L. (2002). Faculty of color reconsidered: Reassessing contributions to scholarship. The Journal of Higher Education 73(5), 582-602. doi:

10.1353/jhe.2002.0043

Arneson, R. (2008). Equality of opportunity. In E. N. Zalta (ed.), The Stanford Encyclopedia of Philosophy. Retrieved from http://plato.stanford.edu/entries/equal-opportunity/

Armstrong, V. (2011). Diversity Integration. Schmidt Labor Research Center Seminar Paper Series. Kingston, RI : University of Rhode Island. Retrieved from http://www.uri.edu/research/lrc/research/papers/Armstrong-Diversity.pdf 
Astin, H. S., Antonio, A. L., Cress, C. M., \& Astin, A. W. (1997). Race and ethnicity in the American professoriate, 1995-96. Los Angeles, CA: Higher Education Research Institute, UCLA.

Avery, D. R., \& Thomas, K. M. (2004). Blending content and contact: The roles of diversity curriculum and campus heterogeneity in fostering diversity management competency. Academy Of Management Learning \& Education, 3(4), 380-396. doi: 10.5465/AMLE.2004.15112544

Babbie, E. (2001). The practice of social research (9th ed.). Belmont, CA: Wadsworth/Thomson Learning.

Baxter, P., \& Jack, S. (2008). Qualitative case study methodology: Study design and implementation for novice researchers. The Qualitative Report, 13(4), 544-559. Retrieved from http://www.nova.edu/ssss/QR/QR13-4/baxter.pdf

Blank, R., Dabady, M., \& Citro, C. (Eds.). (2004). Measuring racial discrimination. Washington, D.C.: National Academies Press.

Bourne, J. (2001). The life and times of institutional racism. Race and Class, 43(2), 7-22. doi:10.1177/0306396801432002

Bower, B. L. (2002). Campus life for faculty of color: Still strangers after all these years?. New Directions for Community Colleges, 2002(118), 79-88. doi: 10.1002/cc.66

Bowen, W. G., \& Bok, D. (1998). The shape of the river: long-term consequences of considering race in college and university admissions. Princeton, NJ: Princeton University Press.

Bradley, A. (2013). Aliens in the promised land: Why minority leadership is overlooked in white Christian churches and institutions. Phillipsburg, NJ: P\&R Publishing.

Brumann, C. (1999). Writing for culture: Why a successful concept should not be discarded. Current Anthropology, 40(S1), S1-S27. doi: 10.1086/200058

Campus Climate Network Group. (2004). Enhancing department climate: A chair's role. Women in Science \& Engineering Leadership Institute. Madison, WI: University of Wisconsin. Retrieved from http://wiseli.engr.wisc.edu/climate/ResourceBook_09.pdf

Carrell, L. J. (1997). Diversity in the communication curriculum: Impact on student empathy. Communication Education, 46(4), 234-244. doi:10.1080/03634529709379098

Chang, M. J. (1999). Does racial diversity matter? The educational impact of a racially diverse undergraduate population. Journal of College Student Development, 40(4), 377395.

Chang, M. J. (2005). Reconsidering the diversity rationale. Liberal Education, 91(1), 6-13. Retrieved 
from http://www.aacu-edu.org/liberaleducation/le-wi05/le-wi05feature1.cfm

Clayton-Pedersen, A. R., Parker, S., Smith, D. G., Moreno, J. F., \& Teraguchi, D. H. (2007). Making a real difference with diversity: A guide to institutional change. Washington, DC: Association of American Colleges and Universities.

Cleveland, C. (2013, August 15). Christena Cleveland: Social psychology + faith + reconciliation. [Blog post]. Retrieved from http://www.christenacleveland.com/

Cleveland, D. (Ed.). (2004). A long way to go: Conversations about race by African American faculty and graduate students. New York, NY: Peter Lang.

Coates, R. D. (2008). Covert racism in the USA and globally. Sociology Compass, 2(1), 208-231. doi: 10.1111/j.1751-9020.2007.00057.x

Confer, C. (2011). Factors affecting institutional choice of minority students admitted to institutions in the council for Christian colleges and universities. (Order No. 3450285, University of Arkansas). ProQuest Dissertations and Theses, 137. Retrieved from http://0-search.proquest.com.library.uark.edu/docview/864271733? accountid=8361. (864271733).

Council for Christian Colleges \& Universities. (2013, April 1). About the CCCU. Retrieved from http://www.cccu.org/about

Council for Christian Colleges \& Universities. (2013, July 10). Blews tells campus diversity officers racial and ethnic diversity a 'top priority' [Press release]. Retrieved from http://www.cccu.org/news/articles/2013/Blews-tells-Campus-Diversity-Officers-Racial-and Ethnic-Diversity-a-Top-Priority

Council for Christian Colleges \& Universities. (2014, February 19). Prominent speakers inspire LA conference attendees [Press release]. Retrieved from http://www.cccu.org/news/articles/2014/ProminentSpeakersInspireLA

Creswell, J. W. (2007). Qualitative inquiry \& research design: Choosing among five approaches (2nd ed.). Thousand Oaks, CA: Sage Publications.

Creswell, J. W. (2008). Educational research: Planning, conducting, and evaluating quantitative and qualitative research (3rd ed.). Upper Saddle River, NJ: Pearson Education.

Creswell, J. W. (2009). Research design: Qualitative, quantitative, and mixed methods approaches (3rd ed.). Thousand Oaks, CA: Sage Publications.

Cross, T., Bazron, B., Dennis, K., \& Isaacs, M. (1989). Towards a culturally competent system of care. Washington, DC: Georgetown University Child Development Center, CASSP Technical Assistance Center. 
Cutcliffe, J. (2003). Reconsidering reflexivity: Introducing the case for intellectual entrepreneurship. Qualitative Health Research,13(1),136-148.

doi:10.1177/1049732302239416

Day, N. E., \& Glick, B. J. (2000). Teaching diversity: A study of organizational needs and diversity curriculum in higher education. Journal of Management Education, 24(3), 338352. doi:10.1177/105256290002400305

Delgado-Romero, E. A., Manlove, A. N., Manlove, J. D., \& Hernandez, C. A. (2007). Controversial issues in the recruitment and retention of Latino/a faculty. Journal of Hispanic Higher Education, 6(1), 34-51.

Denzin, N. K., \& Lincoln, Y. S. (2000). Introduction: The discipline and practice of qualitative research. In N. K. Denzin \& Y. S. Lincoln (Eds.), Handbook of qualitative research (2nd ed., pp. 1-28). Thousand Oaks, CA: Sage Publications.

Denzin, N. K., \& Lincoln, Y. S. (Eds.). (2000). Handbook of qualitative research (2nd ed). Thousand Oaks, CA: Sage Publications.

DeWalt, K. M., \& DeWalt, B. R. (2002). Participant observation: A guide for fieldworkers. Walnut Creek, CA: AltaMira Press.

Diggs, G. A., Garrison-Wade, D., Estrada, D., \& Galindo, R. (2009). Smiling faces and colored spaces: The experiences of faculty of color pursing tenure in the academy. The Urban Review, 41(4), 312-333. doi:10.1007/s11256-008-0113-y

Dovidio, J. F., Gaertner, S. L., \& Kawakami, K. (2003). Intergroup contact: The past, present, and the future. Group Processes \& Intergroup Relations, 6(1), 5-21. doi:10.1177/1368430203006001009

Eck, D. (2006). What is pluralism? Retrieved from http://www.pluralism.org./pages/pluralism/what_is_pluralism

Emerson, M. O., \& Smith, C. (2000). Divided by faith: Evangelical religion and the problem of race in America. New York, NY: Oxford University Press.

Emerson, M. O., \& Woo, R. M. (2006). People of the dream: Multiracial congregations in the United States. Princeton, N.J: Princeton University Press.

Fisher v. University of Texas at Austin et al., 11 U.S. 345 (2013).

García, S. B., \& Guerra, P. L. (2004). Deconstructing deficit thinking. Education \& Urban Society, 36(2), 150-168. doi: 10.1177/0013124503261322

Gasman, M., Kim, J., \& Nguyen, T. H. (2011). Effectively recruiting faculty of color at 
highly selective institutions: A school of education case study. Journal of Diversity in Higher Education, 4(4), 212-222. doi: 10.1037/a0025130

Gasson, S. (2004). Rigor in grounded theory research: An interpretive perspective on generating theory from qualitative field studies. In M. E. Whitman \& A. B. Woszczynski (Eds.), The handbook of information systems research (pp. 79-102). Hershey, PA: Idea Group.

Geertz, C. (1973). The interpretation of cultures: Selected essays. New York, NY: Basic Books.

Geertz, C. (1983). Local knowledge: Further essays in interpretive anthropology. New York, NY: Basic Books.

Glaser, B. G. (1998). Doing grounded theory: Issues and discussions. Mill Valley, CA: Sociology Press.

Glenn, D. (2014, February). Diversity frameworks. [Field note data summary and slide presentation]. From Assimilation to Acculturation. Chief diversity officers' symposium conducted at the CCCU Engaged Community Conference, Los Angeles, CA.

Gohn, L.A., \& Albin, G.A. (Eds.). (2006). Understanding college student subpopulations: A guide for student affairs professionals. Washington, DC: NASPA.

Guba, E. G., \& Lincoln, Y. S. (1994). Competing paradigms in qualitative research. In N. K. Denzin \& Y. S. Lincoln (Eds.), Handbook of qualitative research (pp. 105-117). Thousand Oaks, CA: Sage Publications.

Gurin, P. (1999, Spring). New research on the benefits of diversity in college and beyond: An empirical analysis. Diversity Digest 3(3), 5, 15. Retrieved from http://www.diversityweb.org/Digest/Sp99/benefits.html

Hackett, C., \& Lindsay, D.M. (2008). Measuring evangelicalism: Consequences of different operationalization strategies. Journal for the Scientific Study of Religion, 47(3), 499-514. doi: 10.1111/j.1468-5906.2008.00423.x

Hale, G. E. (2010). Making whiteness: The culture of segregation in the South, 1890-1940. New York, NY: Random House LLC.

Harvey, W. B. (2001). Minorities in higher education 2000-2001: Eighteenth annual status report. Washington, D.C.: American Council on Education.

Helms, J. E., Malone, L. S., Henze, K., Satiani, A., Perry, J., \& Warren, A. (2003). First annual diversity challenge: How to survive teaching courses on race and culture. Journal of Multicultural Counseling and Development, 31(1), 3-11.

Henderson-King, D., \& Kaleta, A. (2000). Learning about social diversity. Journal of 
Higher Education, 71(2), 142-164.

Hibbard, M., Irazábal, C., Manning-Thomas, J., Umemoto, K., \& Wubneh, M. (2011, November). Recruitment and retention of underrepresented faculty of color in ACSP member programs: Status and recommendations. (Diversity Task Force Report). [submitted by the governing body of the Association of Collegiate Schools of Planning]. Retrieved from http://www.acsp.org/sites/default/files/ACSP\%20Diversity\%20Task\%20Force\%20Repor t\% 20final.pdf

Higher Learning Commission. (2013). The criteria for accreditation and core components. Retrieved from http://www.ncahlc.org/Information-for-Institutions/criteria-and-corecomponents.html

Hopwood v. State of Texas, 236 F.3d 256 (5th Cir. 2000).

Hurtado, S. (1999). Reaffirming educators' judgment: Educational value of diversity. Liberal Education, 85(2), 24-31.

Hurtado, S., Milem J., Clayton-Pedersen, A., \& Allen, W. (1999). Enacting diverse learning environments: Improving the climate for racial/ethnic diversity in higher education. ASHE-ERIC Higher Education Report, 26(80), 1-140.

Hussar, W.J., \& Bailey, T.M. (2009). Projections of Education Statistics to 2018 (NCES 2009062). U.S. Department of Education. Washington, D.C.: National Center for Education Statistics. Retrieved from http://nces.ed.gov/pubsearch/pubsinfo.asp?pubid=2009062

Ibarra, R. A. (2001). Beyond affirmative action: Reframing the context of higher education. Madison, WI: The University of Wisconsin Press.

Johnson, A. G. (2001). Privilege, power, and difference. New York, NY: McGraw-Hill.

Kayes, P.E., \& Singley, Y. (2005). Why are 90 percent of college faculty still white? Diverse: Issues in Higher Education, 22 (20), 42.

Kezar, A., \& Eckel, P. D. (2002). The effect of institutional culture on change strategies in higher education: Universal principles or culturally responsive concepts? The Journal of Higher Education, 73(4), 435-460. doi: 10.1353/jhe.2002.0038

King, K. L., \& Watts, I. E. (2004). Assertiveness or the drive to succeed?: Surviving at a predominantly White university. In D. Cleveland (Ed.), A long way to go: Conversations about race by African American faculty and graduate students (pp. 110-119). New York, NY: Peter Lang.

Kohlbacher, F. (2006). The use of qualitative content analysis in case study research. 
Forum Qualitative Sozialforschung / Forum: Qualitative Social Research, 7(1). 1-30. Retrieved from http://www.qualitative-research.net/index.php/fqs/article/view/75/154

Kratt, W. E. (2004). Diversity in evangelical Christian higher education. (Unpublished doctoral dissertation). Claremont Graduate University, Claremont, CA.

Laird, J., DeBell, M., \& Chapman, C. (2006). Dropout Rates in the United States: 2004 (NCES 2007-024). U.S. Department of Education. Washington, D.C.: National Center for Education Statistics. Retrieved from http://nces.ed.gov/pubsearch

Laney, M. J., \& Daniels, D. (2006). A seat at the table: Increasing faculty diversity on CCCU campuses [PowerPoint slides]. Retrieved from http://www.academia.edu/621063/CCCU_International_Forum_A_Seat_At_the_Table_I ncreasing_Faculty_Diversity_on_CCCU_Campuses

Leavy, P. (2009). Method meets art: Arts-based research practice. New York, NY: Guilford Press.

Ledwith, S., \& Seymour, D. (2001). Home and away: Preparing students for multicultural management. International Journal of Human Resource Management, 12(8), 1292-1312. doi:10.1080/09585190110083802.

Lee, D. J. (1991). Ethnic-minorities and evangelical Christian colleges: Basic issues and assumptions. In D. J. Lee, A. L. Nieves, \& H. L. Allen (Eds.), Ethnic-minorities and evangelical Christian colleges (pp. 1-46). Lanham, MD: University Press of America.

Lew, J. (2001). Toward a theology of multiculturalism. La Mirada, CA: Biola University.

Lincoln, Y. S., \& Guba, E. G. (1985). Naturalistic inquiry. Beverly Hills, CA: Sage Publications.

Lincoln, Y. S., \& Guba, E. G. (2000). Paradigmatic controversies, contradictions, and emerging confluences. In N. K. Denzin \& Y. S. Lincoln (Eds.), Handbook of qualitative research (2nd ed., pp. 163-188). Thousand Oaks, CA: Sage Publications.

Lindlof, T. R., \& Taylor, B. C. (2011). Qualitative communication research methods (3rd ed.). Thousand Oaks, CA: Sage Publications.

Longman, K. A., \& Anderson, P. S. (2011, November-December). Gender trends in senior- level leadership: A 12-year analysis of the CCCU U.S. member institutions. Christian Higher Education, 10(5), 422-443.

Maher, F. A., \& Tetreault, M.K. (2009, Jan/Feb.). Diversity and privilege. Academe, 95(1), 1721. Retrieved from http://www.aaup.org/article/diversity-and-privilege

Marsden, G. M. (1996). The soul of the American university: From protestant establishment to established nonbelief. New York, NY: Oxford University Press. 
Marshall University Multicultural Affairs. (2005). Recruitment of underrepresented minority group faculty survey: Final report. Retrieved from http://www.marshall.edu/multicultural/Various\%20Programs\%20Files/Survey/Recruitme ntofUnderrepresentedMinorityGroupFacultySurveyFinalReport-FullDocument.pdf

Maruyama, G., Moreno, J. F., Gudeman, R. H., \& Marin, P. (2000). Does diversity make a difference?: Three research studies on diversity in college classrooms. Washington, DC: American Council on Education and American Association of University Professors.

Mayer, L. (1997). Making sense of institutional mission: Student cultures at an evangelical institution. (Doctoral dissertation). Retrieved from ProQuest Dissertations and Theses. (AAT 9721327)

McCombs, H. G. (1989). The dynamics and impact of affirmative action processes on higher education, the curriculum, and Black women. Sex Roles, 21(1-2), 127-144. doi: 10.1007/BF00289732

McGowan, J. M. (2000). Multicultural teaching: African-American faculty classroom teaching experiences in predominantly white colleges and universities. Multicultural Education, 8(2), 19-22.

McKendall, M. (1994). A course in "work-force diversity": Strategies and issues. Journal of Management Education, 18(4), 407-423. doi:10.1177/105256299401800402

McMinn, L. (1998). Enclave adaptation, multiculturalism and evangelical Christian colleges. Research on Christian Higher Education, 5, 23-52.

Merriam, S. B. (1998). Qualitative research and case study applications in education (2nd ed). San Francisco, CA: Jossey-Bass Publishers.

Merriam, S. B. (2009). Qualitative research: A guide to design and implementation (3rd ed.). San Francisco, CA: Jossey-Bass Publishers.

Milem, J. F. (2000). Why race matters. Academe, 86(5), 26-29.

Miles, M. B. \& Huberman, A. M. (1994). Qualitative data analysis: An expanded sourcebook (2nd ed.). Thousand Oaks, CA: Sage Publications.

Mishler, E. G. (1979). Meaning in context: Is there any other kind? Harvard Educational Review, 49(1), 1-19.

Morrow, S. L., \& Smith, M. L. (2000). Qualitative research for counseling psychology. In S. D. Brown \& R. W. Lent (Eds.), Handbook of counseling psychology (3rd ed., pp. 199230). New York, NY: Wiley. 
Motel, S. \& Patten, E. (2013, February 15). Statistical Portrait of Hispanics in the United States, 2011. Retrieved from Pew Research Hispanic Trends Project site: http://www.pewhispanic.org/

Moustakas, C. (1994). Phenomenological research methods. Thousand Oaks, CA: Sage Publications.

Muller, H. J., \& Parham, P. A. (1998). Integrating workforce diversity into the business school curriculum: An experiment. Journal of Management Education, 22(2), 122-148. doi: $10.1177 / 105256299802200202$

Myers, S. L., \& Turner, C. S. V. (1995). Minority faculty development project (Prepublication Report). Minneapolis, MN: Midwestern Higher Education Commission.

Nieves, A. L. (1991). The minority experience in evangelical colleges. In D. J. Lee, A. L. Nieves \& H. L. Allen (Eds.), Ethnic-minorities and evangelical Christian colleges (pp. 47 - 63). Lanham, MD: University Press of America.

Nieves, A.L. (2012). Race and ethnicity in CCCU schools: Rhetoric and reality. In S. Joeckel \& T. Chesnes (Eds.), Christian college phenomenon: Inside America's fastest growing institutions of higher learning (pp. 199-210). Abilene, TX: Abilene Christian University Press.

Norris, J. (2010). Playbuilding as qualitative research: A participatory arts-based approach. Walnut Creek, CA: Left Coast Press.

Opp, R. D. (1994). Minority versus white administrators'perceptions of the recruitment and retention of minority faculty in two-year colleges. Journal of Applied Research in the Community College, 1(2), 85-99.

Parents Involved in Community Schools v. Seattle School District, 551 U.S. 701 (2007).

Passel, J. \& Cohn, D. (2008, February 11). U.S. Population Projections: 2005-2050. Retrieved from Pew Research Hispanic Trends Project site: http://www.pewhispanic.org/2008/02/11/us-population-projections-2005-2050/

Patterson, J. A. (2001). Shining lights: A history of the Council for Christian Colleges and Universities. Grand Rapids, MI: Baker Academic.

Patton, M. Q. (1990). Qualitative evaluation and research methods (2nd ed.). Thousand Oaks, CA: Sage Publications.

Patton, M. Q. (2002). Qualitative research and evaluation methods (3rd ed.). Thousand Oaks, CA: Sage Publications.

Peart, N. (2000). Separate no more: Understanding and developing racial reconciliation 
in your church. Grand Rapids, MI: Baker Books.

Perez, J. (2010). Drivers that motivate Christian colleges to seek change in the area of diversity. (Unpublished doctoral dissertation). Claremont Graduate University, Claremont, CA.

Phillips, K. W., \& Thomas-Hunt, M. C. (2007). Garnering the benefits of conflict: The role of diversity and status distance in groups. In K. J. Behfar \& L. L. Thompson (Eds.), Conflict in organizational groups (pp. 37-55). Evanston, IL: Northwestern University Press.

Piercy, F., Giddings, V., Allen, K., Dixon, B., Meszaros, P., \& Joest, K. (2005). Improving campus climate to support faculty diversity and retention: A pilot program for new faculty. Innovative Higher Education, 30(1), 53-66. doi: 10.1007/s10755-005-3297-z

Polkinghorne, D. E. (2005). Language and meaning: Data collection in qualitative research. Journal of Counseling Psychology, 52(2), 137-145. doi:10.1037/00220167.52.2.137

Pollard, C. (2013, October 29). Personal interview.

Quezada, R. L., \& Louque, A. (2004). The absence of diversity in the academy: Faculty of color in educational administration programs. Education, 125(2), 213-221.

Reyes, R., \& Case, K. (2011). National profile on ethnic/racial diversity of enrollment, graduation rates, faculty, and administrators among the Council for Christian Colleges \& Universities. Paper presented at The 35th Annual CCCU Presidents Conference, Washington, D.C. Retrieved from https://www.cccu.org/professional_development/resource_library/2011/national_profile_ on_ethnicracial_diversity_of_enrollment_graduation_rates_faculty_and_administrators_a mong_the_council_for_christian_colleges_universities

Riessman, C. K. (2008). Narrative methods for the human sciences. Thousand Oaks, CA: Sage Publications.

Rine, P.J., \& LoMaglio, S. (2012). Charting the Terrain of Christian Higher Education in America: A Profile of the Member Institutions of the CCCU. Washington, DC: Council for Christian Colleges and Universities.

Ringenberg, W. C. (2006). The Christian college: A history of protestant higher education in America (2nd ed.). Grand Rapids, MI: Baker Academic.

Roberson, Q. M. (2004). Disentangling the meanings of diversity and inclusion (CAHRS Working paper \#04-05). Ithaca, NY: Cornell University, School of Industrial and Labor Relations Center for Advanced Human Resource Studies. Retrieved from http://digitalcommons.ilr.cornell.edu/cahrswp/12 
Robinson, B. (2014, February 1). Telephone interview.

Rolls, L. \& Relf, M. (2006). Bracketing interviews: Addressing methodological challenges in qualitative interviewing in bereavement and palliative care. Mortality 11(3), 286-305. doi: 10.1080/13576270600774893

Rosado, C. (1997). Toward a definition of multiculturalism. Retrieved from http://www.rosado.net/articles.html

Rothenberg, P. S. (Ed.). (2004). Race, class, and gender in the United States: An integrated Study $\left(6^{\text {th }}\right.$ ed.). New York, NY: Worth Publishers.

Ryan, G., \& Bernard, H. R. (2000). Data management and analysis methods. In N. Denzin $\&$ Y. Lincoln (Eds.), Handbook of qualitative research (2nd ed., pp. 769-802). Thousand Oaks, CA: Sage Publications.

Sandelowski, M., \& Barroso, J. (2003). Classifying the findings in qualitative studies. Qualitative Health Research, 13(7), 905-923. doi:10.1177/1049732303253488

Schneider, C. G. (2000). Diversity requirements. Liberal Education, 86(4), 2-3.

Sheridan, D. A., \& Anderson, H. (2001). The multicultural competence of resident assistants in Christian colleges and universities. Growth: The Journal of the Association for Christians in Student Development, 1(1), 65-83.

Simoni, J. M., Sexton-Radek, K., Yescavage, K., Richard, H., \& Lundquist, A. (1999). Teaching diversity: Experiences and recommendations of American Psychological Association division 2 members. Teaching of Psychology, 26(2), 89-95. doi: 10.1207/s15328023top2602_2

Smith, B. N., Hornsby, J. S., \& Kite, M. (2000). Broadening the business curriculum via a cross-disciplinary approach: A mobile unit on cultural diversity. Education, 120(4), 713721.

Smith, D. G. (2000). How to diversify the faculty. Academe, 86(5), 48-52.

Smith, D. G. (2009). Diversity's promise for higher education: Making it work. Baltimore, MD: Johns Hopkins University Press.

Smith, D. G., \& Parker, S. (2005). Organizational learning: A tool for diversity and institutional effectiveness. New Directions for Higher Education, 131(Fall 2005), 113125. doi: 10.1002/he.191

Smith, D. G., \& Schonfeld, N. B. (2000). The benefits of diversity: What the research tells us. About Campus, 5(5), 16-23.

Smith, D. G., Turner, C. S., Osei-Kofi, N., \& Richards, S. (2004). Interrupting the usual: 
Successful strategies for hiring diverse faculty. The Journal of Higher Education, 75(2), 133-160. doi: 10.1353/jhe.2004.0006

Smith, D. G., \& Wolf-Wendel, L. E. (2005). The challenge of diversity: Involvement or alienation in the academy?. ASHE Higher Education Report, 31(1), 1-100.

Smith, J. A., Flowers, P., \& Larkin, M. (2009). Interpretative phenomenological analysis: Theory, method, and research. Thousand Oaks, CA: Sage Publications.

Snyder, T. (1992). Digest of Educational Statistics. (NCES 92-097). U.S. Department of Education. Washington, D.C.: National Center for Education Statistics. Retrieved from https://nces.ed.gov/Pubsearch/pubsinfo.asp?pubid=92097

Solorzano, D. (1998). Critical race theory, racial and gender microaggressions, and the experiences of Chicana and Chicano scholars. International Journal of Qualitative Studies in Education 11(1),121-136. doi:10.1080/095183998236926

Stahl, G., Maznevski, M., Voigt, A. \& Jonsen, K. (2010b). Unraveling the effects of cultural diversity in teams: A meta-analysis of research on multicultural work groups. Journal of International Business Studies, 41(4), 690-709.

Stake, R. E. (1995). The art of case study research. Thousand Oaks, CA: Sage Publications.

Tatum, B. D. (2003). Why are all the black kids sitting together in the cafeteria?: And other conversations about race. New York, NY: Basic Books.

Terenzini, P. T., Cabrera, A. F., \& Bernal. E. (2001). Swimming against the tide: The poor in American higher education (No. 2001-1). New York, NY: College Entrance Examination Board. Retrieved from http://research.collegeboard.org/sites/default/files/publications/2012/7/researchreport2001-1-swimming-against-tide-the-poor-american-higher-education.pdf

Terenzini, P. T., Cabrera, A. F., Colbeck, C. L., Bjorklund, S. A., \& Parente, J. M. (2001). Racial and ethnic diversity in the classroom: Does it promote student learning? The Journal of Higher Education, 72(5): 509-531.

Thelin, J. R. (2004). A history of American higher education. Baltimore, MD: Johns Hopkins University Press.

Tillman, L. C. (2001). Mentoring African American faculty in predominantly white institutions. Research in Higher Education, 42(3), 295-325. doi: 10.1023/A:1018822006485

Titscher, S., Meyer, M., Wodak, R. \& Vetter, E. (2000). Methods of Text and Discourse Analysis. Thousand Oaks, CA: Sage Publications. 
Thurgood, D. H., \& Clarke, J. E. (1995). Doctorate recipients from United States universities. (Summary Report 1993). Washington, DC: Doctorate Records Project, National Research Council.

Trower, C. A., \& Chait, R. P. (2002, March-April). Faculty diversity: Too little for too long. Harvard Magazine, 104(4), 33-37. Retrieved from http://www.harvardmagazine.com/online/030218.html

Tufford, L., \& Newman, P. (2012). Bracketing in qualitative research. Qualitative Social Work, 11(1), 80-96. doi: 10.1177/1473325010368316

Turner, C.S.V. (2000). New faces, new knowledge. Academe, 86(5), 34-38.

Turner, C. S. V. (2002). Women of color in academe: Living with multiple marginality. The Journal of Higher Education, 73(1), 74-93. doi:10.1353/jhe.2002.0013

Turner, C. S., \& Myers, S. L., (2000). Faculty of color in Academe: Bittersweet success. Boston, MA: Allyn and Bacon.

Turner, C. S. V., \& Smith, D. (2002). Hiring faculty of color: Research on the search committee process and implications for practice. Paper presented at The University of Minnesota: Office of the Associate Vice President for Multicultural and Academic Affairs Symposium, Minneapolis, MN. Retrieved from http://omaweb.stu.umn.edu/kof/proceedings.html

Turner, C., \& Thompson, J. (1993). Socializing women doctoral students: Minority and majority experiences. Review of Higher Education, 16(3), 355-370.

Umbach, P. D. (2007). How Effective Are They? Exploring the impact of contingent faculty on undergraduate education. The Review of Higher Education, 30(2), 91-123. doi: 10.1353/rhe.2006.0080

Umbach, P. D., \& Kuh, G. D. (2006). Student experiences with diversity at liberal arts colleges: Another claim for distinctiveness. The Journal of Higher Education, 77(1), 169-192. doi:10.1353/jhe.2006.0008

Umbach, P. D., \& Wawrzynski, M. R. (2005). Faculty do matter: The role of college faculty in student learning and engagement. Research in Higher Education, 46(2), 153-184. doi: 0.1007/s11162-004-1598-1

U.S. Department of Education, National Center for Education Statistics. (2012). The condition of education 2012 (NCES 2012-045), Table A-47-2. Retrieved from http://nces.ed.gov/fastfacts/display.asp?id=72

U.S. Department of Education, National Center for Education Statistics. (2009). Table 74: 
12-month unduplicated headcount enrollment at Title IV institutions, by race/ethnicity, gender, and student level: United States, academic year 2008-09. In U.S. Department of Education, National Center for Education Statistics (Ed.), Digest of Education Statistics (2009 ed.). Retrieved from

http://nces.ed.gov/das/library/tables_listings/showTable2005.asp?popup=true\&tableID=7 $215 \& \mathrm{rt}=\mathrm{p}$

Valadez, J. (1998). The social dynamics of mentoring in graduate education: A case study of African-American students and their graduate advisors. In H. T. Frierson (Ed.), Mentoring and diversity in higher education (Vol. 2, pp. 129-140). Stamford, CT: JAI Press.

Varner, I. I. (2001). Teaching intercultural management communication: Where are we? Where do we go? Business Communication Quarterly, 64(1), 99-111. doi:

$10.1177 / 108056990106400109$

Vasques-Scalera, C. (2002). The diversity framework informing this volume. In J. Trent (Ed.), Included in communication: Learning climates that cultivate racial and ethnic diversity (pp. 8-11).Washington D.C.: American Association for Higher Education in cooperation with the National Communication Association.

Verugo, R. R. (2003). Discrimination and merit in higher education: The Hispanic professoriate. In L. Jones \& J. Castellanos (Eds.), The majority in the minority: Retaining Latina/o faculty, administrators, and students in the 21st century (pp. 241-254). Sterling, VA: Stylus Books.

Vescovi, D. (2013). A college education that makes the grade: Enrollment at Christian college is soaring. Christianity Today. Retrieved from http://www.christiancollegeguide.net/article/A-College-Education-That-Makes-the-Grade

Washington, W. O. (2006). The recruitment and retention of African American administrators at member institutions of the Council for Christian Colleges and Universities. (Unpublished Dissertation). Loyola University Chicago, Chicago, IL.

Waterman, A. D., Reid, J. D., Garfield, L. D., \& Hoy, S. J. (2001). From curiosity to care: Heterosexual student interest in sexual diversity courses. Teaching of Psychology, 28(1), 21-26. doi:10.1207/S15328023TOP2801_05

Whitt, E. J., Edison, M. I., Pascarella, E. T., Terenzini, P. T., \& Nora, A. (2001). Influences on students' openness to diversity and challenge in the second and third years of college. The Journal of Higher Education, 72(2), 172-204. doi:10.2307/2649321

Williams, D. A., \& Wade-Golden, K. C. (2013). The chief diversity officer: Strategy structure, and change management. Sterling, VA: Stylus.

Williams, D. A., Berger, J. B., \& McClendon, S. A. (2005). Toward a model of inclusive 
excellence and change in postsecondary institutions. Washington, DC: Association of American Colleges and Universities.

Wilson, J. L. (2013). Emerging Trend: The Chief Diversity Officer Phenomenon within Higher Education. The Journal of Negro Education, 82(4), 433-445.

Wilson, R. (2002, November). A kinder, less ambitious professoriate. The Chronicle of Higher Education, (49), 11, A10-A11.

Wirth, L. (1945). The problem of minority groups. In R. Linton (Ed.), The science of man in the world crisis (pp. 347-372). New York, NY: Columbia University Press.

Wolfe, A. (2006). The Evangelical Mind Revisited. Change: The Magazine of Higher Learning, 38(2), 9-13. Retrieved from: http://ezproxy.jbu.edu/login?url=http://search.ebscohost.com/login.aspx?direct=true\&db= eric\&AN=EJ745666\&scope $=$ site

Wong, T.M. \& Polite, K. (1991). Ethnic-minorities and evangelical Christian colleges: Models in Search of an Identity. In D. J. Lee, A. L. Nieves \& H. L. Allen (Eds.) Ethnicminorities and evangelical Christian colleges (pp. 239-255). Lanham, MD: University Press of America.

Woodley, R. (2001). Living in color: Embracing God's passion for ethnic diversity. Downers Grove, IL: InterVarsity Press.

Wsevolod, I. (1992). Definition and dimensions of ethnicity: A theoretical framework. Paper presented at the Joint Canada-United States Conference on the Measurement of Ethnicity, Ottawa, Ontario, Canada.

Yancey, G. A. (2007). Interracial contact and social change. Boulder, CO: Lynne Rienner Publishers.

Yancey, G. A. (2010). Neither Jew nor gentile: Exploring issues of racial diversity on protestant college campuses. New York, NY: Oxford University Press.

Yin, R. K. (2009). Case study research: Design and methods ( $4^{\text {th }}$ ed.). Thousand Oaks, CA: Sage Publications.

Yoshino, K. (2006). Covering: The Hidden Assault on Our Civil Rights. New York, NY: Random House. 


\title{
APPENDIX A \\ Email Seeking Institutional Participation
}

\begin{abstract}
A Christian Value? : Faculty Diversity at Southern Evangelical Campuses
Principal Researcher: Marquita Smith

Faculty Advisor: Dr. Ketevan Mamiseishvili

Hello, [Participant]:
\end{abstract}

I am working on my doctoral dissertation. My focus is on faculty diversity. I would like to visit [Case Institution] because of the recognition you have received from the CCCU for your commitment to diversity and reconciliation. Attached is a document outlining my request for permission to visit [Case Institution]. Your attention to this request is greatly appreciated. I am enrolled in a doctoral program at the University of Arkansas and hope to present my proposal the first week in December. The details are attached. Please contact me if you need more information.

Blessings,

Marquita 


\title{
APPENDIX B
}

\author{
Consent to Participate in Research Study
}

A Christian Value? : Faculty Diversity at Southern Evangelical Campuses

Principal Researcher: Marquita Smith

Faculty Advisor: Dr. Ketevan Mamiseishvili

\section{INVITATION TO PARTICIPATE}

I seek your participation in a research study exploring institutional efforts to increase faculty diversity at three Christian colleges and universities and examining how these efforts relate to institutional missions. The research study fulfills my dissertation requirement in the higher education doctoral program at the University of Arkansas, in which I am currently enrolled as a doctoral candidate. You participation in the study is useful by nature of the position you hold at [CASE INSTITUTION] or by nature of your experience at [CASE INSTITUTION].

\section{WHAT YOU SHOULD KNOW ABOUT THE RESEARCH STUDY}

Participants in the Study. Three case institutions will participate in the study. Within each case institution, five to seven institutional participants will be selected to participate in the study. The study will be completed over a 6-week period with fieldwork at each case institution lasting between two and three days.

Requirements for Participation. Your participation will require one semi-structured interview. Interviews will be held on campus on [DATE]. Interview duration will be approximately 1 hour. Interviews will be tape recorded for the exclusive use of the principal researcher. In addition, the principal researcher will also take field notes during the interview. During the interview, the participant will be asked several questions about [CASE INSTITUTION]. The participant will also be asked to review a draft of the interview record and provide his or her feedback within 30 days of the completion of the interview. Additionally, the participant may be asked to allow the principal researcher to shadow the participant as a nonparticipant observer for one full day. 
Potential Risks/Discomforts and Benefits of the Study. There are no anticipated risks/discomforts associated with the current study. The results of the study will potentially contribute significantly to the existing body of research on Christian colleges and diversity.

Monetary Costs and Benefits. There are no monetary costs or compensation associated with your participation.

Option to Refuse to Participate. If you do not want to be in this study, you may refuse to participate. Also, you may refuse to participate at any time during the study. Your relationship with the university will not be affected in any way if you refuse to participate.

Protection of Confidentiality. All information will be kept confidential to the extent allowed by applicable State and Federal law and University policy. The principal researcher and faculty advisor will have exclusive access to research data, which will be securely stored electronically and physically. Participant data will only be made available to other individuals if permitted in writing by the participant. Additionally to ensure confidentiality, participants or the principal researcher will choose a pseudonym for participants and institutions.

Right to Know the Study's Results. At the conclusion of the study you will have the right to request feedback about the results. You may contact the faculty advisor, Dr. Kate Mamiseishvili, or Principal Researcher, Marquita Smith. You will receive a copy of this form for your files.

Questions About the Study. You have the right to contact the Principal Researcher or Faculty Advisor as listed below for any concerns that you may have. You may also contact the University of Arkansas Research Compliance office listed below if you have questions about your rights as a participant, or to discuss any concerns about, or problems with the research.

Dr. Ketevan Mamiseishvili

Principal Researcher Faculty Advisor
Ro Windwalker, CIP

Institutional Review Board Coordinator

Research Compliance

University of Arkansas

I have read the above statement and have been able to ask questions and express concerns, which have been satisfactorily responded to by the investigator. I understand the purpose of the study as well as the potential benefits and risks that are involved. I understand that participation is voluntary. I understand that significant new findings developed during this research will be shared with the participant. I understand that no rights have been waived by signing the consent form. I have been given a copy of the consent form.

$\begin{array}{ll}\text { Participant Signature } & \text { Date }\end{array}$

**Please retain the duplicate copy of this form for your records. ${ }^{* *}$ 

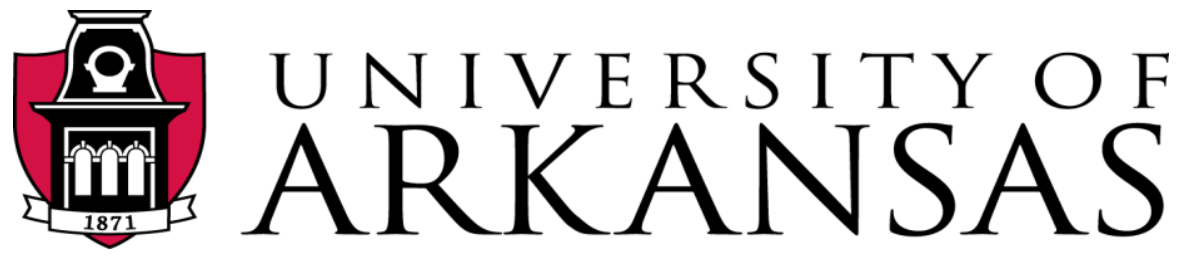

Office of Research Compliance

Institutional Review Board

January 3, 2014

\section{MEMORANDUM}

TO:

Marquita Smith

Ketevan Mamiseishvili

FROM:

Ro Windwalker

IRB Coordinator

RE:

New Protocol Approval

IRB Protocol \#:

13-12-365

Protocol Title:

A Christian Value? Faculty Diversity at Southern Evangelical Campuses

Review Type:

\ЕXEMPT

EXPEDITED

FULL IRB

Approved Project Period:

Start Date: 01/03/2014 Expiration Date: 01/02/2015

Your protocol has been approved by the IRB. Protocols are approved for a maximum period of one year. If you wish to continue the project past the approved project period (see above), you must submit a request, using the form Continuing Review for IRB Approved Projects, prior to the expiration date. This form is available from the IRB Coordinator or on the Research Compliance website (http://vpred.uark.edu/210.php). As a courtesy, you will be sent a reminder two months in advance of that date. However, failure to receive a reminder does not negate your obligation to make the request in sufficient time for review and approval. Federal regulations prohibit retroactive approval of continuation. Failure to receive approval to continue the project prior to the expiration date will result in Termination of the protocol approval. The IRB Coordinator can give you guidance on submission times.

This protocol has been approved for 18 participants. If you wish to make any modifications in the approved protocol, including enrolling more than this number, you must seek approval prior to implementing those changes. All modifications should be requested in writing (email is acceptable) and must provide sufficient detail to assess the impact of the change.

If you have questions or need any assistance from the IRB, please contact me. 


\section{APPENDIX D}

IRB Modification

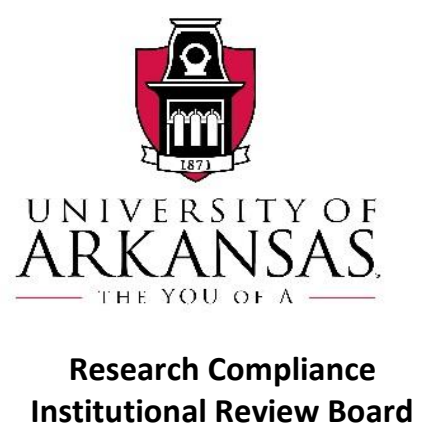

March 19, 2014

MEMORANDUM

TO:

Marquita Smith

Ketevan Mamiseishvili

FROM:

Ro Windwalker

IRB Coordinator

RE:

PROJECT MODIFICATION

IRB Protocol \#:

13-12-365

Protocol Title:

A Christian Value? Faculty Diversity at Southern Evangelical Campuses

Review Type:

$\triangle$ EXEMPT $\square$ EXPEDITED $\square$ FULL IRB

Approved Project Period: $\quad$ Start Date: 03/19/2014 Expiration Date: 01/02/2015

Your request to modify the referenced protocol has been approved by the IRB. This protocol is currently approved for $\mathbf{2 3}$ total participants. If you wish to make any further modifications in the approved protocol, including enrolling more than this number, you must seek approval prior to implementing those changes. All modifications should be requested in writing (email is acceptable) and must provide sufficient detail to assess the impact of the change.

Please note that this approval does not extend the Approved Project Period. Should you wish to extend your project beyond the current expiration date, you must submit a request for continuation using the UAF IRB form "Continuing Review for IRB Approved Projects." The request should be sent to the IRB Coordinator, 210 Administration.

For protocols requiring FULL IRB review, please submit your request at least one month prior to the current expiration date. (High-risk protocols may require even more time for approval.) For protocols requiring an EXPEDITED or EXEMPT review, submit your request at least two weeks prior to the current expiration date. Failure to obtain approval for a continuation on or prior to the currently approved expiration date will result in termination of the protocol and you will be required to submit a new protocol to the IRB before continuing the project. Data collected past the protocol expiration date may need to be eliminated from the dataset should you wish to publish. Only data collected under a currently approved protocol can be certified by the IRB for any purpose. If you have questions or need any assistance from the IRB, please contact me. 


\begin{abstract}
APPENDIX E
E-mail Request to Participants

A Christian Value? : Faculty Diversity at Southern Evangelical Campuses

Principal Researcher: Marquita Smith $\quad$ Faculty Advisor: Dr. Ketevan Mamiseishvili

\section{Dear XXXXX :}

I am contacting you in reference to a research study highlighting faculty diversity at CCCU institutions. Marquita Smith, Chair of the Communication department at John Brown University, is conducting the research for her dissertation. The Institutional Review Board at XXXX has approved her site visit and recommended you for participation. I am asking you to let me know of a time on either March 26, 27 or 28 (she hopes for a two-day visit) when she can meet with you for an hour long interview. She will contact you with a more formal invitation to participate and details about the study next week. But in the meantime, please let me know of a couple of time options that would work for her to meet with you so I can set up her schedule.
\end{abstract}

Your willingness to participate in this study on diversity is greatly appreciated.

Becky Pohle

Administrative Assistant 


\begin{abstract}
APPENDIX F
Participant Interview Protocol

A Christian Value? : Faculty Diversity at Southern Evangelical Campuses
\end{abstract}

Principal Researcher: Marquita Smith

Faculty Advisor: Dr. Ketevan Mamiseishvili

Time of Interview:

Date:

Place:

Interviewer:

Source:

Position of Source:

[Briefly introduce myself and thank the participant for attending the meeting. Give the source the Informed Consent Form (Appendix A) and direct the participant to follow along as I review the information about the study, participant requirements, participant risk and rights, contacts for the current study, and consent to participate. Ask the participant if they have any questions. Instruct the participant to take as much time as he or she needs to review the document and, if they consent, sign the document.]

[Turn on the digital recorder]

[Instruct the participant that the scope of the following interview questions is limited to the last decade at [CASE INSTITUTION].

1. Tell me about your relationship with [CASE INSTITUTION]. Probes: How did you select the [CASE INSTITUTION]? Current position at [CASE INSTITUTION]? Please share what a typical day looks like for you?

2. How would you describe [CASE INSTITUTION] to a prospective student/employee/a new resident? Probes: Brief history... College mission... College vision... Current enrollment... Number of faculty members... Demographics of faculty...Demographics of student body

3. What encourages your commitment to value cultural diversity in teaching, service, and research?

4. What statements, if any, about cultural diversity are key components of the educational priorities for the [CASE INSTITUTION]?

5. What relationships, if any, exist between the [CASE INSTITUTION] mission and diversity initiatives?

6. How does your theological perspective affect the [CASE INSTITUTION's] campus diversity efforts? 
7. What things in the [CASE INSTITUTION's] history prevent or promote change in faculty diversity?

8. What types of efforts are being made to facilitate hiring diverse faculty members? Probes: a. How are you coordinating those efforts?

9. How are you evaluating and monitoring the progress/retention of minority faculty?

10. How would you describe the climate for minority faculty on campus? Probes: a. What do data suggest or offer on the subject? $\mathrm{b}$. What support structures exist for minority faculty at the institution?

11. Is there anything else you would like to add to our discussion?

[Thank the source for his or her participation. Reassure the participant of their rights and my commitment to abiding by ethical practices throughout the research study. Give the participant my contact information and encourage them to contact me anytime.]

Questions

Descriptive Notes

Reflective Notes 


\title{
APPENDIX G
}

\author{
Case Study Protocol
}

\section{A Christian Value? : Faculty Diversity at Southern Evangelical Campuses}

Principal Researcher: Marquita Smith

Faculty Advisor: Dr. Ketevan Mamiseishvili

I. Background a. Purpose of Study: The current study's purpose is to explore institutional efforts to increase faculty diversity at three Christian colleges and universities and examine how these efforts relate to institutional missions. b. Research Questions: $\square$ What diversity efforts exist at southern Christian colleges? $\square$ What aspects within the history of evangelicalism promote or deter the hiring of diversity faculty? $\square$ What are Christian colleges doing to recruit and retain diverse faculty? $\square$ What is the climate for minority faculty at Christian colleges? $\square$ How does faculty diversity or the lack of it impact Christian colleges' educational and scholarly missions?

\section{Design: Qualitative Multiple-Case Study}

a. Rationale: The current study as a qualitative, multiple-case study approach is suitable for helping to develop an in-depth understanding of how universities manage diversity efforts at CCCU institutions. With little scholarly research focused on diversity efforts at Christian institutions, the purpose of the current study and the nature of the present research questions are largely exploratory, aiming to discover different approaches and processes concerning faculty diversity. Additionally, I would like to better understand how institutions' missions influence diversity initiatives. I will also produce a multiple case study to evaluate several cases and understand the similarities and differences between those cases (Baxter \& Jack, 2008). b. Sampling: The current study will employ "nonrandom, purposeful, and small" sampling strategies on two levels: the case level and the participant level (Merriam, 2009, p. 8).

\section{Data Collection}

a. Data collection sources: $\square$ Participant interviews with president or vice president of academic affairs (equivalent); campus diversity officer (if available); two faculty members, one who holds a leadership role in the faculty governing body, and one who represents an ethnic minority group (one faculty member may be acceptable); and two students who hold a leadership roles within the student body (one may be acceptable). The interviews will occur on-campus, face-to-face, approximately 1 hour in duration. The researcher will review and sign participant information and informed consent form. $\square$ Direct and informal observation of institutional happenings. Document analysis of diversity statements; strategic plans; official institutional publications and press releases; and institutional profile and statistics. b. Data Collection Plan: In the current study, data collection will primarily occur during fieldwork. Patton (2002) explained that qualitative data consist of excerpts from recorded, well preserved documents. Personal interviews will be one of my means of collecting data. Patton (2002) described an interview as: "open-ended questions and probes yield in-depth responses about people's experiences, perceptions, opinions, feelings and knowledge. Data consist of verbatim quotations with sufficient context to be interpretable" (p. 4). I will be mindful of Patton and the other researchers' directives when collecting the data, and I will use several strategies to ensure 
trustworthiness and credibility. I will also use field notes and observations to collect data. Patton (2002) advised that field notes and observations be kept separate in a notebook. I will follow that plan. Additionally, I will aim to produce field notes that have "thick, deep, and rich description" and "use quotations" as appropriate (Patton, 2002, p. 331). Finally, I will digitally record interviews and observations as permitted by the study's participants (Patton, 2002). c. Data Storage: Data will be stored on a secure computer during the study, and it will be available exclusively to the principal researcher and faculty advisor. Notes will be destroyed after the project is completed.

IV. Analysis a. During this phase, I will review and organize the transcribed interviews, highlight my observations, and investigate the documents. I will produce a written case record for each case institution, which will be an organized collection of all data gathered for a specific institution (Patton, 2002). After organizing the data for the content analysis, the researcher should begin the process of coding data and developing a case record. Patton (2002) describes content analysis as the most popular form of reviewing the qualitative data. To assist with coding and compiling data into categories, I will look for emerging and overlapping themes from the research questions. Content analysis is an action where coding is "the process of transforming raw data into a standardized form" (Babbie, 2001, p. 309). Ryan and Bernard (2000) suggested that "coding forces the researcher to make judgments about the meanings of contiguous blocks" and that coding is "the heart and soul" of text analysis. In terms of process, Creswell (2008) suggested coding the documents in the left-hand margin and reserving the right margin for developing themes. After evaluating several different qualitative software, I will follow Creswell's strategy and code my own documents. b. Interpretative phase: I will follow the six phases or steps in the interpretive process (Denzin \& Lincoln, 2000). 1. Framing the research question 2. Deconstructing and analyzing pre-conceptions of the phenomenon 3. Capturing the phenomenon, and its perspective in the world. 4. Reducing the phenomenon to a basic level. 5. Constructing the phenomenon, and seeing how everything works together. 6 . Contextualizing the phenomenon as it fits in the general scheme of things.

In this study, Smith's (2009) dimensions of diversity conceptual framework is outlined in the study. Finally, in an effort to provide a high level of data analysis and interpretation, I will determine if the study's themes crossover multiple data sources or perspectives (Creswell, 2008). The study's findings will also be interpreted with respect to past studies, observations and reflections about the current study including the process and potential limitations, and need for future study expansion.

\section{Research Trustworthiness}

a. To ensure trustworthiness and credibility of the findings in the study of diversity and faculty at southern evangelical Christian institutions, I will use multiple strategies. These strategies include: peer debriefers; researcher reflexivity; triangulation, and participant member checks will promote high rigor in this study. A peer reviewer provides support, plays devil's advocate, challenges the researchers' assumptions, and questions the methods (Lincoln \& Guba, 2000). b. To ensure that the research findings can be transferred, I will use highly descriptive data and multiple cases of analysis. 
c. To ensure that I am unbiased and that my assumptions do not appear in the study, I will journal and write reflections throughout my fieldwork. I will also discuss interviews with my peer debriefer.

d. To ensure dependability of results, the study will be guided with the case protocols and an audit trail will provide documentation for the process.

VI. Ethical Considerations a. Please refer to the participant information and informed consent form (Appendix B) for a detailed outline of ethical considerations.

VII. Limitations a. The current study is inherently limited due to its qualitative design; limitations include issues of researcher bias, transferability restrictions, and imperfect validity and reliability of data sources and interpretation (Creswell, 2008; Merriam, 2009).

VIII. Reporting a. The final report of the research study will be submitted in accordance with the dissertation guidelines of the Higher Education Doctoral Program at the University of Arkansas. Each case institution will be furnished with a complete and final copy of the research study.

IX. Schedule a. February-March: Fieldwork and data collection; the researcher will work with institutional contacts to setup a two to three day on-site visit at each case institution. b. AprilMay: Data analysis and interpretation c. May: Finalize report d. June: Distribute complete and final copy of research study to each case institution.

\section{Contact Information:}

This study will be approved by Dr. Ketevan Mamiseishvili, faculty advisor, and Ro Windwalker, institutional review board coordinator at the University of Arkansas. If you have any questions regarding the current study or about your rights as a participant, or if you are concerned at any time with regard to the current study, you may contact me, Dr. Mamiseishvili or Ms.

Windwalker. 